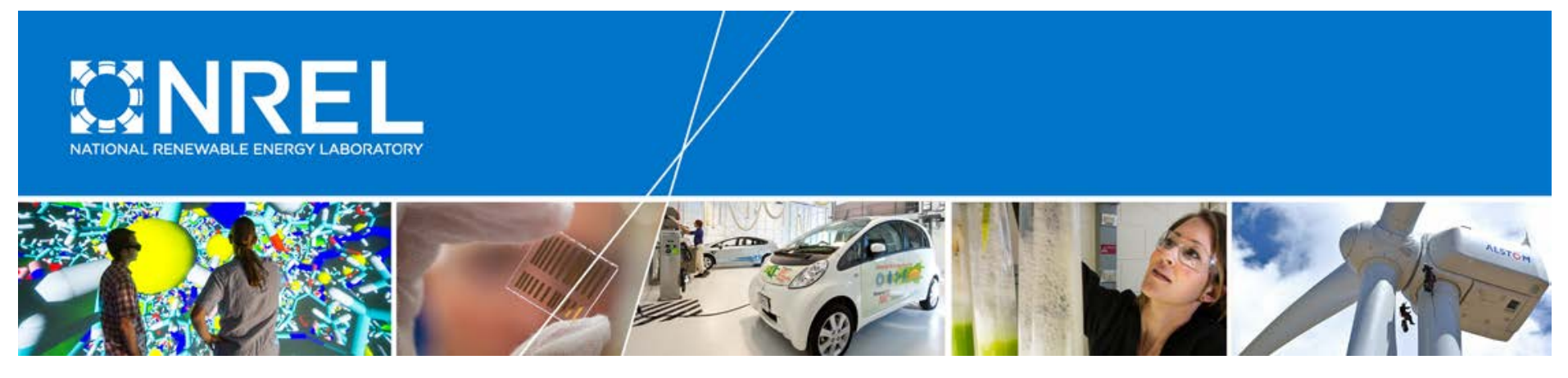

\title{
High-Octane Mid-Level Ethanol Blend Market Assessment
}

Caley Johnson, Emily Newes, Aaron Brooker, and Robert McCormick

National Renewable Energy Laboratory

Steve Peterson

Lexidyne, LLC

Paul Leiby, Rocio Uria Martinez, and Gbadebo Oladosu

Oak Ridge National Laboratory

Maxwell L. Brown

Colorado School of Mines

NREL is a national laboratory of the U.S. Department of Energy Office of Energy Efficiency \& Renewable Energy

Operated by the Alliance for Sustainable Energy, LLC

This report is available at no cost from the National Renewable Energy Laboratory (NREL) at www.nrel.gov/publications.

Technical Report

NREL/TP-5400-63698

December 2015

Contract No. DE-AC36-08GO28308 


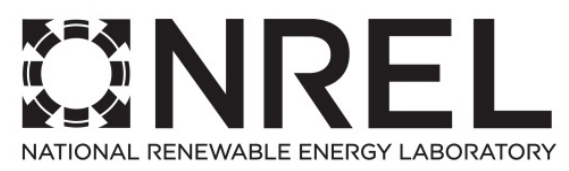

\title{
High-Octane Mid-Level Ethanol Blend Market Assessment
}

\author{
Caley Johnson, Emily Newes, Aaron Brooker, \\ and Robert McCormick \\ National Renewable Energy Laboratory \\ Steve Peterson \\ Lexidyne, LLC \\ Paul Leiby, Rocio Uria Martinez, and \\ Gbadebo Oladosu \\ Oak Ridge National Laboratory \\ Maxwell L. Brown \\ Colorado School of Mines
}

Prepared under Task No. BB14.4630

NREL is a national laboratory of the U.S. Department of Energy Office of Energy Efficiency \& Renewable Energy Operated by the Alliance for Sustainable Energy, LLC

This report is available at no cost from the National Renewable Energy Laboratory (NREL) at www.nrel.gov/publications.

National Renewable Energy Laboratory 15013 Denver West Parkway Golden, CO 80401

303-275-3000 • www.nrel.gov
Technical Report

NREL/TP-5400-63698

December 2015

Contract No. DE-AC36-08G028308 


\section{NOTICE}

This report was prepared as an account of work sponsored by an agency of the United States government. Neither the United States government nor any agency thereof, nor any of their employees, makes any warranty, express or implied, or assumes any legal liability or responsibility for the accuracy, completeness, or usefulness of any information, apparatus, product, or process disclosed, or represents that its use would not infringe privately owned rights. Reference herein to any specific commercial product, process, or service by trade name, trademark, manufacturer, or otherwise does not necessarily constitute or imply its endorsement, recommendation, or favoring by the United States government or any agency thereof. The views and opinions of authors expressed herein do not necessarily state or reflect those of the United States government or any agency thereof.

This report is available at no cost from the National Renewable Energy Laboratory (NREL) at www.nrel.gov/publications.

Available electronically at SciTech Connect http:/www.osti.gov/scitech

Available for a processing fee to U.S. Department of Energy and its contractors, in paper, from:

U.S. Department of Energy

Office of Scientific and Technical Information

P.O. Box 62

Oak Ridge, TN 37831-0062

OSTI http://www.osti.gov

Phone: 865.576.8401

Fax: 865.576.5728

Email: reports@osti.gov

Available for sale to the public, in paper, from:

U.S. Department of Commerce

National Technical Information Service

5301 Shawnee Road

Alexandria, VA 22312

NTIS http://www.ntis.gov

Phone: 800.553 .6847 or 703.605 .6000

Fax: 703.605.6900

Email: orders@ntis.gov 


\section{Acknowledgments}

This work is sponsored by the U.S. Department of Energy's Bioenergy Technologies Office. The guidance of the Bioenergy Technology Office's Alicia Lindauer was particularly helpful. The authors are very grateful to the representatives from the vehicle manufacturing, fuel production, fuel sales, and driving industries that shared valuable insight and gave direction to this report. They helped identify potential benefits of high-octane fuel, barriers to its adoption, and potential strategies to curtail these barriers. The authors also received valuable help and technical insight from Michael Wang and Jeongwoo Han (Argonne National Lab); Brian West, Tim Theiss, Scott Sluder, and John Thomas (Oak Ridge National Lab); Brian Bush, Kristy Moriarty, Ethan Warner, Laura Vimmerstedt, Margo Melendez, John Farrell, Adam Bratis, Robin Newmark, and Barb Goodman (National Renewable Energy Laboratory). Despite the large amount of help that the authors received from industry and lab collaborators, any errors or misconceptions are the fault of the authors. 


\section{Acronyms}

ADOPT

AEO

AFDC

AFV

AKI

API

AST

BSM

CAFE

DI

DOE

E0

EIA

EISA

EMV

EPAct

FFV

GDI

gge

GHG

GPY

HEV

HOF

HOFV

LDV

MON

MSRP

MY

NACS

NPV

NREL
Automotive Deployment Options Projection Tool

Annual Energy Outlook

Alternative Fuels Data Center

alternative fuel vehicle

anti-knock index

American Petroleum Institute

above-ground storage tank

Biomass Scenarios Model

Corporate Average Fuel Economy

direct injection

U.S. Department of Energy

ethanol-free certification fuel

Energy Information Administration

Energy Independence and Security Act

Europay, Mastercard and Visa

Energy Policy Act

flexible fuel vehicle

gasoline direct injection

gasoline gallon equivalent

greenhouse gas

gallons per year

hybrid electric vehicle

high-octane fuel

high-octane fuel vehicle

light-duty vehicle

motor octane number

manufacturer's suggested retail price

model year

National Association of Convenience Stores

net present value

National Renewable Energy Laboratory 


$\begin{array}{ll}\text { ORNL } & \text { Oak Ridge National Laboratory } \\ \text { PADD } & \text { Petroleum Administration for Defense District } \\ \text { RFA } & \text { Renewable Fuels Association } \\ \text { RFID } & \text { radio frequency identification } \\ \text { RFS } & \text { Renewable Fuel Standard } \\ \text { RFS2 } & \text { Second-generation Renewable Fuel Standard } \\ \text { RIN } & \text { Renewable Identification Number } \\ \text { RON } & \text { research octane number } \\ \text { RVP } & \text { Reid vapor pressure } \\ \text { SI } & \text { spark ignition } \\ \text { UL } & \text { Underwriters Laboratories } \\ \text { USDA } & \text { U.S. Department of Agriculture } \\ \text { UST } & \text { underground storage tank } \\ \text { VMT } & \text { vehicle miles traveled }\end{array}$




\section{Executive Summary}

\section{Introduction}

The United States government has been promoting increased use of biofuels, including ethanol from non-food feedstocks, through policies contained in the Energy Independence and Security Act of 2007. The objective is to enhance energy security, reduce greenhouse gas (GHG) emissions, and provide economic benefits. However, the United States has reached the ethanol blend wall, where more ethanol is produced domestically than can be blended into standard gasoline. Nearly all ethanol is blended at 10 volume percent (vol\%) in gasoline. At the same time, the introduction of more stringent standards for fuel economy and GHG tailpipe emissions is driving research to increase the efficiency of spark ignition (SI) engines. Advanced strategies for increasing SI engine efficiency are enabled by higher octane number (more highly knockresistant) fuels. Ethanol has a research octane number (RON) of 109, compared to typical U.S. regular gasoline at 91-93. Accordingly, high RON ethanol blends containing $20 \mathrm{vol} \%$ to $40 \mathrm{vol} \%$ ethanol are being extensively studied as fuels that enable design of more efficient engines. These blends are referred to as high-octane fuel (HOF) in this report.

HOF could enable dramatic growth in the U.S. ethanol industry, with consequent energy security and GHG emission benefits, while also supporting introduction of more efficient vehicles. HOF could provide the additional ethanol demand necessary for more widespread deployment of cellulosic ethanol. However, the potential of HOF can be realized only if it is adopted by the motor fuel marketplace. This study assesses the feasibility, economics, and logistics of this adoption by the four required participants - drivers, vehicle manufacturers, fuel retailers, and fuel producers. It first assesses the benefits that could motivate these participants to adopt HOF. Then it focuses on the drawbacks and barriers that these participants could face when adopting HOF and proposes strategies - including incentives and policies - to curtail these barriers. These curtailment strategies are grouped into scenarios that are then modeled to investigate their feasibility and explore the dynamics involved in HOF deployment. This report does not advocate for or against incentives or policies, but presents simulations of their effects.

\section{Approach}

The participation of four main stakeholder groups is predicated upon the benefits of HOF outweighing the costs. Drivers have the potential to benefit from projected fuel cost savings, reduced price volatility, increased torque in performance applications, and the energy security and environmental attributes. Vehicle manufacturers could benefit from HOF as a means to meet future fuel economy and GHG requirements and as a way to increase torque in performance applications. Fuel retailers could fetch higher per-gallon margins from HOF than from gasoline, could see increased visits to their stores due to the potentially lower price of HOF versus gasoline, and could use HOF as a means to differentiate their stations from the competition. Fuel producers have the potential to benefit from HOF as a way to comply with the Renewable Fuel Standard (RFS), because its resulting increase in ethanol demand could come at a strategic time for the transition to cellulosic ethanol, and because it could enable the use of less expensive fuel blendstocks.

Despite the potential benefits of HOF, there are also barriers and associated costs that must be resolved before it is adopted at large scale. Thirty of these barriers were identified through 
interviews with 16 companies and industry associations representing fleet managers, individual drivers, vehicle manufacturers, vehicle dealers, retail fuel stations, ethanol producers (corn and cellulosic), large oil companies, and midstream fuel distributors. This barrier identification was supplemented by information from a literature review and HOF-related workshops. Ninety-four potential strategies to curtail these barriers were also identified and explored. Complementary subsets of these strategies were grouped into eight deployment scenarios:

1. Replace Mid-Grade with HOF and Market Performance Attributes. Stations offer regular E10, premium E15, and HOF from just two underground storage tanks. HOF is introduced to high-performance vehicle models first.

2. HOF-Tolerant, Premium-Optimized Intermediary. These vehicles can use HOF and capture much of HOF's high-octane benefits.

3. Price-Driven Adoption. HOF vehicles (HOFVs) are marketed to owners trying to minimize the total cost of vehicle ownership. The first HOFVs introduced are the most efficient models, fuel retailers and vehicle purchasers are incentivized, and the historically lower price of ethanol relative to petroleum gasoline leads to a lower price for HOF compared to E10.

4. Accelerated Deployment. A bookend scenario with the fastest vehicle market penetration and HOF adoption. All new vehicles are optimized for HOF beginning in 2018, and all dispensing equipment sold is HOF compatible.

5. E51 Intermediary. HOFVs are optimized to E40 but use E51 sold through the current flex fuel infrastructure until the HOF market is large enough to support dedicated refueling.

6. Blender Pumps. E10, E15, HOF, and flex fuel are blended from two tanks containing E0 (or E10) and flex fuel (E51-E83).

7. Regional Deployment. Resources for achieving critical mass of both supply and demand for HOF are focused on the Midwest market.

8. Expensive. A bookend designed to represent conditions most likely to lead to slow deployment (expensive vehicles and retail dispensing equipment, HOF is E40).

\section{Results}

The eight deployment scenarios were modeled by the Automotive Deployment Options Projection Tool (ADOPT) to estimate the adoption rate of HOFVs. As shown in Figure ES-1, all scenarios showed the potential for HOFVs to comprise a substantial percentage $(43 \%-79 \%)$ of the light-duty vehicle (LDV) stock by 2035. In general, more HOFVs are adopted if HOF is E40 because they offer greater fuel cost savings and offer vehicle manufacturers a greater GHG emissions benefit than if HOF is E25. The estimated HOFV penetration from ADOPT was used as an input to analyze HOF's potential impacts on the fuel supply chain. The Biomass Scenario Model (BSM) and the BioTrans model were used for this scenario analysis. The two models are complementary because they are focused on different ways that HOF-related investments could be made along the fuel supply chain. Their HOF ethanol consumption estimates are summarized in Figure ES-2. 


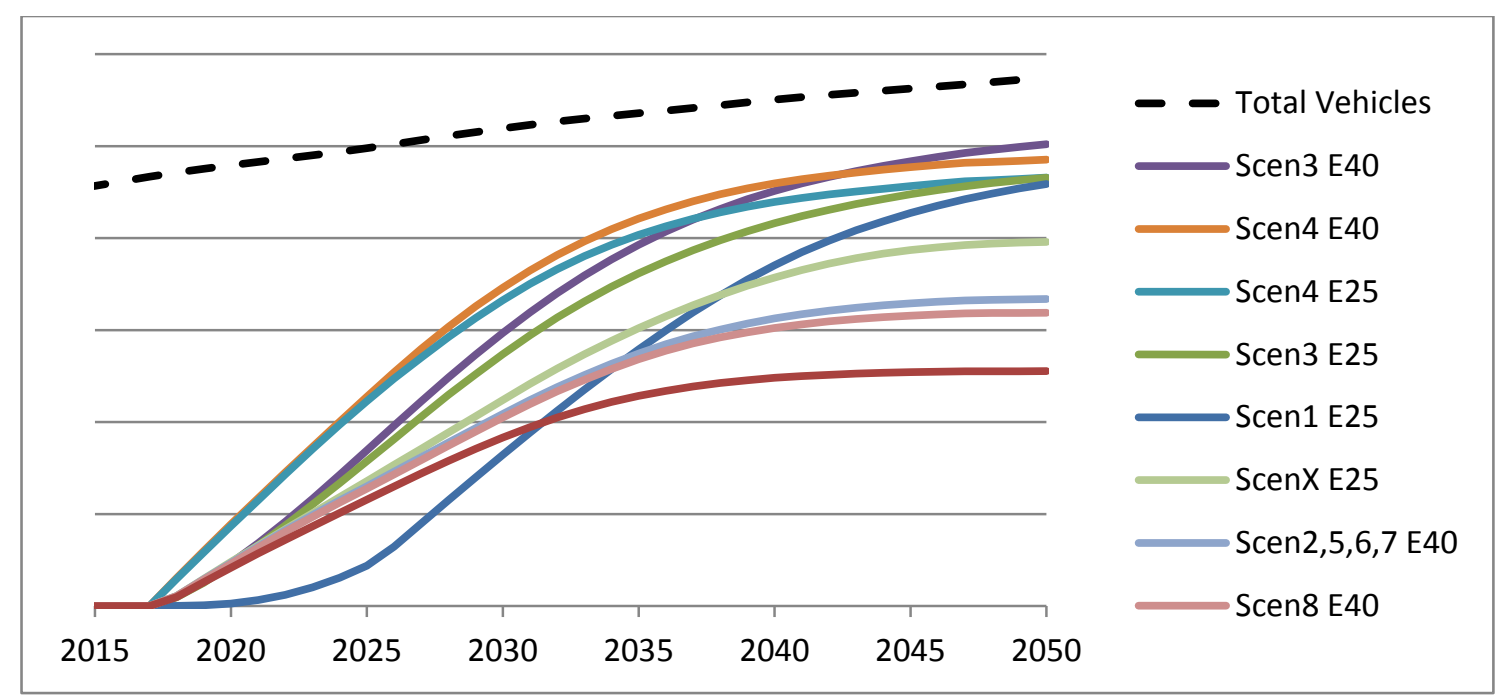

Figure ES-1. Stock of HOFVs estimated by ADOPT under the various scenarios

The modeling analyses concur that feedstock availability and cost are not expected to be obstacles to the substantial development of a HOF market across all of the scenarios considered. In numerous scenarios, HOF costs are sufficiently competitive that substantial market share is attained - up to 75 billion gallons of E40 (30 billion gallons of fuel ethanol) by 2035 . This would meet over $60 \%$ of LDV fuel demand in that year, given projections from the ADOPT model. However, all scenarios fell short of satisfying $100 \%$ of the fuel demanded by LDVs and were therefore limited. The limiting factors affected the eight scenarios in the following pattern:

1. Regulations that have not yet taken HOF into account would be a limiting factor in all scenarios. Therefore, most scenarios included the following assumptions in order to allow market adoption:

a. HOF is registered as a fuel and listed as an emissions certification fuel, through one of the methodologies discussed in sections 3.2.6 and 3.2.4, respectively.

b. The RFS is set to increase predictably, so that Renewable Identification Number prices remain within historical levels.

c. Future fuel economy and GHG regulations are set so their accounting systems adequately reward the production of HOFVs.

2. The fuel retailers' investment in HOF-compatible equipment is a limiting factor in many scenarios. At varying degrees of market penetration, the economics were not favorable enough for the marginal retailer to invest. The retailers' decision to invest in HOF equipment is no longer the limiting factor if the following elements are in place:

a. The retailer is incentivized to invest through a grant, rebate, or tax credit. Scenarios where incentives covered $40 \%$ of investment had greater market penetration, which was increased even more when $80 \%$ of costs were covered.

b. Retail equipment cost is reduced by incentivizing equipment manufacturers, by assisting in development of equipment, subsidizing the equipment, or through economies of scale. These strategies assume a competitive market where savings to equipment manufacturers result in lower equipment price. 
c. Only compatible equipment is sold in advance of HOF introduction, which would effectively reduce the up-front cost for retailers that had retired and replaced their equipment after normal useful life.

3. The number of new biorefineries that can be constructed in a year is the limiting factor in scenarios that are not limited by the retail investment barrier, especially in the early years of rapid-growth scenarios. The constraint results in a higher ethanol price, which can subsequently deter the use of HOF. This barrier is curtailed in scenarios where:

a. Enough time passes to allow biorefinery construction to catch up with ethanol demand. This happens around 2025 in applicable cases.

b. Biorefinery construction is performed at an annual rate greater than previously seen in the United States.

4. HOFV adoption is the limiting factor for the two scenarios where adequate retailer investment has been made and biorefinery construction has caught up with demand. The specific level of HOFV adoption depended on a number of factors:

a. More HOFVs are adopted if HOF is E40 because it offers greater fuel cost savings to drivers and greater fuel economy and GHG emissions benefits to vehicle manufacturers under future regulations that sufficiently reward the fuel economy benefits associated with HOF.

b. Proactive vehicle conversion schedules, where entire model lines are converted to HOFVs, resulted in greater estimated HOFV adoption than conversion schedules that follow market demand and converted portions of model lines.

c. ADOPT estimated that a $\$ 2,500$ incentive to the driver would significantly increase HOFV adoption.

d. High oil prices had little effect on the estimated rate of HOFV adoption because high gasoline prices led consumers to purchase slightly more efficient vehicles, alleviating the incentive of future GHG requirements on vehicle manufacturers.

The composition of HOF changes some aspects of the adoption scenarios. E25 scenarios typically produced a simulated HOF ethanol consumption of roughly 10 to 15 billion gallons per year, while many E40 scenarios showed much higher simulated HOF ethanol demand. Using E40 instead of E25 has the advantage of requiring fewer vehicles to displace the same amount of petroleum, but also has the disadvantage of much higher infrastructure investment costs. The BSM and BioTrans utilize different logic when exploring dispensing station investment decisions and demand for HOF, which led to diverging estimates of E25 and E40 consumption. BSM showed lower ethanol consumption in E40 scenarios due to higher capital costs. In contrast, BioTrans showed higher ethanol consumption in E40 scenarios. This was because the reference share of HOF consumption by HOFVs remained the same under both E25 and E40 cases and because relative prices made large HOF availability optimal to minimize net costs of combined consumers and producers. 


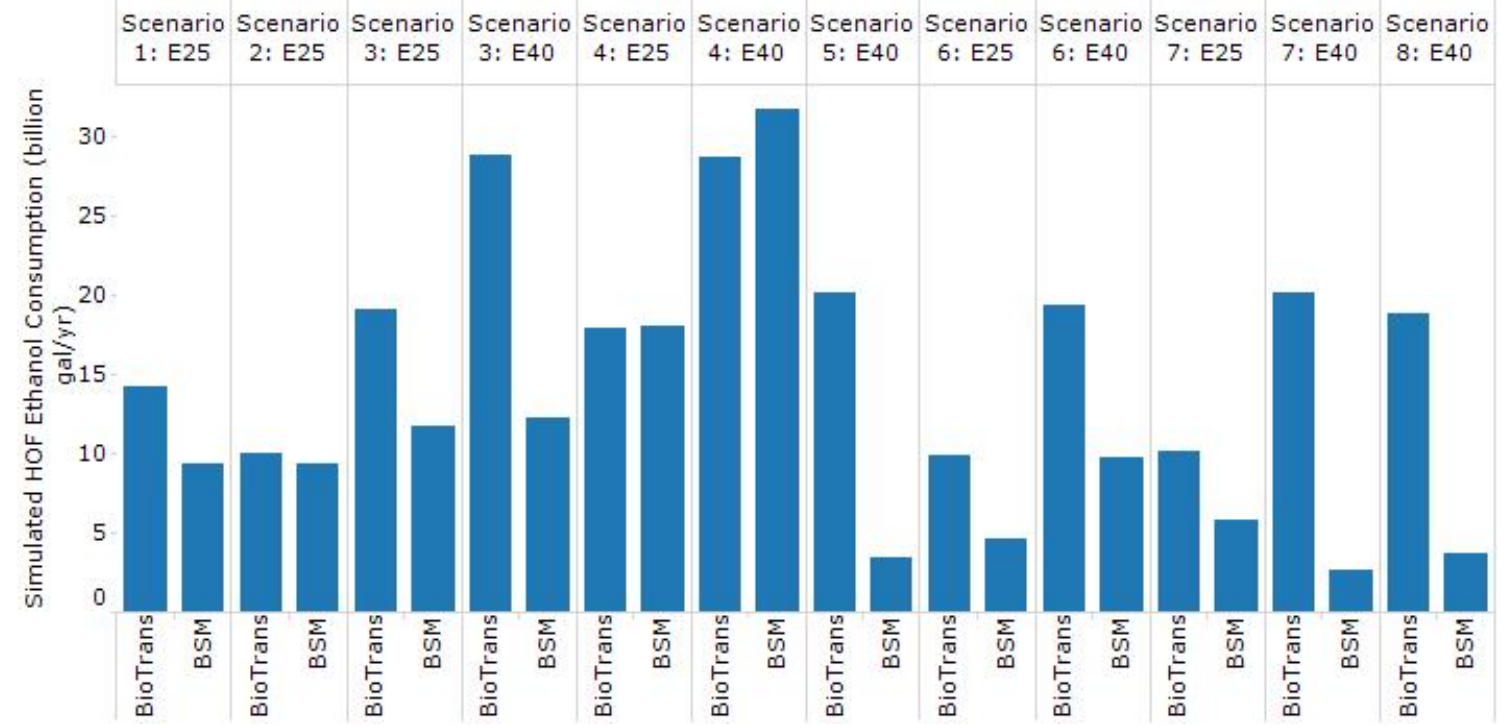

Figure ES-2. Comparison of the simulated HOF ethanol demand in 2035, given vehicle fleet, by scenario for the BSM and BioTrans models: The differences between the HOF ethanol demand in the two models illustrate the impact of assumptions of a short-term net-presentvalue focus (BSM) and a long-term social welfare focus (BioTrans). 


\section{Table of Contents}

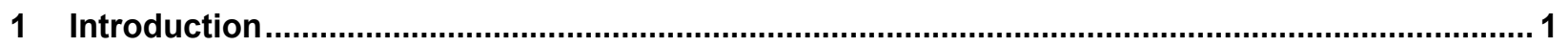

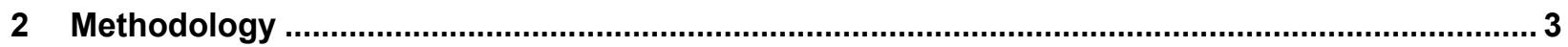

3 High-Octane Fuel Benefits, Barriers, and Curtailment Strategies................................................. 4

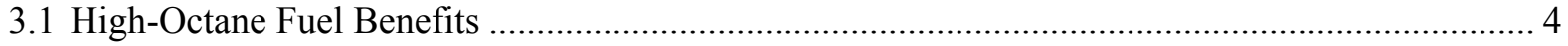

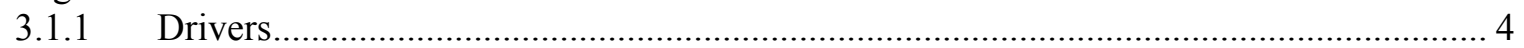

3.1.2 Vehicle Manufacturers ........................................................................................ 6

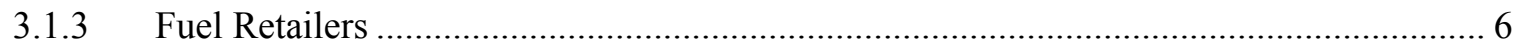

3.1.4 Fuel Producers and Distributors............................................................................ 7

3.2 High-Octane Fuel Barriers and Curtailment Strategies ……………………………………….... 8

3.2.1 Coordinated Growth of Supply and Demand ........................................................... 12

3.2.2 Renewable Fuel Standard...................................................................................... 16

3.2.3 Misfueling Legacy Vehicles on High-Octane Fuel......................................................... 16

3.2.4 High-Octane Fuel Is Not a Certification Fuel ................................................................ 17

3.2.5 Fuel Volatility Regulations ................................................................................. 18

3.2.6 Fuel Registration Requirement ............................................................................. 20

3.2.7 Corporate Average Fuel Economy Credits and the Greenhouse Gas Ruling...................2 21

3.2.8 Retailer Investment Requirements ........................................................................ 24

3.2.9 High-Octane Fuel Pricing ………………………………………………….... 26

3.2.10 Lower Tier Barriers and Barrier Summary …………………………………………... 28

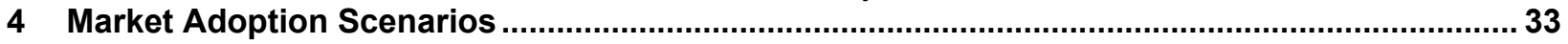

4.1 Scenario 1: Replace Midgrade with High-Octane Fuel and Market Performance Attributes......... 34

4.2 Scenario 2: HOF-Tolerant, Premium-Optimized Intermediary …………………………………..... 36

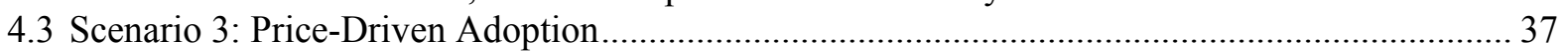

4.4 Scenario 4: Accelerated Deployment...................................................................................... 38

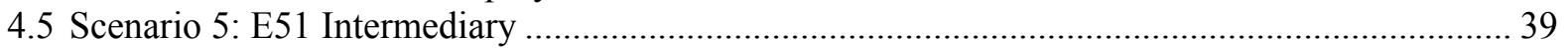

4.6 Scenario 6: Blender Pumps .................................................................................................. 40

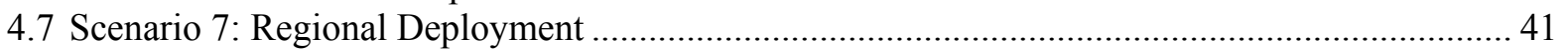

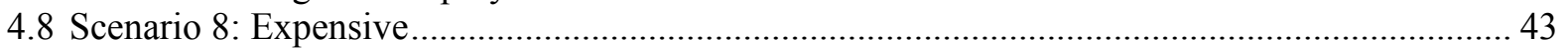

5 High-Octane Fuel Vehicle Adoption Modeling ……….............................................................45

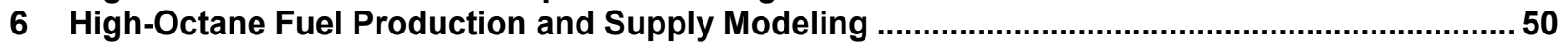

6.1 Brief Description of the Biomass Scenario Model ……………..............................................5 50

6.2 System-Level Insights from Biomass Scenario Model Analysis ................................................. 52

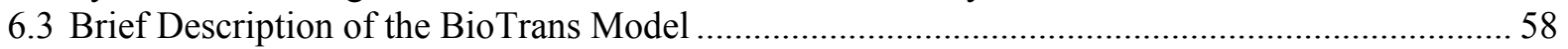

6.4 System-Level Insights from BioTrans Scenario Analysis .......................................................... 60

6.4 Discussion of Differences between Biomass Scenario Model and BioTrans Scenario Analyses.. 70

7 Conclusions ........................................................................................................................75

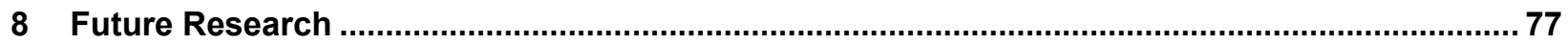

8.1 Integrated Market Analysis..................................................................................................... 77

8.2 High-Octane Fuel Vehicle Supply and Demand .......................................................................... 77

8.3 Fuel Supply and Retail Outcomes....................................................................................... 77

8.4 Net Benefit Analysis ....................................................................................................... 78

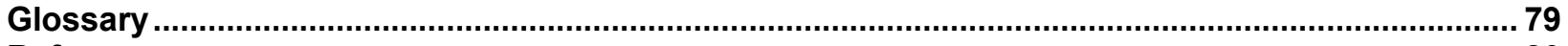

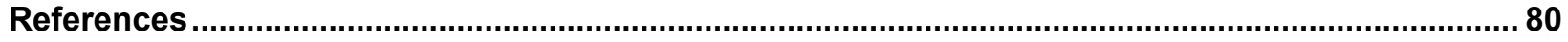

Appendix A: Biomass Scenario Model: High-Octane Fuel-Specific Model Logic and Assumptions89

Appendix B: Biomass Scenario Model: Explicit Values Included in Net Present Value Logic..........93

Appendix C: BioTrans: High-Octane-Fuel-Specific Model Approach and Assumptions .................94

Appendix D: Brief Overview of Biomass Scenario Model and BioTrans Approaches To Modeling

the Biomass-to-biofuel Supply Chain

Appendix E: Overview of the Literature and Empirical Analysis of the Role of Ethanol in the Gasoline Market. 


\section{List of Figures}

Figure ES-1. Stock of HOFVs estimated by ADOPT under the various scenarios........................... viii

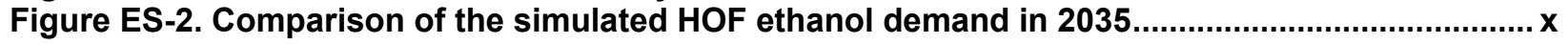

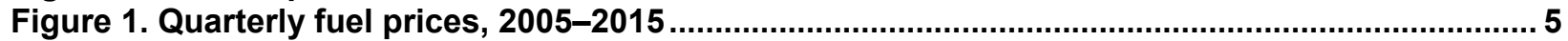

Figure 2. Gross margins of product categories in a convenience store 2013............................... 7

Figure 3. Octane variation in current gasoline supply ..................................................................... 12

Figure 4. Flex fuel retail stations in the United States .............................................................. 15

Figure 5. RVP for ethanol-gasoline blends.................................................................................... 19

Figure 6. U.S. summer gasoline RVP requirements ................................................................ 20

Figure 7. Influence of energy density and R-factor on calculated 1975 fuel economy results......... 22

Figure 8. Renewable fuel production required by the RFS2 ....................................................... 27

Figure 9. One strategy to offer HOF from a station with only two gasoline USTs .............................. 34

Figure 10. GM's EV1 (1998) and Tesla's Roadster (2008). Representative of a marketing shift....... 35

Figure 11. Two fuel configurations at ethanol blender pumps ................................................... 41

Figure 12. Indicators of a strong supply and demand for flex fuel................................................... 42

Figure 13. Production share of GDI and turbocharged vehicles....................................................4 44

Figure 14. Value of vehicle characteristics by purchaser income .....................................................45

Figure 15. Five means of ADOPT validation through comparison with historical sales data .......... 46

Figure 16. Baseline LDV sales estimates without HOF .............................................................. 47

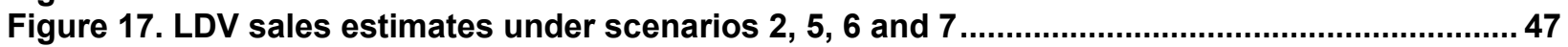

Figure 18. Stock of HOFVs estimated by ADOPT under the various scenarios ...............................48

Figure 19. Potential ethanol demand, given vehicle fleet, versus actual ethanol demand ..............54

Figure 20. Ethanol production and number of cellulosic ethanol biorefineries from 2015-2035.....56

Figure 21. Feedstock production from 2015-2035 by feedstock type............................................5 57

Figure 22. Pump prices by scenario from 2015-2035 for different AEO 2014 oil price cases .......... 57

Figure 23. Potential versus simulated total ethanol consumption in 2025 and 2035 .......................61

Figure 24. Achieved and potential ethanol consumption by HOFVs............................................63

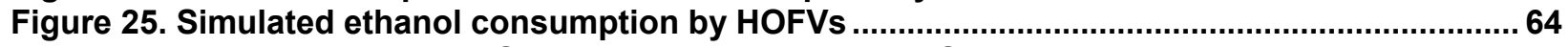

Figure 26. Weighted average HOF consumption share by HOFVs .................................................65

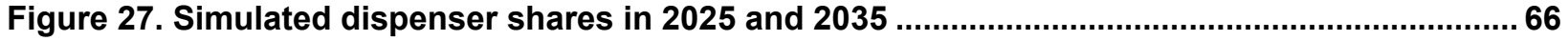

Figure 28. Cumulative investment in retail infrastructure (undiscounted, net of incentives) .......... 68

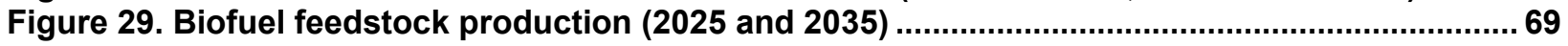

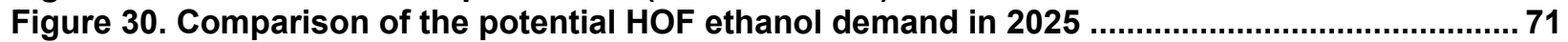

Figure 31. Comparison of the simulated HOF ethanol demand in 2035............................................ 72

Figure 32. Comparison of the feedstock production by feedstock type ........................................ 74

Figure A-1. BSM decision logic around investment in flex fuel dispensing stations ......................... 89

Figure A-2. Payback period versus NPV for different levels of fixed capital investment................. 91

Figure E-1. Refiner oil acquisition cost, ethanol inputs and ethanol price 1994-2014 ................... 105

Figure E-2. Preliminary estimates of historical monthly gasoline price elasticities ........................ 107 


\section{List of Tables}

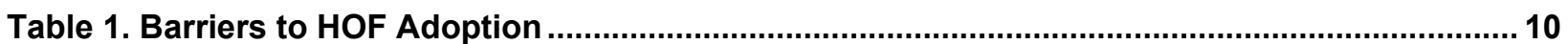

Table 2. Methods by Which CAFE and GHG Calculations Could Account For HOF........................ 23

Table 3. Cost Estimates To Add Two HOF Refueling Positions at One Station ...............................24

Table 4. Summary of the Barriers That HOF Is Facing and Potential Strategies to Curtail ............. 28

Table 5. Barrier Curtailment Strategies Common to All Scenarios except Variance Scenarios ....... 33

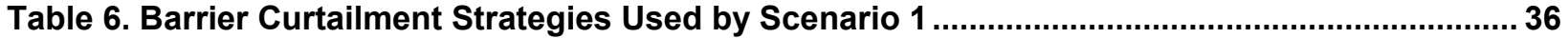

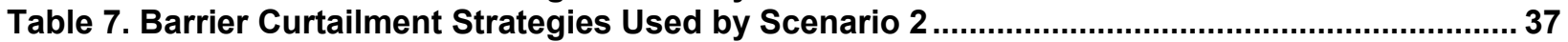

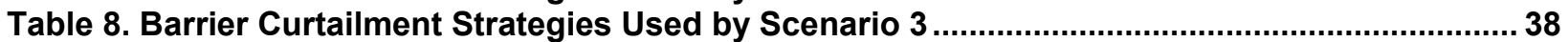

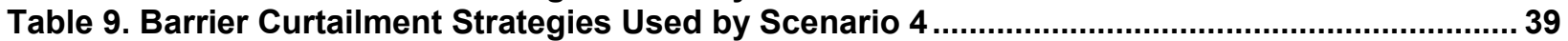

Table 10. Barrier Curtailment Strategies Used by Scenario 5 ..................................................... 40

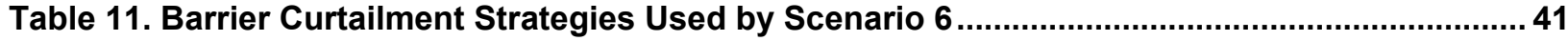

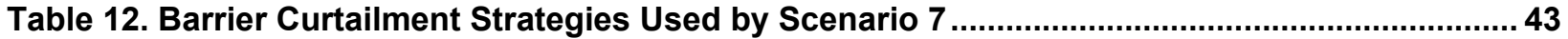

Table 13. Barrier Curtailment Strategies Used by Scenario 8 ........................................................ 44

Table 14. Insights on HOF Deployment along the Supply Chain ................................................... 52

Table 15. Ethanol Volumes (Billion Gallons per Year) in 2035 for Each Scenario .............................55

Table 16. Insights on HOF Deployment along the Supply Chain ......................................................60

Table 17. Number of Years in Which the Biorefinery Capacity Introduction Rate Is Binding........... 69

Table 18. Differing Logic When Modeling HOF Investment Decisions............................................... 73

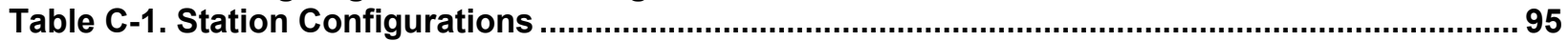

Table D-1. Comparison of Key Model Characteristics for the BSM and BioTrans Models ...............97 


\section{Introduction}

Fuel-grade ethanol is a domestically produced gasoline blendstock that can increase energy security, reduce greenhouse gas (GHG) emissions, and provide economic benefits (Wang et al. 2011; Oladosu et al. 2012). The U.S. government has been promoting increased use of biofuels, including ethanol from non-food-based feedstocks, through legislation contained in the Energy Independence and Security Act (EISA) of 2007 (U.S. Congress 2007). However, the United States has reached the ethanol blend wall, where more ethanol is produced domestically than can be readily and ubiquitously blended into standard gasoline. Nearly all ethanol is blended as 10 volume percent (vol\%) in gasoline, although $15 \mathrm{vol} \%$ is allowable in 2001 and newer conventional vehicles (EPA 2011). Two major issues that hinder increased use of fuel ethanol in the United States are the blend wall and the overpricing of flex fuel (E51-E83) on an energy basis (AFDC 2014a). Nevertheless, renewable fuel usage is mandated to increase under the Renewable Fuel Standard (RFS) (U.S. Congress 2007).

Additionally, efforts to improve fuel economy and reduce GHG emissions are driving research to increase the efficiency of spark ignition (SI) engines. Approaches for increasing SI engine efficiency include increased compression ratio, direct injection (DI), turbocharging, downsizing, and down-speeding. In general these technologies are enabled by higher octane number (more highly knock-resistant) fuels (Anderson et al. 2012; Stein et al. 2013; Chow et al. 2014). Ethanol has a research octane number (RON) of 109, compared to typical U.S. regular gasoline at 91-93 (Anderson et al. 2012). Accordingly, high octane number ethanol blends containing from 20 vol\% to $40 \mathrm{vol} \%$ ethanol are being extensively studied as fuels that enable greater engine efficiency (Milpied et al. 2009; Stein et al. 2013; Splitter and Szybist 2014; Leone et al. 2014). These blends are referred to as high-octane fuel (HOF) in this report.

While research to determine the exact property requirements for HOF is still ongoing, most researchers believe it will be comprised of $20 \%-40 \%$ ethanol because blends in this range have characteristics that allow an optimized engine to be much more efficient (on an energy basis) than current engines. These characteristics are high octane ( 100 RON), high octane sensitivity (the difference between RON and motor octane number or MON), and charge cooling effects that allow a much higher compression ratio without engine knock or current knock-avoidance strategies that reduce engine efficiency. Knock occurs when unburned fuel-air mixture prematurely auto-ignites during compression; this can cause rough operation and engine damage. Higher compression ratio translates into improved thermal efficiency, greater torque, and increased performance.

If properly implemented, HOF could enable dramatic growth in the U.S. ethanol industry by using blends well beyond the current blend wall. Furthermore, HOF could provide the additional ethanol consumption that brings costs down low enough to make cellulosic ethanol cost competitive. Or put in industry terms, HOF could bring about the " $\mathrm{n}$ "th" plant production prices, which would then be competitive with gasoline (Tao et al. 2014).

The potential of HOF to reduce petroleum use and greenhouse gas emissions (Han et al. 2015) can be realized only if it is adopted by the motor fuel marketplace. This study assesses the feasibility, economics, and logistics of this adoption by the four required participants - the drivers, vehicle manufacturers, fuel retailers, and fuel producers. It first assesses the benefits that 
could motivate these participants to adopt HOF. Then it focuses on the drawbacks and barriers that these participants face when adopting HOF and proposes strategies to curtail these barriers. These strategies are grouped into scenarios that are then modeled to investigate their feasibility and explore the dynamics involved in deploying HOF in the marketplace. 


\section{Methodology}

A number of analytical techniques, strategies, and models were used to assess the market potential for HOF. These include expert interviews from the required parties (drivers, vehicle manufacturers, fuel retailers, and fuel producers/distributors), meeting and conference participation with the required parties, a literature search, the Automotive Deployment Options Projection Tool (ADOPT), the Biomass Scenarios Model (BSM), and the BioTrans model.

First, the benefits and drawbacks of HOF adoption were identified for each required party to determine their potential reasons for participating in the HOF market. A review of the literature and analysis of the historical gasoline market data were also performed to provide quantitative insights into stakeholder behavior in the vehicle and fuel markets. Next, barriers to HOF adoption were identified and characterized. Potential strategies to curtail specific barriers were then highlighted, based on interviews and literature search. These strategies were then grouped into eight scenarios, based on synergies and compatibility among the strategies.

Models were then used to investigate these scenarios to explore under what conditions the benefits of HOF might allow for its profitable adoption by the four stakeholders. They also analyzed a subset of potential strategies to curtail the barriers. The ADOPT model took demographic-based consumer preference, fuel prices, Corporate Average Fuel Economy (CAFE) standards, and other factors into account and estimated how many people would purchase HOF vehicles. The BSM and BioTrans model assessed the economics of feedstock supply, ethanol production, distribution networks, and retail stations to explore supply chain interactions and scenario-specific economic environment of HOF under various scenarios. 


\section{High-Octane Fuel Benefits, Barriers, and Curtailment Strategies}

Large-scale adoption of HOF will require the market participation of four main stakeholder groups: drivers, vehicle manufacturers, fuel retailers, and fuel producers/distributors (gasoline and ethanol). If these stakeholders are to adopt HOF, they must benefit from it either financially or by facilitating regulatory compliance. They must also curtail barriers to adoption. This section summarizes the benefits, barriers, and strategies to curtail those barriers that the four main stakeholders face. This assessment was given direction by interviews with sixteen companies and industry associations representing fleet managers, individual drivers, vehicle manufacturers, vehicle dealers, retail fuel stations, ethanol producers (corn and cellulose), large oil companies, and midstream fuel distributors. It was supplemented by information from literature reviews and HOF-related workshops.

\subsection{High-Octane Fuel Benefits}

For HOF to enter the marketplace, each stakeholder group must benefit from it either financially, through improved performance, or by facilitating regulatory compliance. This section describes the main ways through which each group could benefit from HOF and, therefore, their motivation for supporting it.

\subsubsection{Drivers}

The drivers category includes individuals and fleets. Individuals are assumed to purchase, fuel, maintain, and drive their own household's vehicles. Fleet vehicles are assumed to be purchased, fueled, maintained, and driven according to a fleet manager's direction. Some of the benefits and barriers mentioned later in this report differentiate between the two driver categories. Potential HOF-related benefits to both driver types include reduced fuel costs, increased performance, and sustainability merits.

HOF has the potential to offer substantial fuel cost savings. From 2005-2015, E25 (if offered at a similar markup to E10) would have cost an average of \$0.08/gallon less than regular E10 and E40 would have cost $\$ 0.16$ less. $^{1}$ Given that optimized vehicles operating on HOF are expected to have the same volumetric fuel economy as conventional vehicles operating on regular gasoline ${ }^{2}$ this savings is the same as if regular gasoline were reduced by these amounts. Furthermore, under the Energy Information Administration's (EIA) Annual Energy Outlook's (AEO) reference fuel price projections (EIA 2014a), HOF cost savings are projected to increase to $\$ 0.18 / \$ 0.36$ per gallon (E25/E40) in 2040 (EIA 2014a). This is largely driven by developments in the cellulosic ethanol industry. Furthermore, a preliminary econometric analysis

\footnotetext{
${ }^{1}$ E25 and E40 prices (as reported by Clean Cites 2015) are assumed to be proportional mixes of E74 (the average flex fuel blend [EIA 2014a]) and E10 fuels.

${ }^{2} \mathrm{HOF}$ allows for a much higher fuel economy on an energy basis, yet has lower energy density. The vehicle manufacturers have set a general goal of using a HOF/vehicle combination that balances these two attributes, resulting in HOF having the same volumetric fuel economy as regular E10.
} 
of the historical data revealed that increases in the use of ethanol reduced the per-gallon cost of gasoline in the United States in 10 of the 13 years from 2001 to 2012 (see Appendix D).

Based on historical data, HOF prices are likely to be less volatile than those of gasoline. The average savings for E40 during the six major gasoline price spikes shown in Figure 1 would have been $\$ 0.232$ /gallon while the savings during the seven largest price dips would have been $\$ 0.089 /$ gallon. This relative price stability is especially important for businesses (such as delivery or transport) whose costs are dominated by fuel costs. If the greatest savings occur at the gasoline price peaks, HOF could be especially marketable because customers tend to pay the most attention to fuel prices when they increase and spike (Klier and Linn 2013).

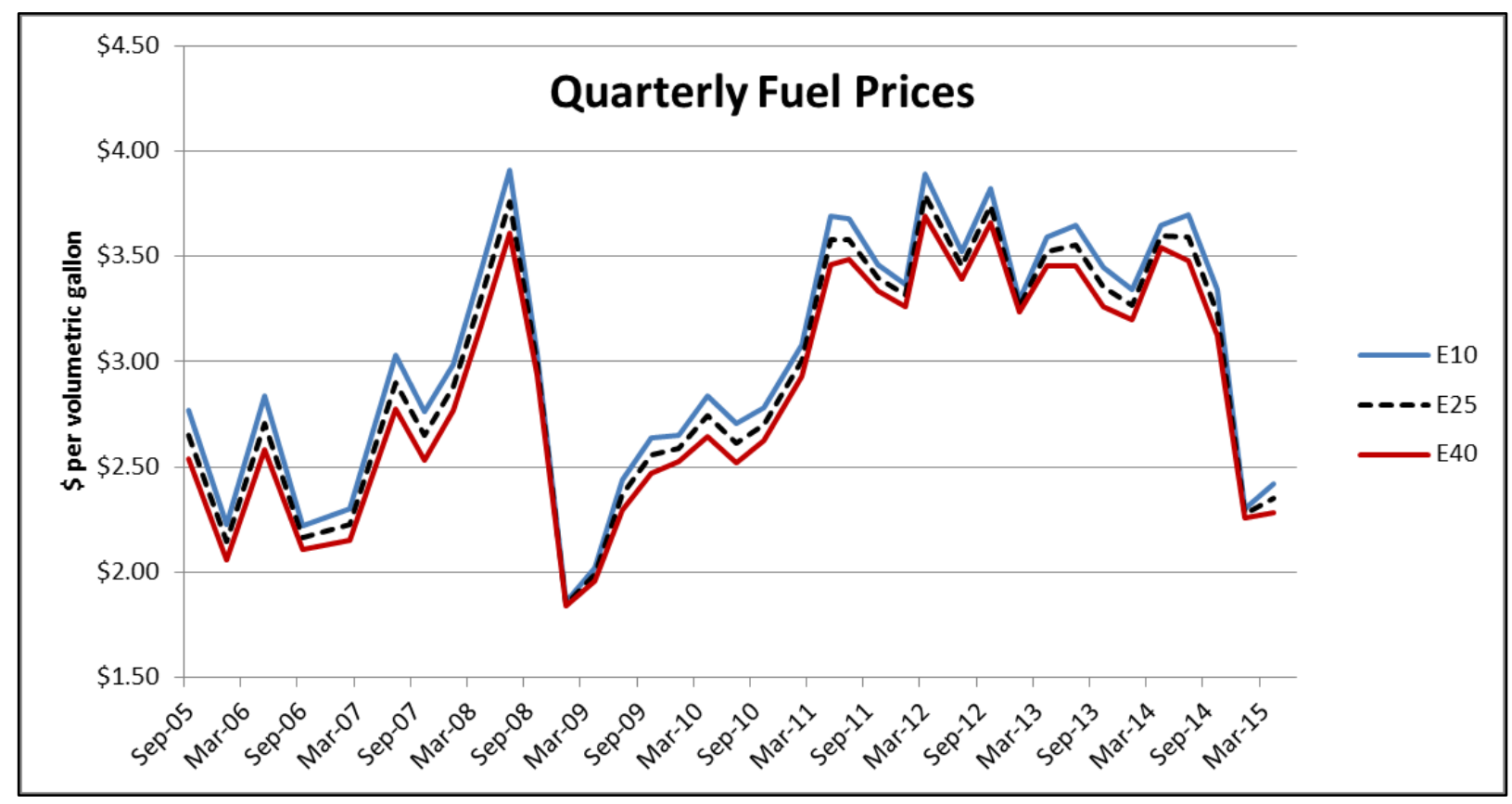

Figure 1. Quarterly fuel prices, 2005-2015

Source: E25 and E40 based on proportionally combined E10 and E74 prices from Clean Cities (2015)

The qualities of HOF can also be directed toward improved performance instead of improved efficiency (SAE 2013-01-1321; SAE 2014-01-1228). Although vehicle manufacturers would most likely use HOF to meet future CAFE and GHG requirements for most vehicles (depending on changes mentioned in Section 3.2.7), performance benefits are more likely to be harnessed for certain vehicle models such as sports cars, trucks used for towing heavy loads, and vehicles operating on drive cycles requiring high torque. The benefits for fleets depend on fleet type; police fleets are likely to utilize its increased acceleration, and light-duty truck fleets are likely to utilize its increased torque.

Many drivers see fuels that reduce petroleum consumption and that have lower emissions (GHG and criteria pollutants) as beneficial if they are concerned with sustainability. By using an increased amount of ethanol, HOF uses less petroleum, which increases U.S. energy independence. The GHG emissions impacts from increased octane were first analyzed by the Japan Clean Air Program, which estimated an overall increase in GHG emissions under their set 
of assumptions (Koseki 2014). Further studies (Speth et al. 2014; Hirshfeld et al. 2014; Han et al. 2015) have since estimated that HOF would substantially reduce lifecycle GHG emissions in the United States. HOF may also improve tailpipe pollutants - especially particulate matter, nonmethane hydrocarbons, 1-3 butadiene, and benzene (Anderson et al. 2014).

\subsubsection{Vehicle Manufacturers}

Vehicle manufacturers could benefit from HOF to attain three vehicle design objectives: increased performance, better fuel economy, and reduced emissions. When HOF is used in an optimized vehicle, its high octane and charge cooling characteristics translate to higher torque capability. This capability can be used to improve acceleration, payload capacity, and towing capacity. All these attributes increase the vehicle's desirability and sales.

The extra torque capability can also be converted into fuel economy improvements that could enable vehicle manufacturers to meet future CAFE and GHG reduction requirements. If efforts are taken to ensure that the manufacturers are properly rewarded for these improvements and that HOF is properly accounted for (see Section 3.2.7) in the next generation of CAFE requirements, HOF could be a major tool to meet these stringent requirements. HOF could help vehicle manufacturers meet any future lifecycle GHG emissions reduction requirements as well (Han et al. 2015). Likewise, if HOF is appropriately blended and an HOF certification fuel is approved, it would help vehicles meet their criteria pollutant regulations (Anderson et al. 2014).

\subsubsection{Fuel Retailers}

HOF could lead to greater profits for fuel retailers via three mechanisms:

1. HOF has the potential to command a higher margin than regular gasoline, which is extremely cost competitive and therefore sold at very low margins (Johnson and Melendez 2007).

HOF's margins could more closely mirror those of premium gasoline because both fuels are less price competitive and higher performance than regular. According to the National Association of Convenience Stores (NACS), premium gasoline fetched a 13\% larger margin in 2013 than regular gasoline (NACS 2014), and it would be a substantial benefit to retailers if HOF did the same. This benefit is partially in conflict with the drivers' benefit of less expensive fuel. The dynamics of these two benefits need to be further analyzed.

2. HOF could increase the number of trips to retail stations and thus increase total sales and profits. This would also include increasing sales of the high-margin merchandise and foodservice. These sales are more important to retailers than fuel sales because, as shown in Figure 2, their gross margins (equation 1) are six times higher than those of fuel.

$$
\text { Gross Margin }(\%)=\frac{\text { Revenue }- \text { Cost of Goods Sold }}{\text { Revenue }}
$$


Given that HOF is projected to be priced on average $9 \%$ less than regular gasoline ${ }^{3}$ (Figure 1) and that the long-run price elasticity of demand for motor fuel is estimated to be about 0.31 (Havranek et al. 2012), drivers of HOF vehicles (HOFVs) would demand 3\% more fuel than their gasoline counterparts. Assuming that fuel economy will be set to meet future CAFE regardless of fuel price, this increase in fuel demand translates to a $3 \%$ increase in miles driven and a concomitant increase in the number of trips to the convenience store.

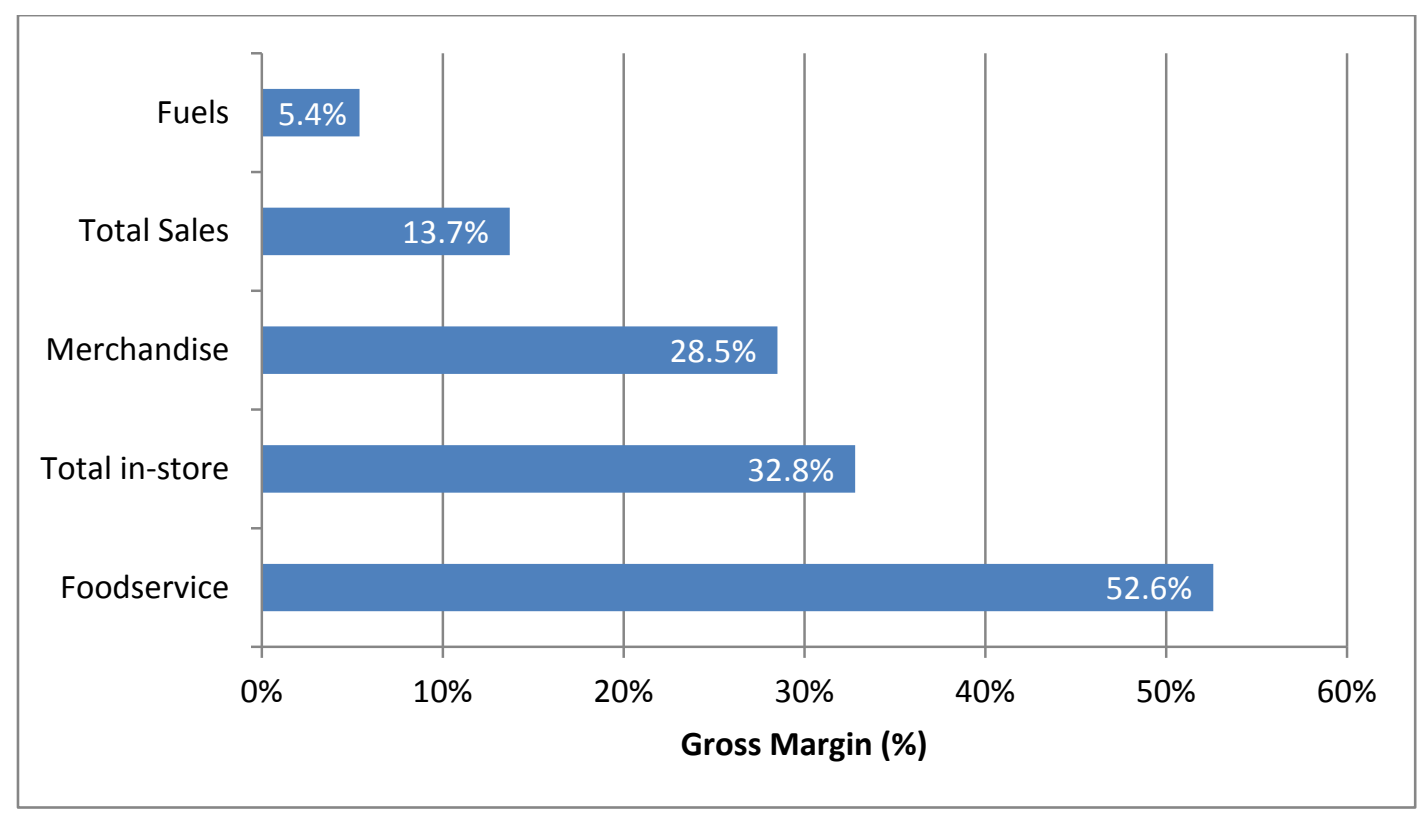

Figure 2. Gross margins of product categories in a convenience store 2013

Source: NACS (2014)

3. Retailers could use HOF to differentiate their stations from competitors. As explained by Johnson and Melendez (2007), gasoline is a very uniform product with an incredibly transparent price. These attributes combine to make it an extremely low-margin product. Gasoline retailers therefore place a high value on differentiating themselves from their competitors, as shown by the amount they are willing to pay for branded gasoline, green marketing, building remodels, and signage. Becoming an early adopter of HOF could serve as a good way for a retailer to differentiate itself as a cutting-edge, high-performance, green, and energy-secure refueling station.

\subsubsection{Fuel Producers and Distributors}

HOF is likely to reduce gasoline consumption (see Section 6), so gasoline producers are the stakeholders least likely to realize a financial net benefit from its introduction to the market. However, gasoline producers can use HOF to meet the alternative fuel mandates of the RFS. Renewable fuel markets have been in a phase shift since the E10 blend wall was hit in 2011 (see

\footnotetext{
${ }^{3}$ Average difference for each year between 2014 and 2030. Based on E10 and E74 price projections in AEO 2014, proportionally combined to make HOF.
} 
Figure 8), and E10 ceased to be able to absorb the increasing production of ethanol (EIA 2011). If the regulatory barriers can be curtailed (as laid out later in this report), HOF could be more attractive than flex fuel for increasing ethanol demand well beyond the E10 blend wall. The fundamental reason it is more promising than flex fuel for large-scale ethanol use is that it does not waste fuel octane value the way flex fuel usage in flexible fuel vehicles (FFVs) does. Using ethanol as E30 in optimized vehicles instead of equivalent amounts of E10 and E85 is estimated to result in net savings to refiners by avoiding this "octane give-away" (Hirshfeld et al. 2014).

HOF could also benefit gasoline producers by enabling the use of lower quality, less expensive blendstocks that are balanced by the environmentally attractive, high-performance properties of ethanol. Just as E10 enabled the most common blendstock to be reduced from 87 anti-knock index (AKI) to $84 \mathrm{AKI}, \mathrm{E} 25$ or E40 could enable a further drop in blendstock octane and still provide an overall increase in the performance of the finished product. One estimate for the HOF blendstock is at 85 RON (Splitter and Szybist 2014), which would be as low as 79 AKI. Because each single point drop in octane value ${ }^{4}$ typically reduces costs by $\$ 0.05 /$ gallon (Higgins 2014 ), HOF could be an economically sound decision for the fuel producers. Furthermore, if a lower quality blendstock were acceptable, a greater portion of natural gas liquids could be used at an even greater cost savings to the petroleum industry. ${ }^{5}$ Note that ethanol blended with lower-cost blendstocks must still meet the U.S. Environmental Protection Agency’s (EPA) Tier III requirements and applicable ASTM fuel specifications.

Ethanol producers stand to benefit from the HOF market. The increased ethanol demand could come at an opportune time, as cellulosic ethanol production has recently been modeled to meet its U.S. Department of Energy (DOE) targets to be cost competitive with corn ethanol if economies of scale can be reached (Tao et al. 2014). ${ }^{6}$ Progress is being made toward these economies of scale, as commercial-scale cellulosic ethanol plants are being built and operated (Peplow 2014; RFA 2014; POET 2014; INEOS 2013), and additional facilities would need to be constructed to satisfy additional demand for HOF. The combination of cost-competitive cellulosic ethanol and increased demand for ethanol could result in a strong foothold for the cellulosic ethanol industry.

The introduction of HOF could also free up enough gasoline supply to enable U.S. refineries to expand into foreign markets (Han et al. 2015). Therefore, the overall volume of product sold by U.S. fuel suppliers could expand.

\subsection{High-Octane Fuel Barriers and Curtailment Strategies}

Although the potential benefits to adopting HOF are significant, each stakeholder group must curtail substantial barriers to adopt it. This section discusses the barriers to HOF adoption and proposes strategies to curtail. Because many of the barriers apply to multiple stakeholder groups, the barriers are tiered according to the magnitude of their impact if not curtailed and how many

\footnotetext{
${ }^{4}$ Prices studied were for blendstocks between 84 and 90 AKI.

${ }^{5}$ The prospects for natural gas liquids are being researched and will be reported in parallel to this report.

${ }^{6}$ Assumes that RSF2 keeps to its original targets and oil costs $\$ 110 /$ barrel.
} 
stakeholders they directly affect (Table 1). Within each tier, the barriers are also categorized by type: regulatory, economic, logistical, or behavioral. The barriers and their curtailment strategies are then described in the text below; there are many barriers, but there are also many curtailment strategies. 
Table 1. Barriers to HOF Adoption

\begin{tabular}{|c|c|c|c|c|c|c|}
\hline 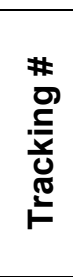 & Barrier & Type & 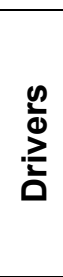 & 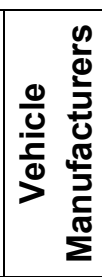 & 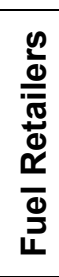 & 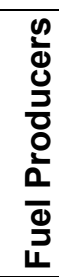 \\
\hline 1 & Level 1 barriers (most formidable barriers-show-stoppers if not properly addressed) & & & & & \\
\hline 1.1 & Coordinated growth of supply and demand & Logistical & $\mathrm{X}$ & $\mathrm{X}$ & $\mathrm{X}$ & $\mathrm{x}$ \\
\hline 1.2 & RFS: unpredictability leads to investment uncertainty & Regulatory & & $\mathrm{x}$ & $\mathrm{X}$ & $\mathrm{X}$ \\
\hline 1.3 & Misfueling legacy vehicles on HOF & Behavioral & $\mathrm{X}$ & $\mathrm{x}$ & $\mathrm{X}$ & \\
\hline 1.4 & Emissions certification: HOF is not currently a certification fuel & Regulatory & & $\mathrm{x}$ & & \\
\hline 1.5 & $\begin{array}{l}\text { Fuel volatility regulations: volatility of E25 (with current blendstock) would be too high, and therefore } \\
\text { illegal }\end{array}$ & Regulatory & & & & $\mathrm{x}$ \\
\hline 1.6 & Fuel registration requirements: HOF is not an EPA-registered fuel & Regulatory & & & $\mathrm{X}$ & $\mathrm{X}$ \\
\hline 1.7 & CAFE Credits: Current calculation may not adequately reward HOFVs & Regulatory & & $x$ & & \\
\hline 1.8 & Retailer investment requirements: cost of upgrading a retail station to offer HOF & Economic & & & $\mathrm{X}$ & \\
\hline 1.9 & HOF pricing: problem if HOF price exceeds the price of regular gasoline & Economic & $\mathrm{X}$ & $\mathrm{x}$ & $\mathrm{X}$ & $\mathrm{x}$ \\
\hline 2 & Level 2 barriers (difficult to work around; must be addressed by numerous industries) & & & & & \\
\hline 2.1 & Compatibility with boats, small engines, and classic cars & Economic & $\mathrm{x}$ & & $\mathrm{X}$ & $\mathrm{x}$ \\
\hline 2.2 & Concern about "ethanol creep" necessitating numerous technology transitions & Behavioral & $\mathrm{X}$ & $\mathrm{X}$ & $\mathrm{X}$ & \\
\hline 2.3 & Must coordinate HOF rollout between U.S. and Canada & Regulatory & & $\mathrm{x}$ & & \\
\hline 2.4 & Need to increase cellulosic ethanol production & Logistical & & & & $\mathrm{x}$ \\
\hline 2.5 & Need to move large quantities of ethanol from biorefineries to market & Logistical & & & & $\mathrm{X}$ \\
\hline 2.6 & Concern about terminal/tank-farm storage needs for third blendstock and additional ethanol & Economic & & & & $\mathrm{X}$ \\
\hline 2.7 & Misfueling HOFVs with regular unleaded & Behavioral & $\mathrm{x}$ & $\mathrm{x}$ & $\mathrm{X}$ & \\
\hline 3 & Level 3 barriers (easier to address, or HOF could succeed even if not fully addressed. & & & & & \\
\hline 3.1 & State gasoline regulations vary, some allow only E10 & Regulatory & & & $\mathrm{X}$ & \\
\hline
\end{tabular}




\begin{tabular}{|c|c|c|c|c|c|c|}
\hline 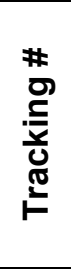 & Barrier & Type & 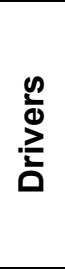 & 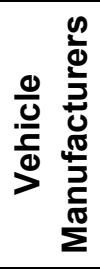 & 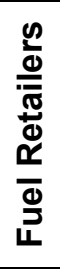 & $\begin{array}{l}\frac{0}{0} \\
\frac{0}{0} \\
\frac{0}{0} \\
\frac{0}{2} \\
\frac{0}{0} \\
\frac{0}{2}\end{array}$ \\
\hline 3.2 & Reduced E10 availability would lower/eliminate used vehicle trade-in value & Economic & $\mathrm{X}$ & & & \\
\hline 3.3 & $\begin{array}{l}\text { Reformulated gasoline requirements could interact with HOF in complicated way, because } \\
\text { reformulated gasoline requires a specialized blendstock to match the ethanol content }\end{array}$ & Regulatory & & & $\mathrm{X}$ & $\mathrm{X}$ \\
\hline 3.4 & Lack of ASTM specification for HOF & Regulatory & & & & $\mathrm{X}$ \\
\hline 3.5 & Damage that HOF may cause to dispensers is usually not covered by warranty & Regulatory & & & $\mathrm{X}$ & \\
\hline 3.6 & Some see ethanol as an inferior fuel because of properties and press coverage of E15 and flex fuel & Behavioral & & $X$ & $X$ & $\mathrm{X}$ \\
\hline 4 & $\begin{array}{l}\text { Level } 4 \text { barriers (seen as barriers by few industries, easily overcome, could be } \\
\text { misconceptions) }\end{array}$ & & & & & \\
\hline 4.1 & No consensus on what blend level HOF should be creates confusion & Logistical & & $\mathrm{X}$ & $\mathrm{X}$ & $\mathrm{X}$ \\
\hline 4.2 & Cost of vehicle technologies to realize full benefits of HOF & Economic & & $X$ & & \\
\hline 4.3 & Mechanics need to learn how to service HOFVs; training costs & Logistical & $\mathrm{X}$ & $\mathrm{X}$ & & \\
\hline 4.4 & Having HOF and non-HOF versions could double number of vehicle models for dealers & Logistical & & $X$ & & \\
\hline 4.5 & Corn ethanol is not favored by most environmentalists & Behavioral & & $\mathrm{X}$ & $\mathrm{X}$ & \\
\hline 4.6 & Introducing new fuel into a shrinking market is more difficult than into an expanding market & Economic & & & $X$ & $X$ \\
\hline 4.7 & FFV drivers don't buy flex fuel, so they probably won't buy HOF & Behavioral & & & $\mathrm{X}$ & \\
\hline 4.8 & Many vehicles requiring premium fuel are pre-2001 and therefore can't legally use E15 (in scen. 1) & Logistical & $\mathrm{X}$ & & & \\
\hline
\end{tabular}




\subsubsection{Coordinated Growth of Supply and Demand}

The most formidable barrier affecting all stakeholders is building supply and demand in concert with one another. HOF needs to be available to sell HOFVs, yet vehicles need to be available before retailers will offer the fuel.

A key strategy to curtail this barrier would be to enable HOFVs to operate on premium fuel when HOF is not available. This would be a drop of about $2 \mathrm{AKI}^{7}{ }^{7}$ which is well within the range of random variation of regular gasoline (Figure 3). Other examples where a 2-3 AKI drop in octane is tolerable to drivers includes the thousands of $87 \mathrm{AKI}$ vehicles are operating on 85 AKI in high-altitude states and the thousands of 91/93 AKI "premium" vehicles operating on 89 AKI midgrade throughout the nation, which account for most midgrade sales (over 3\% of all gasoline sales) (EIA 2014b). Despite the fact that drivers might often find a 2 AKI drop in fuel acceptable, they may be reluctant to purchase HOF vehicles before HOF is widely available and affordable, and they may not perceive premium fuel as a viable alternative due to its high cost. Once HOF is available in a given area, HOFV drivers are likely to use it because of the performance improvements and assumed price reduction. They will likely find the new stations even more quickly than the estimated 2 months it takes for FFV drivers to find and patronize a new E85 station (Anderson 2012) due to the attractive value proposition.

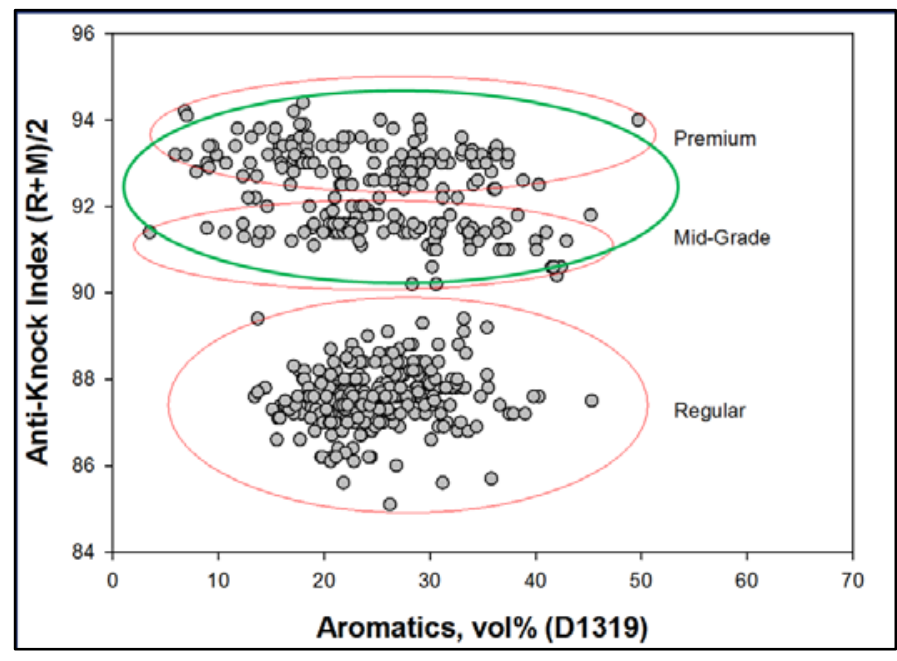

Figure 3. Octane variation in current gasoline supply

Source: AAM (2011)

When enabling premium as a backup fuel, it is important to recognize that theoretical price of E25/E40 would have been $\$ 0.29 / \$ 0.38$ lower than premium fuel in 2012 and on a trajectory to

\footnotetext{
${ }^{7} \mathrm{AKI}$ is the common octane rating posted on gas dispensers in the U.S. It is the average of the RON and the MON. HOF is assumed to be approximately $95 \mathrm{AKI}$; premium fuel is approximately $93 \mathrm{AKI}$. See glossary for the relationship between the three octane ratings.
} 
offer even greater savings in the future. ${ }^{8}$ If this differential holds true, drivers would have an incentive to refuel with $\mathrm{HOF}$ whenever possible. This preference is a key difference between the HOF market and the flex fuel market: HOFVs will perform better on HOF and HOF is cheaper on both an absolute and per-mile basis, while FFVs perform better on conventional gasoline and gasoline is usually cheaper on a per-mile basis. It should be noted, however, that a balance must be struck between consumer cost savings and fuel provider and retailer profits. In addition to price differences, HOFVs would be discouraged from refueling on regular gasoline because spark retard and torque inhibition would likely lead to decreased performance and an approximate $2.3 \%$ or greater efficiency penalty (estimate based on interpolation between Leone 2014 and Chow et. al. 2014, but highly variable and dependent on vehicle size, engine, and driving behavior).

Another potential strategy to curtail the coordinated rollout barrier is to incentivize a key party to participate. The RFS provides adequate incentive for the fuel providers, if kept to its original schedule. CAFE could provide adequate incentive for the automakers if properly calibrated (as discussed in Section 3.2.7). Perhaps incentives could focus on one of the two remaining stakeholders: vehicle purchasers and fuel retailers. Incentives have targeted these market sectors before for alternative fuels, and can provide good case studies for HOF incentives. In the US, three tax credits have been particularly influential:

- The Alternative Fuel Infrastructure Tax Credit was active from 2006 through 2013 for most alternative fuels. It provided a tax credit to fuel retailers worth $30 \%$ of the cost of adding alternative refueling capability and was capped at $\$ 30,000$. For a brief period it increased credits to $50 \%$ or $\$ 50,000$.

- The Light-Duty Hybrid Electric Vehicle (HEV) Tax Credit was active from 2006 through 2010 for qualified HEVs. The original amount of the credit ranged from $\$ 450$ to $\$ 2,600$, depending on the fuel economy of the vehicle. A half year after a manufacturer sold $60,000 \mathrm{HEVs}$, the credit would be cut in half, then down to a quarter of the value 1 year after the 60,000 mark. This credit was the primary incentive behind the now-successful HEV market.

- Some innovative incentives have also been implemented at the state and local levels. The Alternative Fuels Data Center (AFDC) Laws and Incentives database shows 424 targeting vehicle drivers and 180 targeting fuel retailers (AFDC 2014b). Some of these ( 37 for drivers and 11 for retailers) are rebates or sales tax waivers, which have proven to be more effective because the money returns to the customer immediately; the customer does not need to wait until it is time to file taxes (Diamond 2009; Gallagher and Muehlegger 2011). At present, only New Jersey and Washington have these waivers for alternative fuel vehicles (AFVs).

When using monetary incentives to spur investment in HOFVs and infrastructure, there may be a potential to spread available money too thin by incentivizing all sectors. During interviews, the

\footnotetext{
${ }^{8}$ Per EIA 2012 prices of premium, regular, and HOF extrapolated proportionally from E74 and E10. The additional amount that is paid for premium over regular has increased steadily from \$0.187 in 1995 to \$0.317 in 2013 .
} 
vehicle manufacturers recommended focusing all incentives on the retailers and the retailers recommended focusing all incentives on the vehicles. Both parties would prefer that the other one takes the first steps, so if incentives are sufficient to entice one stakeholder group to invest in HOFVs or equipment, the other side will follow. It seems as though incentivizing the retailers to invest in HOF refueling equipment would be relatively affordable. Even if the government provided the ultimate incentive in the form of grants covering $100 \%$ of HOF equipment costs, the roughly 31,000 stations needed to ensure HOF refueling convenience ${ }^{9}$ would cost an estimated \$2.5 billion for E25 and \$2.9 billion for E40 (see Barrier 1.8). Conversely, if the entire stock of 23 million light-duty vehicles (LDVs) ${ }^{10}$ that use premium unleaded (a number worth carrying a separate fuel for) were replaced with HOFVs and a grant were to cover the $\$ 455$ incremental cost, ${ }^{11}$ it would total $\$ 10.4$ billion.

In addition to incentives, the federal government has also used requirements in the past. For example, in January 1973 the EPA required all stations over a certain size to offer unleaded gasoline by July 1, 1974 ( 38 Federal Register 1253.) The size threshold was set at 200,000 gallons/year (GPY) in urban areas and 150,000 GPY in rural areas. By targeting the largest stations, the new fuel reached many more vehicles per installed dispenser. A similar strategy could be used for HOF.

A fourth option to help build supply and demand together would be to use fleets. To do this, fleets would need to determine that the cost savings of HOF are great enough to invest in the vehicles and the refueling infrastructure, possibly improved by opening the refueling infrastructure up to the public. In cases where the fleets do not provide adequate demand for their own refueling stations, they could partner with other fleets to "aggregate demand." This aggregated demand for an alternative fuel can then be supplied by a refueling station owned by one of the fleets or a third party. This fleet-based strategy and demand aggregation are already being pursued for numerous other fuels and have a substantial support network in the form of programs such as the DOE's Clean Cities ${ }^{12}$ and EPA's Smartway. ${ }^{13}$ Clean Cities' territory alone covers $80 \%$ of the U.S. population and has facilitated the use of nearly 600,000 advanced vehicles (Johnson and Singer 2014). These programs could aid the deployment of HOF alongside their suite of other market-ready fuels. Furthermore, the Federal Fleets program mandates the purchase of AFVs and reduction of petroleum use and GHG emissions. The program was originally established by the Energy Policy Act (EPAct) 2005 (U.S. Congress 2005) and has been directed by multiple executive orders since then. There are many options to encourage the Federal Fleet to adopt HOFVs and therefore create a substantial demand for the fuel.

\footnotetext{
${ }^{9}$ See Section 3.2.1.

${ }^{10}$ Of the 208 million LDVs using gasoline in 2013 (EIA 2014a), 10\% used premium (EIA 2014b).

${ }^{11}$ This is on the expensive end of the range to fully optimize for HOF (\$355 for direct injection and turbocharging [Duleep 2012] and \$100 for ethanol tolerance [IBTimes 2010; Congressional Record 2005]). In all likelihood, most cars will have DI and turbocharging during this timeframe so incremental cost should be less than $\$ 100$.

${ }^{12}$ wwwl.eere.energy.gov/cleancities/

${ }^{13} \mathrm{http}$ //www.epa.gov/smartway/
} 
A fifth strategy to curtail this barrier is to use the established 2,950 flex-fuel stations (AFDC 2014d) and 17.9 million FFVs (Polk 2015). All this equipment and these vehicles are tolerant of HOF, and FFV drivers could prefer it because their vehicles' fuel economy would be $22 \%$ greater on E40 than on E85 (based on energy density). This option would be more attractive if HOF were E40 (rather than E25) because the cost of equipping new stations for E40 is higher than for E25.

To build on the existing pool of FFVs, vehicle manufacturers could start making their regular vehicles HOF tolerant, which implies that they are not HOF-optimized, but could run on HOF when it hits the market. This option has marketing disadvantages in that anybody who tries HOF in one of these non-optimized vehicles would see a fuel economy reduction and therefore believe HOF to be an inferior fuel. This fuel economy reduction could be minimized if the HOF-tolerant vehicles were optimized to run on premium instead of regular gasoline.

Finally, regional deployment of HOF could curtail the coordination problem by attaining critical mass in one area, and could then expand into other areas. The Midwest makes the most sense to be first in a regional rollout, as two thirds of all flex fuel refueling stations (as shown in Figure 4) and $30 \%$ of the FFVs are registered in the Midwest (Polk 2015). However, California could have been an attractive initial region because the vehicle manufacturers have a history of manufacturing California-specific vehicles, though, with the implementation of Tier3/Lev3 emissions standards this will cease. The state also has substantial experience introducing new fuels for conventional vehicles. Furthermore, California has a framework of legislation (including the Low Carbon Fuel Standard ${ }^{14}$ ) that could quickly adopt and promote HOF if its ethanol component is cellulosic.

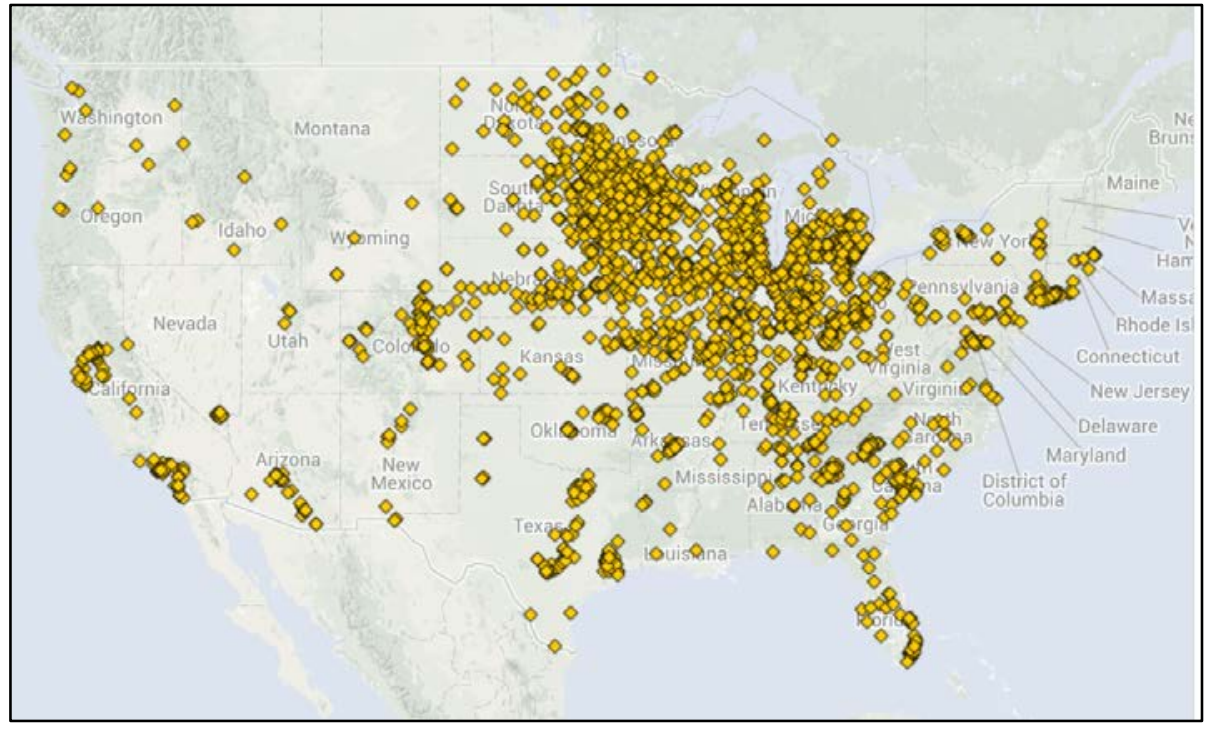

Figure 4. Flex fuel retail stations in the United States

Source: AFDC (2014a)

\footnotetext{
${ }^{14}$ www.arb.ca.gov/fuels/lcfs/lcfs.htm
} 


\subsubsection{Renewable Fuel Standard}

Ethanol producers need to make substantial investments in new cellulosic ethanol plants to supply the quantities of ethanol needed for large-scale deployment of HOF. The four commercial-scale cellulosic biofuels plants (EERE 2015) included in their financial calculations estimates of a value stream based on second-generation RFS (RFS2) regulations. EPA changes to the RFS2 schedule add to the risk of such an investment and reduce the chances that investments will be made at sufficient levels for HOF. At current ethanol and petroleum prices, the RFS is critical to ethanol investments because it ensures a demand for the ethanol produced by these and future plants. For investment to occur in time to meet future ethanol targets, the cellulosic ethanol industry needs to have confidence during investment decisions that quantities of ethanol targeted in the RFS will actually be demanded in the market, when making investment decisions years in advance.

\subsubsection{Misfueling Legacy Vehicles on High-Octane Fuel}

Drivers, fuel retailers, and vehicle manufacturers are concerned that legacy non-HOFVs will be damaged from being accidentally or intentionally filled with HOF. This concern is legitimate, primarily because long-term use of ethanol at levels above those for which an engine is designed can cause combustion enleanment, which leads to increased exhaust and engine temperatures, as well as materials compatibility issues in a conventional vehicle (Searle et al. 2014). In addition, any problems attributed to misfueling events are not covered by vehicle warranties, meaning that drivers would have to pay for all repairs. Fuel retailers are concerned because they are liable for vehicle damage and fines of up to $\$ 37,500$ because of Clean Air Act violations resulting from misfueling events (NACS 2014). Vehicle manufacturers are concerned because customers may attempt to claim warranty coverage for damage caused by misfueling, leading to extra cost for vehicle manufacturers and/or customer dissatisfaction.

A key component to overcoming this barrier is consumer education, including signage and audio messaging at the dispenser where drivers are a captive audience and their interest is most piqued. Beyond education, there are multiple ways that misfueling can be prevented at the pump. HOF could use a nozzle and gas tank opening that are larger than those for conventional gasoline. That way HOFVs could refuel on either HOF or gasoline but conventional vehicles could fit only the gasoline nozzle into their tanks. Alternatively, HOF could use colored hoses, nozzles, and matching gas caps to indicate a high ethanol blend just as flex fuel does today. An audio or visual warning could be engaged once the driver selects HOF to double check that he or she is driving a compatible vehicle. Finally, HOFVs and dispensers could be equipped with radio frequency identification (RFID) devices or Bluetooth Low Energy beacons so the HOF dispenser would dispense HOF to the appropriate vehicles only. RFID technology is already in use (SC Fuels 2014) and could expand rapidly. Early cost estimates are $\$ 10$ per tagged vehicle, $\$ 1,000$ for the nozzle's reader, and $\$ 5,000$ for software and installation (Swedberg 2013). Bluetooth Low Energy beacons cost $\$ 10-\$ 40$ and Gilbarco has integrated one into a fuel dispenser but did not make cost estimates for doing so available (Gilbarco 2013). The American Petroleum Institute (API) commissioned a study that summarizes 18 misfueling mitigation measures, their feasibility, cost, stakeholder acceptability, pros and cons, funding sources, and implementation timeframes (API 2010a). Many of these measures could be used for HOF. 
In addition to measures that prevent misfueling events, retailers need protection against misfueling liability. Such protections were proposed in the Domestic Fuels Protection Act of 2013, which is now being deliberated in committee (Congress.gov 2014). These protections would extend to federal, state, and local laws.

\subsubsection{High-Octane Fuel Is Not a Certification Fuel}

Under the EPA's current emissions control regulations (Tier 2), vehicles need to pass emissions tests while using conventional E0 or E85-the only certification fuels available. The same test fuel used for emissions also must be used for fuel economy and GHG testing for purposes of CAFE compliance and fuel economy labels. Therefore, vehicle manufacturers would not want to optimize their vehicles to HOF because it would have lower fuel economy when tested with E0.

The new Tier 3 regulations, which will replace Tier 2 beginning in 2017, facilitate increased ethanol consumption by using E10 test fuel instead of E0. Furthermore, the Tier 3 final rulemaking has opened some possibilities to use HOF as a test fuel, which would be critical to capitalize on the potential CAFE-related benefits discussed in Section 3.1.2. It states that "We will continue to monitor the in-use gasoline supply and based on such review may initiate rulemaking action to revise the specifications for emissions test fuel to include a higher ethanol blend level" (EPA 2014a). This statement seems to indicate some willingness to allow higher level ethanol blends to proliferate before certification. The rulemaking becomes more specific with the following line: "We allow vehicle manufacturers to request approval for an alternative certification fuel such as a high-octane 30 percent ethanol by volume blend (E30) for vehicles that may be optimized for such fuel." However, the EPA also requires that to have the fuel approved, the manufacturers need to demonstrate that HOF meets the following requirements:

- HOF would be used by the operator. This can be demonstrated by showing that HOF has a lower cost per mile of travel and would not be too inconvenient to refuel.

- HOF would be readily available nationwide. The EPA does not strictly define the term readily available. It could be interpreted to mean that equipment is readily available. As referred to in Section 3.2.8, "readily available" could be defined by as few as $10 \%$ of all retail stations if optimally located. Furthermore, in multiple scenarios stations could convert their equipment at minimal cost, as discussed as strategies to curtail barrier 1.1.

- One way to make HOF readily available at many stations before HOFVs are widespread is to have it at retail stations as a blendstock. As described in scenarios 1 and 2 later in this report, if a retailer swapped HOF into its premium underground storage tank (UST), with E10 in its regular UST, it could blend an E15 premium fuel. If enough stations did this, HOF could be considered readily available even though they were not actively selling it. The station economics for this strategy would be improved if the octane floor were lifted from 87 to $91 \mathrm{AKI}$, as proposed in scenario 2 .

- If HOF is not made available as a certification fuel, HOFVs could certify on the 91-93 AKI premium certification fuel under Tier 3. If HOF were 95 AKI (100 RON), these premium-optimized HOF-tolerant vehicles could use the 91-93 AKI fuel but would see a reduction in fuel economy and/or performance because the lower energy content in HOF would not be fully compensated by capturing the 
additional benefits from additional octane. This change should (conservatively assuming linear relationship between energy content and fuel economy) result in premium-optimized vehicles having approximately $3 \%$ worse fuel economy than HOFVs if HOF were E25 and an 8\% reduction in fuel economy if HOF were E40.

- HOFVs would not operate appropriately on other available fuels. This requirement would probably need to be amended if HOFVs were able to operate on premium unleaded. However, the 3\%/8\% reduction in fuel economy when switching from E25/E40 HOF would arguably qualify as "not operating appropriately," which should be taken into consideration when determining the final composition of HOF.

- HOF would result in equivalent emissions performance. This can be done, as shown by the numerous studies cited in Anderson et al. 2014.

One last option is available if the four requirements for $\mathrm{HOF}$ as a certification fuel cannot be met. HOF could be set to $51 \%$ ethanol and therefore qualify as flex fuel (assuming it met the flex fuel ASTM standard requirements). However, when Tier 3 is instated it will use a blend of E8183 as the emissions test fuel to represent flex fuel which could complicate emissions test for vehicles intending to use E51.

\subsubsection{Fuel Volatility Regulations}

RVP is a measure of how easily a fuel evaporates. The EPA regulates it because when gasoline evaporates, it contributes to ozone pollution or smog. The specific regulations, under Section 211(h) of the Clean Air Act, prohibit the sale of gasoline with an RVP higher than 9 psi during summer months; ozone non-attainment and reformulated gasoline areas have lower requirements. Blends of 9 to $10 \mathrm{vol} \%$ ethanol are allowed to be 1 psi higher in many areas, but not other blends. As Figure 5 shows, neither E25 nor E40 would consistently meet these requirements if made from conventional summer blendstock or lower RVP summer gasoline. There are four potential paths over this barrier.

- Congress could grant a 1 psi RVP waiver to HOF, just as it did for E10 in 1990. The logic is firm behind the waiver because HOF made with conventional blendstocks would have a lower RVP than E10 (Figure 5). Therefore, the waiver for HOF could be even less than 1 psi. In H.R. 1736, congressmen Adrian Smith and Dave Loebsack have drafted legislation that would expand the 1 psi waiver to HOF and all ethanol blends greater than E10. There is some uncertainty about whether the EPA could grant the waiver instead, but the EPA denied having this ability in the preamble to its E15 Misfueling Mitigation Regulation (EPA 2011). 


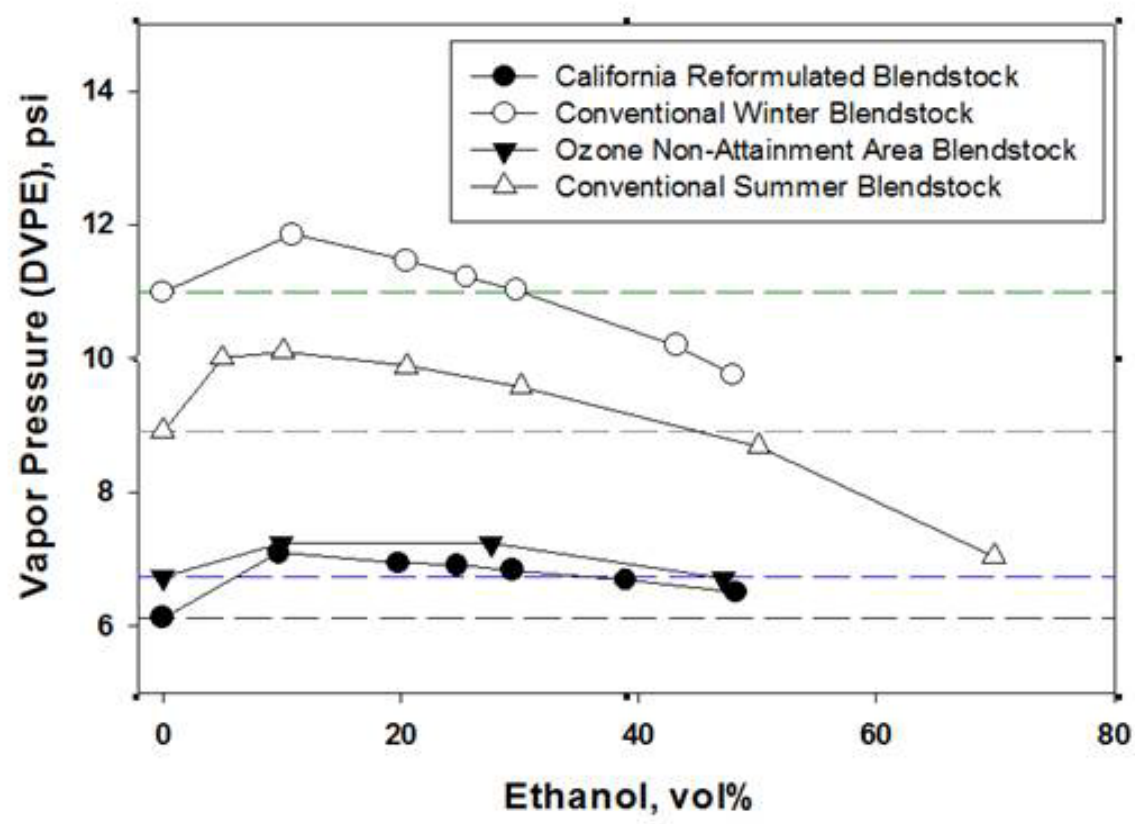

Figure 5. RVP for ethanol-gasoline blends

Source: Andersen et al. (2010) and McCormick et al. (2014)

- Eliminate E10's RVP waiver. If E10 did not have the 1 psi waiver, fuel suppliers would have to reduce the RVP of their blendstocks. Such blendstocks are already in use (see Figure 5). E10 has the highest RVP of all blends; thus, this new blendstock would reduce the RVP of all other summertime ethanol blends to less than 9 psi. This change would most effectively be done at the federal level, but states also have the right to do it. In fact, Maine, New York, Pennsylvania, and Texas have already done so (Greenhouse 2011). The primary disadvantage of this method is that the new blendstock would be more expensive. In 2002, EPA estimated that it would cost \$0.004/gallon more (Congressional Record 2002).

- Set the ethanol level of HOF higher. Figure 5 shows the RVP at various ethanol blend levels of four typical blendstocks and gasolines. There are many more blendstocks from which to choose (API 2010b), but all demonstrate that RVP decreases as the ethanol level of HOF increases beyond E25. Therefore, additional ethanol is one way to reduce the RVP of HOF. The other way is to use a blendstock with reduced RVP, which adds costs (Congressional Record 2002).

- Sell in winter, states that have opted out of the 1 psi waiver, counties with a lower RVP requirement, and states exempt from volatility requirements. Pending deeper analysis, this patchwork of markets could provide enough HOF demand to achieve critical mass for the market. RVP limitations apply from June 1 to September 15 at the retail level only - less than one third of the year. HOF with an RVP higher than 9 psi could be sold during the less-restricted months, and the HOF infrastructure (if compatible) could serve E51 to FFVs during the restricted summer months so the equipment would remain productive year round. 
States have the option to opt out of or circumvent the 1 psi Waiver, which results in a blendstock that brings the RVP of HOF below 9 psi; Maine, New York, Pennsylvania, and Texas have already exercised this right (EPA 2014b). Furthermore, Alaska, Hawaii, and U.S. territories are exempt from federal volatility regulations, so the RVP of HOF is not a barrier. Finally, more than 100 counties throughout the United States require fuels with an RVP lower than 9 psi for certain times of the year (EPA 2014b). Most of these counties have no waiver for E10. The counties that do (located in Georgia, Indiana, Michigan, and Ohio) are still considered good areas to introduce HOF because they require unique blendstocks that could be changed more easily since they are being produced in smaller quantities. All areas with RVP regulations that are conducive to HOF, as shown in Figure 6, cover 1/3 of U.S. landmass and hold approximately 1/3 of U.S. population.

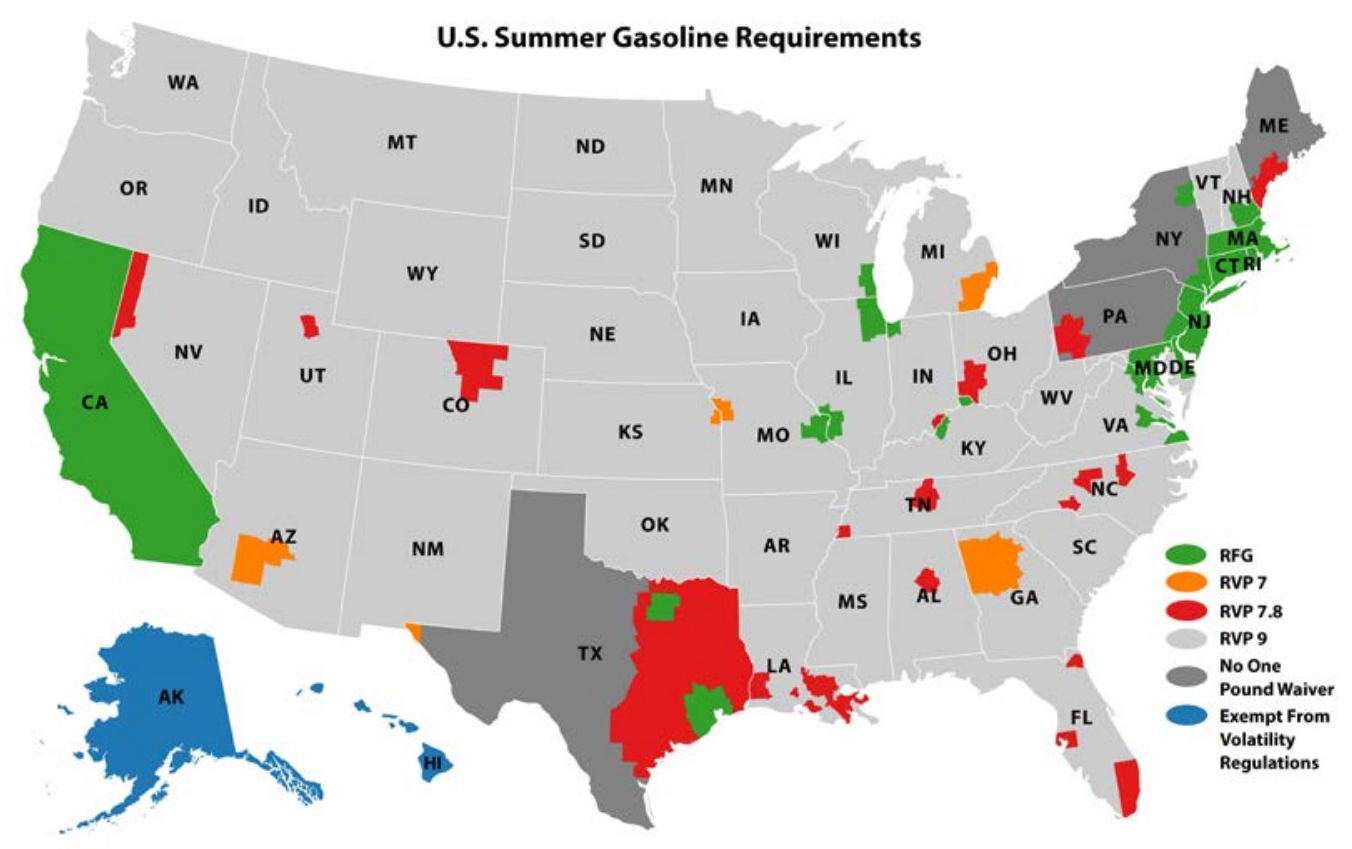

Figure 6. U.S. summer gasoline RVP requirements

Source: NREL map from EPA data. Note: 4 of the 25 regions with RVP of 7 or 7.8 allow a 1 psi waiver for E10. These are included in the map because they still require a unique blendstock and would therefore be areas where it is easier to introduce HOF.

\subsubsection{Fuel Registration Requirement}

The Clean Air Act (part 79) and EPA regulations require that HOF producers must register their fuels with EPA before selling them. HOF is currently not registered, so it is illegal to sell. There are three potential paths forward.

- HOF could be registered as an alternative fuel by DOE (per EPAct 1992 protocol [U.S. Congress 1992]) or by Congress. For DOE to do so, they would need to determine that HOF yields substantial energy security benefits, offers substantial environmental benefits, and is substantially non-petroleum (U.S. Congress 1992). It is unknown what threshold of ethanol composition DOE considers "substantial." Registering HOF as an 
alternative fuel could have the advantage of flexibility, as the registered fuel could be E16-E50 rather than a specific blend level. It would also be in agreement with the fact that only HOFVs and FFVs could use it. The EPA is actively considering this registration option, as stated in the Tier 3 final rulemaking. After designation as an alternative fuel, fuel producers would still need to work with the EPA and vehicle manufacturers to develop fuel quality standards for HOF (EPA 2014a).

- HOF could be set to $51 \%$ ethanol, and therefore qualify as flex fuel if meeting the ASTM D5798 requirements. This strategy has disadvantages for octane optimization and ethanol availability for critical mass. However, it has significant advantages for clearing multiple regulatory barriers and potentially enabling low-octane, low-cost hydrocarbon blendstocks.

- There is speculation that HOF could be registered as "substantially similar" to gasoline under Section 211(f)(1) of the Clean Air Act, which is how E15 was registered. However, HOF would have to prove that it is compatible with the legacy fleet to obtain this registration. This compatibility is unlikely, rendering the investment in a costly demonstration program as very risky.

\subsubsection{Corporate Average Fuel Economy Credits and the Greenhouse Gas Ruling}

The CAFE standards were set in place by the Energy Policy and Conservation Act of 1975, shortly after the price spikes caused by the Arab oil embargo. The fuel economy tests for CAFE compliance have historically been conducted with ethanol-free certification fuel (E0). In 1988 the "R-factor" equation was put in place to correct for slight differences in heating value of the various certification fuels being used at the time (Sluder et al. 2013, EPA 2012a). Even though the fuels were ethanol free, slight variations in heating value caused small differences in fuel economy that were important to the manufacturers on a corporate average basis. The R-factor equation attempts to adjust the fuel economy for a given test to what would have been measured had the 1975 E0 fuel been used. The R-factor equation contains a constant "R," which was determined to be 0.6 based on tests with carbureted 1970s and 1980s vehicles (Sluder et al. 2014). In the early 1990s, the Auto/Oil test program established that $R$ was about 0.93 based on tests of model year (MY) 1990 vehicles (Hochhauser et al. 1993). A similar recent analysis of test data from the DOE Intermediate Ethanol Blends program suggests that $\mathrm{R}$ should be about 0.96 (Sluder and West 2013; Sluder et al. 2014).

Differences in the R-factor-adjusted fuel economy for CAFE are small for slight variations in energy density that occur with E0 fuels (on the right side of Figure 7), but would be more significant if ethanol blends were used for certification (left side of Figure 7). As shown in Figure 7, for an arbitrary vehicle with 25 miles-per-gallon $(\mathrm{mpg})$ fuel economy, the error associated with using an R-factor of 0.6 as opposed to 0.95 is most significant for lower density fuels such as those containing ethanol (because ethanol is 33\% less energy dense than gasoline). Thus if $\mathrm{R}$ were to remain at 0.6 , HOF would be penalized. Changing the R-factor would curtail one important barrier from HOF introduction. In the Tier 3 final rule the EPA indicated the intent to "address it as part of a future action" rather than change it as part of the Tier 3 rule. In the near term, manufacturers will have to conduct emissions certification tests on E10 and fuel economy tests for CAFE compliance with E0 (EPA 2014a). 


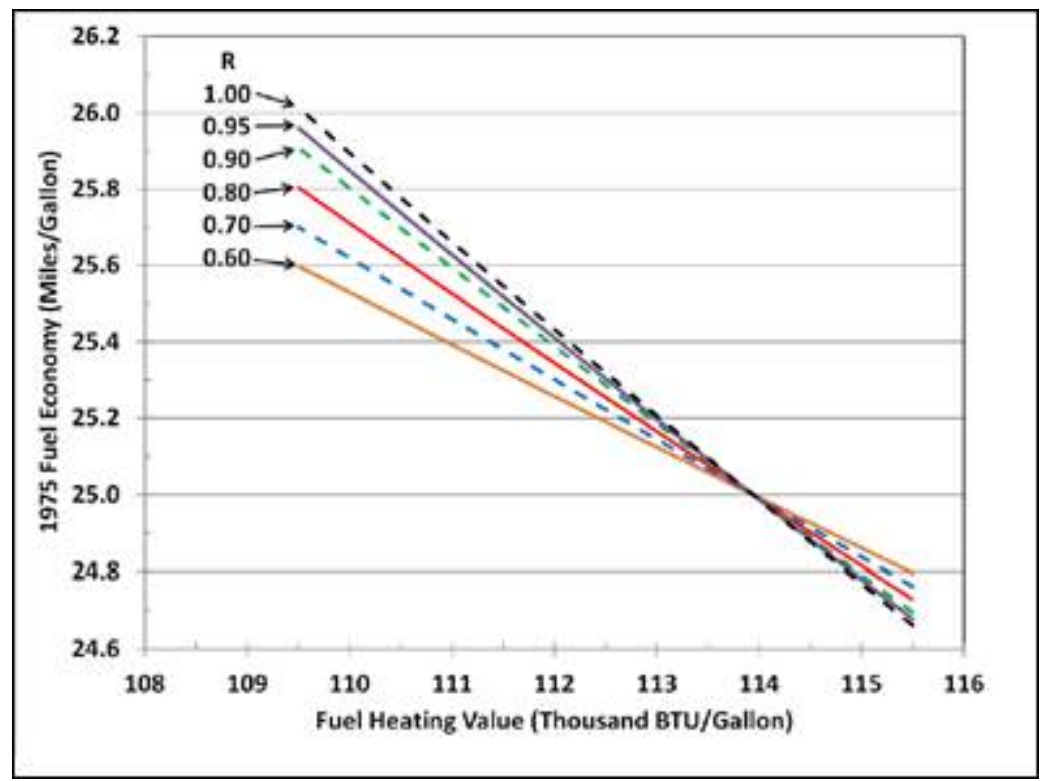

Figure 7. Influence of energy density and R-factor on calculated 1975 fuel economy results. BTU/gallon values cover the typical E10 to E0 range.

Source: Sluder et al. (2014)

For FFVs that use high-level ethanol blends such as E85, CAFE has excluded the volume of ethanol from the fuel economy calculations. For example, it accounts for only the $15 \%$ of E85 that is gasoline. This calculation also takes into account an "F-factor," which is the percent of time FFVs are using E85 instead of gasoline. The F-factor then proportionally combines the (gasoline-only) fuel economy of the vehicle using E85 with the fuel economy of the vehicle when using gasoline. In the Energy Policy and Conservation Act (EPCA) the F-factor was set at 0.5 , which effectively assumes that E85 was used $50 \%$ of the time, when in actuality it was used much less. ${ }^{15}$ To limit the distortions of this assumption, a cap was placed so that FFVs could not increase a manufacturer's fuel economy rating by more than $1.2 \mathrm{mpg}$. This had the effect of limiting the incentive to produce FFVs to $10 \%-15 \%$ of the vehicles built by a manufacturer. This cap will be phased out from MY2016-2019 with complete removal in MY2020 when an Ffactor based on actual E85 use will be implemented.

In 2007, the EPA gained the authorization to regulate GHGs as a pollutant (Supreme Court 2007). EPA then applied their GHG limitations in conjunction with the CAFE program for the first time in MY2012. The GHG standards limited the average LDV to 250 grams $\mathrm{CO}_{2}$ per mile in MY2016, which is projected to reduce to 163 grams per mile in model year 2025 (EPA 2012 b). For petroleum based vehicles, this is consistent with NHTSA's mpg-based standards. For alternative fuel vehicles, the rulings diverge (EPA and NHTSA 2012). Whichever is more stringent will be the one that the vehicle manufacturers strive to comply with. EPA's GHG

\footnotetext{
${ }^{15}$ FFVs in Minnesota are estimated to use E85 6\% of the time, based on the number of gallons of E85 consumed in Minnesota (MDOC 2014), number of FFVs in Minnesota (R.L. Polk 2014), and average fuel efficiency and vehicle miles traveled (VMT) for LDVs (AFDC 2014c).
} 
standards for ethanol apply to tailpipe emissions instead of lifecycle emissions. Multiple industry groups are advocating a shift from tailpipe emissions tracking to lifecycle emissions tracking, which would provide greater incentive to produce HOFVs, particularly if HOF used cellulosic ethanol.

It is unclear how CAFE and the GHG ruling will apply to HOFVs. Several possibilities are summarized in Table 2. HOFVs could be tested using E0 for CAFE and HOF for emissions, as will be done beginning in 2017 for E10 (low-blend method). For these approaches, the current Rfactor of 0.6 could be used, or 0.96 in order to bring CAFE and tailpipe GHG calculations into closer agreement. HOF could be designated an alternative fuel similar to Flex Fuel, and use the actual petroleum displaced for CAFE and tailpipe emissions for the GHG rule. Alternatively, lifecycle emissions could be used for the GHG rule to reflect the overall impact of the vehicles.

HOFVs will likely use HOF as often as possible, assuming it has a lower price and improves vehicle performance, which would mean that the F-factor could be close to 1 . In which case, HOFVs would be most attractive to manufacturers if their fuel economy were calculated with the alternative fuel method. However, to be calculated this way, HOF would have to be designated as an alternative fuel (see Section 3.2.6). Even if instated for HOF, the F-factor calculation is riskier for the vehicle manufacturers. If HOFVs did not actually use HOF very often (meaning that the F-factor were low), their production could be better rewarded by the other methods. Calculating CAFE based on lifecycle GHG emissions (assuming a majority cellulosic ethanol, according to RFS requirements) would be the second most beneficial to HOF. Preliminary calculations done at ORNL and NREL show that tailpipe GHG accounting and CAFE accounting with $\mathrm{R}=0.96$ yield similar results. ${ }^{16}$ The tradeoffs between the various ways of calculating CAFE credits will be further explored through the ADOPT model in future research.

Table 2. Methods by Which CAFE and GHG Calculations Could Account For HOF

\begin{tabular}{|l|l|c|}
\hline \multicolumn{1}{|c|}{ Strategy } & \multicolumn{1}{c|}{ Required changes } & $\begin{array}{c}\text { Rank of } \\
\text { Incentive to } \\
\text { Produce HOFVs }\end{array}$ \\
\hline Alternative fuel method, assuming F=1 & $\begin{array}{l}\text { DOE or Congress would need to } \\
\text { designate HOF as alternative fuel }\end{array}$ & 1 \\
\hline $\begin{array}{l}\text { Track lifecycle GHG emissions, } \\
\text { assuming RFS mix of corn and } \\
\text { cellulosic feedstocks }\end{array}$ & $\begin{array}{l}\text { EPA would have to change } \\
\text { tracking method in next standards } \\
\text { (beyond 2025) }\end{array}$ & 2 \\
\hline Track tailpipe GHG emissions & $\begin{array}{l}\text { None for EPA, NHTSA would need } \\
\text { to adjust R }\end{array}$ & 3 (tied) \\
\hline Low-blend method, changing R to 0.96 & $\begin{array}{l}\text { None for EPA, NHTSA would need } \\
\text { to adjust R }\end{array}$ & 3 (tied) \\
\hline Low-blend method, leaving R at 0.6 & None & 4 \\
\hline
\end{tabular}

\footnotetext{
${ }^{16}$ These calculations assume that tailpipe GHG emissions are 5,754 grams per gallon for ethanol and 8,672 grams per gallon of gasoline (GREET 2014)
} 


\subsubsection{Retailer Investment Requirements}

Fuel retailers bear a substantial part of the investment burden for building HOF infrastructure. Table 3 shows some of the required projects to enable the sale of HOF and their associated costs. Details may be found in Moriarty et al. 2014, which was done in conjunction with this market assessment. Many retailers do not have the money to make these investments because the average store has an operating profit of just less than $\$ 16,500$ per year (NACS 2014).

Table 3. Cost Estimates to Add Two HOF Refueling Positions at One Station

Derived from component and labor costs in Moriarty et al. (2014)

\begin{tabular}{|l|r|}
\hline \multicolumn{1}{|c|}{ Infrastructure Upgrades } & Project Cost \\
\hline E25 at station that already has E25 dispensers & $\$ 1,500$ \\
\hline E25 retrofit to older dispenser & $\$ 7,100$ \\
\hline E25 repurpose tank, new dispenser & $\$ 20,860$ \\
\hline E25 new tank and dispenser & $\$ 114,360$ \\
\hline E40 repurpose tank, new dispenser & $\$ 26,882$ \\
\hline E40 new tank and dispenser & $\$ 120,382$ \\
\hline
\end{tabular}

The magnitude of this barrier is reduced because only $20 \%$ of current gasoline stations need to offer HOF for the fuel to be conveniently available. Or in the terms of the studies into this subject, after $10 \%-20 \%$ of stations (with maximum geographical dispersion) offer a new fuel, most of the convenience penalty of limited fuel availability has been eliminated. This statement is based on studies that have assessed the "availability cost" of alternative fuels using methodologies including stated preference surveys (Greene 1998; Greene et al. 2008; Melaina et al. 2013; Liu and Greene 2014), microsimulation, and geospatial analysis of travel and access time (Nicholas et al. 2004). Greene et al. (2008) combined the insight from these approaches for DOE's modeling of market transitions to hydrogen, and a similar approach was used by the National Academy of Sciences (2013). These studies broadly conclude that the costs of limited fuel retail availability decline rapidly with station share increase (typically as a geometric or power function), with most of the availability cost reduction occurring with the first $10 \%-20 \%$ of stations. Although it can depend on how effectively stations are distributed, for retail station shares above $10 \%$ and $20 \%$, the estimated penalty of limited availability has typically declined to less than one quarter of its value at low shares ( $5 \%$ or less).

HOF upgrade costs can be significantly reduced by setting HOF's blend level to E25 or lower (perhaps E23 to allow room for blending inaccuracies). These lower level blends will be substantially less expensive to dispense than any blend higher than E25, because E25 equipment is available for purchase and is only marginally more expensive than conventional E10 equipment - it requires only upgraded elastomer materials. Conversely, any higher blend level will require flex fuel dispensers that are significantly more expensive because they use specialized metals - higher ethanol blends may corrode conventional metals. Depending on what year HOF enters the marketplace, a substantial number of E25-compatible dispensers could already be in use by retailers willing to pay the small incremental cost to be prepared for E15 or any other blends between E11 and E25. Furthermore, retrofit kits are readily available (for 
$\$ 1,950)$ that enable an E10 dispenser to safely dispense E25. Finally, if a new dispenser is needed for HOF, the E25 Underwriters Laboratories (UL)-certified dispensers cost about \$6,000 less than the flex fuel dispensers that are required for blends higher than $25 \%$ ethanol (Moriarty et al. 2014).

Another way to make upgrades more affordable to retailers is to require or incentivize equipment manufacturers to make all new equipment be HOF-compatible as soon as possible. This way, retailers will be equipping themselves for HOF as they replace expiring equipment. The incremental cost of installing HOF-compatible equipment at the point of needed replacement is negligible as opposed to the high incremental cost of purchasing new equipment before the end of its predecessor's useful life. This strategy is already in use for USTs, so most are compatible with HOF (Clean Cities 2013). Dispensers are replaced on average once every 15 years (NACS 2014), so each year that an HOF-compatibility requirement precedes the arrival of HOF should reduce the required investment in the United States by $1 / 15$ or $7 \%$. Lost assets could be minimized if stations were required to replace their dispensers with HOF-compatible upgrades within the next 15 years. Dispensers will need to become compatible with Europay-MastercardVisa (EMV) credit cards by October 2017 (Medich 2014) which could provide an opportunity for other upgrades to occur at the same time. The overall cost of HOF upgrades will be reduced if done at the same time that retailers are making their EMV upgrades, so the fuel retailers could save much money if HOF-compatible dispensers were readily available before this date.

Another way to reduce project cost is to choose stations that do not need to add new USTs for HOF. Nearly all USTs are compatible with high-level ethanol blends (Clean Cities 2013), so most gasoline or diesel tanks can be used for HOF. If a station has a UST dedicated to midgrade gasoline, HOF can replace midgrade in the tank, but midgrade can still be offered by blending premium and regular unleaded. However, only a small portion of stations have dedicated midgrade tanks. For stations that have only two gasoline tanks, an option is to reconfigure the fuel products as shown in Figure 9 and stop offering midgrade. This option will be further elaborated upon in Section 4. Another option to minimize the cost of an HOF project is to store it in an above-ground storage tank (AST). These are federally legal, but restricted by numerous state and local regulations.

Many stations now have USTs and dispensers that are physically_ but not legally_compatible with HOF (more so for E25 than for E40). This legal compatibility of the equipment is usually determined by the Authority Having Jurisdiction, unless overruled by the state government. Because UL certification of dispensers is such a lengthy and expensive process, many authorities having jurisdiction have issued waivers and variances to allow dispensers to use flex fuel (AFDC 2014d). Because HOF contains less ethanol than flex fuel, these waivers could presumably be extended to HOF and more waivers could be promulgated for HOF. This is one way that HOF could be served through legacy dispensers, which would greatly reduce the retailer's investment costs.

HOF-related costs can be further reduced by selling old dispensers on the robust used dispenser market. Used E25 and flex fuel dispensers are even available on the secondhand market for very discounted prices (www.graffco.com, www.gaspumpexchange.com). 
Given that some stations are positioned for a less expensive addition of HOF, it is important to strategically target the most appropriate early adopters. As explained above, only $20 \%$ of all gasoline stations need to sell HOF for consumer convenience. The targeted $20 \%$ of the stations should be the ones that can convert least expensively. Furthermore, the targeted station should be the largest ones because they can reach more HOFVs, and they tend to have more cash to invest. These stations could be targeted by offering grants and including items such as station throughput, dispenser type, and tank configuration in the screening process. Or these stations could self-select if properly informed about the potential competitive advantage they would have in being early adopters of HOF. This information could be disseminated through the Clean Cities program, NACS, the Society of Independent Gasoline Marketers of America, Growth Energy, or the Renewable Fuels Association (RFA).

Other than strategic grants, the government has many more ways to help gasoline retailers add HOF capability. Many of the infrastructure creation incentives found on the AFDC's Laws and Incentives search engine (AFDC 2014a), such as the Alternative Fuel Infrastructure Tax Credit, could serve as examples for how to craft pro-HOF incentives. Furthermore, the technical and outreach help of DOE's Clean Cities program could be made available to HOF retailers.

\subsubsection{High-Octane Fuel Pricing}

One of the main reasons that drivers are expected to purchase HOFVs and use HOF, as explained in Section 3.1, is because the fuel is projected to be less expensive than regular E10. Therefore, an HOF price higher than that of E10 could be a significant barrier.

A tool has already been put in place that can help resolve this barrier: the RFS2 with its associated Renewable Identification Number (RIN) market. The RFS2 sets targets for fuel refiners and importers to sell an increasing amount of renewable fuels, as represented by the "Conventional Ethanol" and "Cellulosic" categories in Figure 8. To track compliance, the EPA built a trading program into the fuel tracking mechanism of the legislation. Through this program, every gallon of ethanol or other qualifying renewable fuel is assigned a RIN when produced. Obligated parties must retire a certain number of each of four categories of RINs (Figure 8) each year, based on the amount of gasoline and diesel that they produce. Ethanol may have a cellulosic biofuel RIN (category D3), an advanced biofuel RIN (category D5), or a renewable fuel RIN (category D6), depending on what feedstock it was produced from. Obligated parties can obtain RINs by producing biofuel, purchasing biofuels, or by purchasing the RINs from the RIN market. The revenue from selling RINs allows the producer to cover that portion of their production costs, reducing the break-even price. 


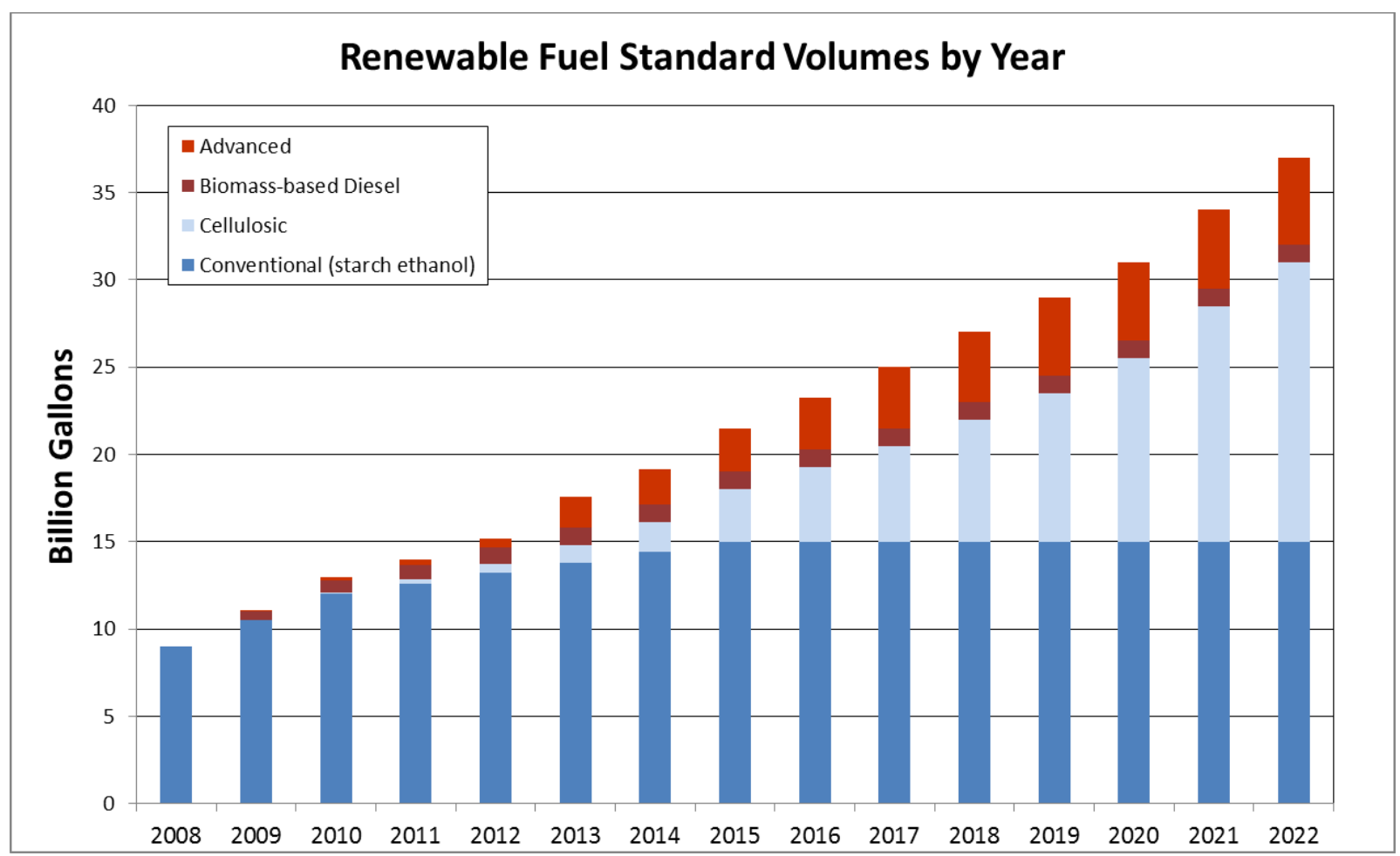

Figure 8. Renewable fuel production required by the RFS2

Source: AFDC (2014e). Note: this figure does not reflect changes to the RFS2 proposed in EPA (2015)

RINs could help keep HOF at a price where it is competitive to gasoline. However, the EPA has the authority to reassess the cellulosic biofuel target every year and is required to base the actual target on a projection that aims to accurately estimate the next year's production, without bias toward higher production (U.S. Court of Appeals 2013). In addition, because the cellulosic biofuels target can be met using cellulosic diesel fuel, cellulosic renewable hydrocarbon fuel, or cellulosic ethanol fuel, this target alone will not guarantee cellulosic ethanol industry growth, as cellulosic ethanol must compete with other fuels to provide the least-cost option to meet the regulatory requirements. Because of the nesting structure of RIN categories, if the reassessed mandate is lower than the actual production, the price of cellulosic biofuel RINs would fall toward the price of the broader advanced biofuel RINs (EPA 2014c).

Another potential strategy to curtail the possibility of HOF being priced higher than gasoline is to allow for flexibility in HOF's ethanol content while retaining a consistent octane level. This flexibility would allow blenders to choose the cheapest way to produce the fuel given real-time ethanol- and octane-related refining costs (such as type of crude oil being used). This strategy would greatly reduce the risk of HOF price spikes caused by drought-related ethanol shortages. Before this strategy is pursued, the fuel performance characteristics that are attributed to ethanol must be researched and better understood. The National Renewable Energy Laboratory (NREL) and Oak Ridge National Laboratory (ORNL) are currently undertaking research to estimate how many of HOF's performance characteristics (mostly related to charge-cooling) would be lost if octane remained the same while ethanol levels were reduced. 
A third way to increase the chances that HOF is priced lower than gasoline is to introduce it to the Midwest first. Because most corn is grown in the Midwest, transportation costs of both fuel and feedstock are minimized if ethanol is consumed there. Thus, the Midwest average price for flex fuel has been 3.2\% lower than the national average for the past 3 years (Clean Cities 2015); over the same period Midwest gasoline has cost $1.9 \%$ more than the national average (EIA 2014b).

Even if the price of HOF cannot be kept lower than that of regular gasoline, a market for HOF can still be created and sustained. To develop such a market, the value of HOF's improved performance characteristics and green attributes must be communicated to potential HOFV purchasers. A marketing strategy would need to be undertaken to establish HOF as a performance fuel, for which some drivers have shown a willingness to pay. ${ }^{17}$ This approach could best be paired with a vehicle conversion strategy where the first HOFVs are sports cars and other high-performance vehicles, which is further elaborated in Market Adoption Scenario 1 below.

\subsubsection{Lower Tier Barriers and Barrier Summary}

Table 4 summarizes the barriers to HOF adoption and their curtailment strategies. Tier 1 barriers were described in the text above and Tier 2-4 barriers are introduced in the table along with their curtailment strategies. This table illustrates that the barriers to HOF introduction are numerous, yet the curtailment strategies to these barriers are even more numerous. These strategies are promising, but some are conflicting and others are complementary. Section 4 attempts to pair complementary barriers together into HOF adoption scenarios that can then be modeled.

Table 4. Summary of the Barriers That HOF Is Facing (in Order of Formidability and Importance) and Potential Strategies to Curtail Those Barriers

\begin{tabular}{|l|l|}
\hline \multicolumn{1}{|l|}{ Tracker } & \multicolumn{1}{|c|}{ Barriers and Potential Strategies to Curtail } \\
\hline 1 & Level 1 barriers (most formidable barriers-show-stoppers if not properly addressed) \\
\hline 1.1 & Coordinated growth of supply and demand \\
\hline a & Enable HOFVs to operate on premium fuel \\
\hline b & $\begin{array}{l}\text { Incentivize fuel retailers, refueling equipment manufacturers, or vehicle purchasers to } \\
\text { participate }\end{array}$ \\
\hline c & Provide a fuel retailer requirement \\
\hline d & Fleet purchase of vehicles and fuel infrastructure \\
\hline e & Use the current 2,950 flex fuel stations and 18 million FFVs \\
\hline $\mathrm{f}$ & Manufacture HOF-tolerant vehicles that are optimized to premium gasoline \\
\hline $\mathrm{g}$ & Deploy HOF regionally \\
\hline
\end{tabular}

${ }^{17}$ Drivers have paid an average of $8.5 \%$ more for premium fuel over the past decade (EIA 2014b), and racing fuel currently sells for \$9-\$14/gallon while regular gasoline is \$2.63 (Sunoco 2015). In 1993, a model of willingness to pay found that on average consumers are willing to pay $\$ 0.04-\$ 0.08$ more per octane gallon (Setiawan and Sperline 2001). 


\begin{tabular}{|c|c|}
\hline Tracker & Barriers and Potential Strategies to Curtail \\
\hline 1.2 & RFS: unpredictability leads to investment uncertainty \\
\hline a & Keep the RFS increasing predictably, resulting in higher RIN prices \\
\hline 1.3 & Misfueling legacy vehicles on HOF \\
\hline a & Consumer education through dispenser signage and audio messaging \\
\hline $\mathrm{b}$ & Incompatible nozzle and gas tank opening \\
\hline c & Yellow hoses, nozzles, and gas caps \\
\hline d & RFID or Bluetooth devices \\
\hline e & Retailer liability protection \\
\hline 1.4 & Emissions certification: HOF is not currently a certification fuel \\
\hline a & "Readily available" could be defined as available in as few as $10 \%$ of stations \\
\hline $\mathrm{b}$ & Store HOF at retail stations as a blendstock \\
\hline c & Certify on 91-93 AKI premium instead of HOF \\
\hline d & $\begin{array}{l}\text { Argue that } 8 \% \text { reduction in fuel economy when using regular gasoline is "not operating } \\
\text { appropriately" }\end{array}$ \\
\hline e & Set HOF to E51, which qualifies as flex fuel \\
\hline 1.5 & $\begin{array}{l}\text { Fuel volatility regulations: volatility of E25 (with current blendstock) would be too high, and } \\
\text { therefore illegal }\end{array}$ \\
\hline a & Congress grants a 1 psi RVP waiver to HOF \\
\hline $\mathrm{b}$ & Eliminate E10's 1 psi RVP waiver so the blendstock must be changed \\
\hline d & Set ethanol level of HOF higher \\
\hline e & $\begin{array}{l}\text { Sell in winter, in states that have opted out of the } 1 \text { psi Waiver, and in counties with a lower } \\
\text { RVP requirement }\end{array}$ \\
\hline 1.6 & Fuel registration requirements: HOF is not an EPA-registered fuel \\
\hline a & Register HOF as an alternative fuel \\
\hline $\mathrm{b}$ & Set HOF to E51, which qualifies as flex fuel \\
\hline c & HOF could be registered as "substantially similar" to gasoline (not likely) \\
\hline 1.7 & CAFE Credits and the GHG ruling: Current calculation may not adequately reward HOFVs \\
\hline a & $\begin{array}{l}\text { Treat HOF as a low-level blend and adjust the R-factor to } 0.96 \text {, in conjunction with tracking } \\
\text { tailpipe GHGs }\end{array}$ \\
\hline $\mathrm{b}$ & Treat HOF as a high-level blend and adjust the F-factor to a number deemed reasonable \\
\hline c & Track lifecycle GHGs \\
\hline 1.8 & Retailer investment requirements: cost of upgrading a retail station to offer HOF \\
\hline a & Install HOF equipment at only $20 \%$ of gasoline stations \\
\hline b & Set HOF's blend level to E25 or lower \\
\hline c & $\begin{array}{l}\text { Require or incentivize equipment manufacturers to make all equipment HOF compatible as } \\
\text { soon as possible }\end{array}$ \\
\hline
\end{tabular}




\begin{tabular}{|c|c|}
\hline Tracker & Barriers and Potential Strategies to Curtail \\
\hline d & Choose stations, or tank configuration strategies, that do not need to add new USTs for HOF \\
\hline e & Legalize the USTs and dispensers that are physically compatible with HOF \\
\hline $\mathrm{f}$ & Sell old dispensers on the used dispenser market \\
\hline $\mathrm{g}$ & Select the early adopters that will have the most economically viable projects \\
\hline $\mathrm{h}$ & Offer grants to strategic fueling stations \\
\hline $\mathrm{i}$ & Implement tax incentives to install HOF equipment \\
\hline $\mathrm{j}$ & Use ASTs instead of USTs \\
\hline 1.9 & HOF pricing: problem if HOF price exceeds the price of regular gasoline \\
\hline a & Use RFS to drive up RIN prices and production \\
\hline $\mathrm{b}$ & Regional deployment in Midwest, where ethanol prices are lower \\
\hline c & Retain flexibility in ethanol content while focusing on consistent octane level \\
\hline $\mathrm{d}$ & Market as a performance fuel and charge a premium \\
\hline 2 & Level 2 barriers (difficult to work around; must be addressed by numerous industries) \\
\hline 2.1 & Compatibility with boats, small engines, and classic cars \\
\hline a & Offer E0 through blender pumps \\
\hline $\mathrm{b}$ & Offer E0 in ASTs at home improvement stores and marinas \\
\hline c & Keep a fuel E20 or lower available \\
\hline 2.2 & Concern about "ethanol creep" necessitating numerous technology transitions \\
\hline a & Determine ethanol content of HOF and stick to it \\
\hline $\mathrm{b}$ & Make E0 (or at least E10) available \\
\hline 2.3 & Must coordinate HOF rollout between U.S. and Canada \\
\hline a & Similar pro-ethanol incentives and requirements as active or proposed for the US \\
\hline $\mathrm{b}$ & $\begin{array}{l}\text { Focus on refueling equipment manufacturers since they service both U.S. and Canadian } \\
\text { markets }\end{array}$ \\
\hline C & Ensure that HOF benefits from British Columbia's carbon tax \\
\hline $\mathrm{D}$ & Leverage Petro Canada's SuperClean 94 and Ultra 94 gasoline in HOFVs \\
\hline 2.4 & Need to increase cellulosic ethanol production \\
\hline a & Aggressive RFS, or other biofuel policy, is mandatory to encourage cellulosic investment \\
\hline 2.5 & Need to move large quantities of ethanol from biorefineries to market \\
\hline a & Build ethanol-capable pipelines similar to the Central Florida Pipeline (AFDC 2009) \\
\hline $\mathrm{b}$ & Develop ways to make current pipelines compatible with ethanol \\
\hline c & Expand rail coverage to widely distributed cellulosic ethanol plants \\
\hline $\mathrm{d}$ & Remove Chicago rail bottleneck, possibly funded by a tax on rail delays \\
\hline 2.6 & Concern about terminal/tank-farm storage needs for third blendstock and additional ethanol \\
\hline a & Should limit the blendstocks to two, even if they have to be changed \\
\hline
\end{tabular}




\begin{tabular}{|c|c|}
\hline Tracker & Barriers and Potential Strategies to Curtail \\
\hline 2.7 & Misfueling HOFVs on regular unleaded \\
\hline a & $\begin{array}{l}\text { Remove high-altitude } 85 \mathrm{AKI} \text { regular unleaded to minimize octane discrepancy between HOF } \\
\text { and regular unleaded }\end{array}$ \\
\hline $\mathrm{b}$ & $\begin{array}{l}\text { Switch high-performance vehicles over first because they can afford spark retard without } \\
\text { becoming dangerously under-torqued }\end{array}$ \\
\hline c & Switch current premium models over first because those owners are more fuel cognizant \\
\hline $\mathrm{d}$ & Matching nozzle color or size \\
\hline e & Signage and audio warnings \\
\hline f & RFID or Bluetooth devices \\
\hline 3 & Level 3 barriers (easier to address, or HOF could succeed even if not fully addressed) \\
\hline 3.1 & State gasoline regulations vary, some allow only E10 \\
\hline a & $\begin{array}{l}\text { Get ASTM to codify the HOF standards, then states would be more likely to accept higher } \\
\text { blends }\end{array}$ \\
\hline $\mathrm{b}$ & $\begin{array}{l}\text { Outreach through organizations such as the National Governors Association and regional } \\
\text { governors associations }\end{array}$ \\
\hline c & Midwest states tend to be ethanol friendly, so regional deployment would alleviate this barrier \\
\hline 3.2 & Reduced E10 availability could lower/eliminate used vehicle trade-in value \\
\hline a & Slow timing of the transition would minimize depreciation of conventional vehicles \\
\hline $\mathrm{b}$ & Time E10 phase-out with the expiration of these vehicles \\
\hline c & Cash for Clunkers-type program could take the last ones off the streets \\
\hline $\mathrm{d}$ & Only $20 \%$ of the stations need to offer E10 to be convenient \\
\hline 3.3 & $\begin{array}{l}\text { Reformulated gasoline requirements could interact with HOF in complicated way, because } \\
\text { reformulated gasoline requires a specialized blendstock to match the ethanol content }\end{array}$ \\
\hline a & Blendstock suppliers would need to re-optimize to achieve emissions and octane ratings \\
\hline $\mathrm{b}$ & HOF and HOFVs could possibly replace reformulated gasoline for Clean Air Act compliance \\
\hline 3.4 & Lack of ASTM specification for HOF \\
\hline a & Takes ASTM 1-5 years to write new standards \\
\hline 3.5 & Damage that HOF may cause to dispensers is usually not covered by warranty \\
\hline a & Dispenser manufacturers already offer warranties to E25 on some models \\
\hline $\mathrm{b}$ & UL testing should be rigorous enough to make manufacturers comfortable with warranty \\
\hline 3.6 & $\begin{array}{l}\text { Some see ethanol as an inferior fuel because of properties or press coverage of E15 and flex } \\
\text { fuel }\end{array}$ \\
\hline a & $\begin{array}{l}\text { Market as a performance fuel both directly and through retailers. Teach retailers about merits } \\
\text { of HOF so they know that it will be easier to sell than flex fuel. }\end{array}$ \\
\hline $\mathrm{b}$ & Educate customers about octane in general \\
\hline
\end{tabular}




\begin{tabular}{|c|c|}
\hline Tracker & Barriers and Potential Strategies to Curtail \\
\hline 4 & $\begin{array}{l}\text { Level } 4 \text { barriers (seen as barriers by few industries, easily overcome, could be } \\
\text { misconceptions) }\end{array}$ \\
\hline 4.1 & No consensus on what blend level HOF should be creates confusion \\
\hline a & $\begin{array}{l}\text { Could just focus on performance characteristics of fuel, with flexible ethanol level and } \\
\text { equipment compatibility }\end{array}$ \\
\hline $\mathrm{b}$ & $\begin{array}{l}\text { Needs to be decided upon by considering technical, logistical, and economic tradeoffs of } \\
\text { various blends }\end{array}$ \\
\hline 4.2 & Cost of vehicle technologies to realize full benefits of HOF \\
\hline $\mathrm{a}$ & Technological investments are being made to meet CAFE anyway \\
\hline $\mathrm{b}$ & Most vehicles will have direct fuel injection and turbocharging \\
\hline c & Economies of scale will be reached for ethanol tolerance \\
\hline 4.3 & Mechanics need to learn how to service HOFVs; training costs \\
\hline a & Vehicle manufacturers will train dealers' mechanics, which they do regularly \\
\hline $\mathrm{b}$ & Opportunity for trade schools \\
\hline 4.4 & Having HOF and non-HOF versions could double number of vehicle models for dealers \\
\hline a & Vehicle manufacturers may convert entire models to HOFVs \\
\hline $\mathrm{b}$ & Modern inventory systems and technology should make this easier \\
\hline 4.5 & Corn ethanol is not favored by most environmentalists \\
\hline a & Sell it on its economic and performance merits \\
\hline b & Educate public about cellulosic ethanol \\
\hline 4.6 & Introducing new fuel into a shrinking market is more difficult than into an expanding market \\
\hline a & Focus on increasing in-store sales and expanding retailer business model \\
\hline 4.7 & FFV drivers don't buy flex fuel, so they probably won't buy HOF \\
\hline a & Many FFV drivers don't know that they can use flex fuel \\
\hline $\mathrm{b}$ & $\begin{array}{l}\text { Flex fuel reduces the fuel economy of FFVs, whereas HOF should not reduce the fuel } \\
\text { economy of HOFVs }\end{array}$ \\
\hline c & Flex fuel is not properly priced. HOF must be properly priced. \\
\hline $\mathrm{d}$ & HOFVs will not be allowed to use regular gasoline the way FFVs can \\
\hline 4.8 & Most vehicles requiring premium fuel are pre-2001 and therefore can't use E15 (in scenario 1) \\
\hline a & $\begin{array}{l}\text { By } 2018 \text { these cars are } 17 \text { years old so there is generally less concern about potential long- } \\
\text { term damage }\end{array}$ \\
\hline $\mathrm{b}$ & These vehicles can conveniently refuel at non-HOF gas stations, as long as $20 \%$ of them stay \\
\hline
\end{tabular}




\section{Market Adoption Scenarios}

Many potential strategies to curtail the marketing barriers of HOF are complementary or even synergistic with one another. This section tries to group those strategies together into HOF adoption scenarios. The scenarios are compiled so that they can test the barrier curtailment strategies and the entire fuel production and distribution system through fast adoption and slow adoption scenarios. By testing the system, they may offer systemic insights through modeling.

Many of the curtailment strategies are used in multiple scenarios, and some are not used. Table 5 lists the strategies that apply to all scenarios along with the exceptions to those assumptions. Each scenario will list the incorporated strategies and how they are modeled. In many cases, a scenario serves as a baseline for a sensitivity analysis to be done on a specific parameter. These sensitivity analyses will be discussed in the model-specific sections of this report.

Table 5. Barrier Curtailment Strategies Common to All Scenarios except Variance Scenarios

\begin{tabular}{|c|c|}
\hline Common Barrier Curtailment Strategies Except for Variance Scenarios & $\begin{array}{l}\text { Variance } \\
\text { Scenario }\end{array}$ \\
\hline HOF refueling considered convenient when offered at $20 \%$ of gasoline stations & none \\
\hline Allow HOFVs to operate on premium fuel & none \\
\hline RIN prices are given at $\$ 0$ and $\$ .50 /$ gallon ethanol & none \\
\hline RFS schedule varies between 13-34 billion GPY by 2035 & none \\
\hline HOF is an EPA-registered fuel & 5 \\
\hline HOF is allowed as a Tier-3 certification fuel & 1,5 \\
\hline E25 receives the same $1-\mathrm{lb}$ waiver as E10, or the RVP of E40 is below $9 \mathrm{lb}$ & 5 \\
\hline $\begin{array}{l}\text { CAFE calculates HOF as low-level blend, uses R-factor of } 0.96 \text {. This has a similar effect } \\
\text { to tracking the tailpipe GHG emissions }\end{array}$ & none \\
\hline Equipment manufacturers make all new equipment HOF-compatible immediately & 2,4 \\
\hline Only 1 dispenser (two refueling positions) converted to HOF & 8 \\
\hline $30 \%$ of retail stations have a UST that can be repurposed & none \\
\hline Misfueling mitigation techniques are successful & none \\
\hline Various retailer subsidies given at $0 \%, 40 \%$, and $80 \%$ of total investment & none \\
\hline No vehicle rebates are given. & 3 \\
\hline Ethanol can be profitably transported to retailers in adequate quantities for HOF & none \\
\hline State limitations on ethanol blends are curtailed & 7 \\
\hline $\begin{array}{l}\text { Incremental cost of HOFV is } \$ 100 \text { for ethanol tolerance. All vehicles have DI and } \\
\text { turbocharging in year of implementation. }\end{array}$ & 8 \\
\hline A maximum of 25 ethanol refineries can be constructed per year & all \\
\hline
\end{tabular}




\subsection{Scenario 1: Replace Midgrade with High-Octane Fuel and Market Performance Attributes}

Scenario 1 replaces midgrade gasoline at the stations with HOF and converts performance vehicles to be the first HOFVs.

Replacing midgrade gasoline with HOF significantly decreases the equipment costs to the station because it avoids installing a third UST. It is accomplished through the tank use scenario shown in Figure 9, where premium is replaced with HOF in the UST and is instead blended from E10 and HOF. All estimates were made based on linear relationships between blend level and octane, which is an oversimplification (especially when moving beyond E30) that would have to be closely evaluated by fuel experts. The regular blendstock would likely have to have some premium BOB blended in to allow for a 91 AKI fuel that is E15.

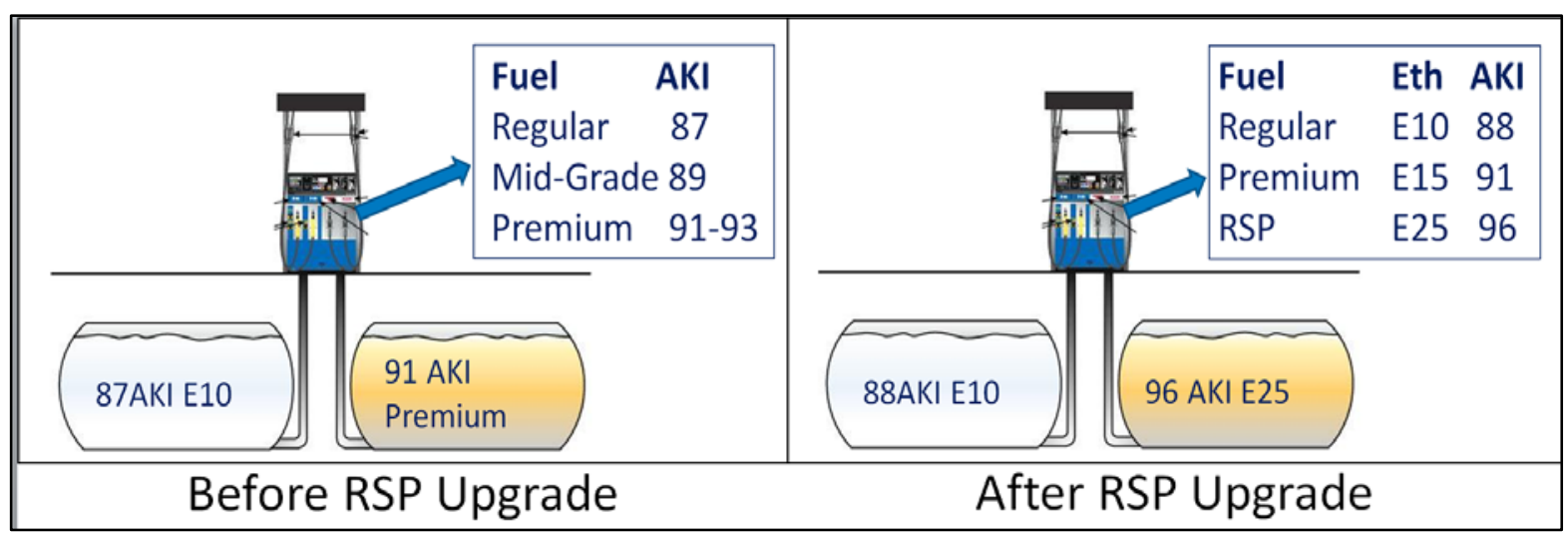

Figure 9. One strategy to offer HOF from a station with only two gasoline USTs

Removing midgrade from the suite of fuels sold is deemed acceptable because no vehicles actually require midgrade. Therefore, the people purchasing it are either using it in regular vehicles (and therefore wasting the octane) or in premium vehicles (and are therefore slightly reducing their fuel economy or performance).

Ninety-one AKI is on the low end of premium's octane range, but is deemed acceptable by premium vehicle owners in many parts of the country, including those served by the widely utilized Colonial Pipeline and all high-altitude states.

The configuration shown in Figure 9 creates a potential problem in that premium is now E15, which pre-2001 vehicles cannot use. However, as long as $20 \%$ of the stations still sell premium E10 these vehicles will be able to refuel conveniently. By the time HOF is offered at $80 \%$ of the stations (meaning that premium E10 is offered at the remaining $20 \%$ of the stations), the pool of pre-2001 premium vehicles will be very small. ${ }^{18}$

\footnotetext{
${ }^{18}$ Calculate this based on vehicle retirement rates.
} 
The first vehicle models in this scenario to be converted to HOF are the models currently using premium fuel. Afterward, it will expand to other models from the highest to the lowest performance. These vehicles tend to be the ones that are already equipped with DI and turbocharging, which enable them to best take advantage of HOF's performance-enabling attributes with very low incremental cost. This rollout strategy helps to curtail multiple barriers as described below.

The strategy also minimizes the greatest risk associated with misfueling if the owner does happen to fuel with regular gasoline: that the regular gasoline would reduce the torque generated by the engine to the point where the vehicle is not functional. The lack of functionality could be the inability to tow a load, scale a steep incline, or accelerate. In some cases this risk could pose a danger to the driver and passengers and is therefore a liability to all parties involved. Highperformance vehicles (identified by fast acceleration times) can safely afford more torque reduction than low-performance vehicles before they move into a dangerous situation.

Furthermore, converting high-performance vehicles first also implements a sound marketing strategy. HOF would become known as a performance fuel to be used in performance vehicles, which could allow retailers to charge more for it. Note that this would be a different sales strategy than the one predicated on consumer cost savings. Premium fuel already demands a higher price; it has been selling on average for $8.5 \%$ more than regular gasoline over the past decade (EIA 2014b). It is certainly the case for racing fuels that currently sell for \$9-\$14/gallon while regular gasoline is $\$ 2.63 /$ gallon (Sunoco 2015). The high-performance reputation is likely to help to sell fuel and should help to sell vehicles. Marketing on performance instead of economics has been key to numerous products, including the second generation of electric vehicles after the discontinuation of the first generation (Figure 10). Such a marketing strategy could enable fuel retailers to charge a higher margin on HOF, resulting in more retailers offering the fuel.

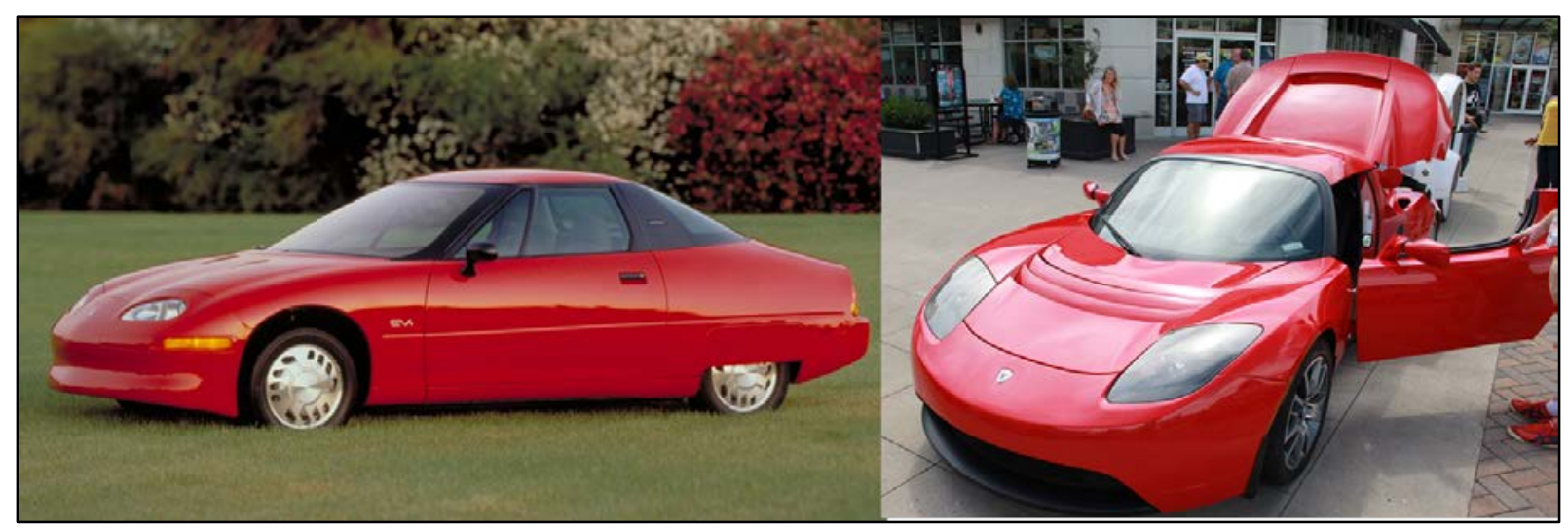

Figure 10. GM's EV1 (1998) and Tesla's Roadster (2008). Representative of a marketing shift

Sources: General Motors (left) and Matthew Abele (right)

Scenario 1, as with all other scenarios to follow, is much more than the sum of component curtailment strategies. That said, the strategies that it employs are listed in Table 6. 
Table 6. Barrier Curtailment Strategies Used by Scenario 1

\begin{tabular}{|l|}
\hline Scenario 1 Barrier Curtailment Strategies \\
\hline HOF is E25, which minimizes equipment costs \\
\hline $\begin{array}{l}\text { First HOFVs are high performance to establish reputation as performance fuel, minimize } \\
\text { misfueling, and avoid danger in case of spark retard }\end{array}$ \\
\hline Remove 85 AKI from high-altitude areas to reduce misfueling-based spark retard \\
\hline Vehicle rollout from best accelerating to least \\
\hline Replace premium UST with HOF, and mix E15 premium \\
\hline Market HOF as a performance fuel, and possibly charge more \\
\hline Use HOF as a blendstock, rendering it readily available before demand is fully developed
\end{tabular}

\subsection{Scenario 2: HOF-Tolerant, Premium-Optimized Intermediary}

The first step in scenario 2 is to eliminate 85 AKI gasoline in high-altitude states and replace it with 87 AKI. This sets the stage for engines to be optimized to higher octane (such as premium or HOF) because if these vehicles refuel on regular gasoline, the difference in octane, and therefore spark retard and reduced performance, won't be as great. Many industry experts have asserted that 85 AKI should be eliminated regardless of HOF, for the benefit of the current fleet of vehicles. The reasoning behind $85 \mathrm{AKI}$ at high altitude is no longer valid because of advances in engine technology. The carbureted vehicles that performed just as well on $85 \mathrm{AKI}$ as on 87 AKI (the reason for the current allowance of 85AKI) comprise only $2 \%$ (and declining) of the U.S. vehicle stock (USA Today 2013). Conversely, all modern regular gasoline vehicles are optimized to $87 \mathrm{AKI}$, and running them on $85 \mathrm{AKI}$ results in loss of power, reduced fuel efficiency, and increased emissions (Alliance of Automobile Manufacturers 2012).

The next step in scenario 2 is to optimize all new vehicles to 93 AKI ( 98 RON) - current U.S. premium gasoline. This move alone is estimated to lower fuel consumption in the United States by $4.5 \%-6 \%$ by 2040 (Chow et al. 2014). Furthermore, all new vehicles would be ethanol tolerant, meaning that they could handle HOF. A vehicle that is optimized to E10 premium can easily run on HOF with only modest efficiency losses because of its lower energy content (estimated 3\% loss on E25). ${ }^{19} \mathrm{HOF}$ is projected to be priced so that HOFV drivers can still see a cost savings despite these losses in fuel economy (see Section 3.1.1). However, one negative aspect of optimizing to premium instead of HOF is that HOF would not be perceived as a performance fuel because performance will not improve on HOF and fuel economy will drop.

\footnotetext{
${ }^{19}$ Estimated by accounting for the reduction in energy content in a fuel but adding $2.3 \%$ efficiency increase to account for better octane usage. The 2.3\% figure was derived based on Chow et al. 2014 and Leone et al. 2014.
} 
As demand for HOF increases and demand for $87 \mathrm{AKI}$ is reduced (following the shift in vehicle population), individual fuel retailers will decide to convert their equipment to HOF. Because HOF would be replacing regular gasoline and midgrade would be eliminated, most retailers would not need to install new tanks. If they want to continue selling regular along with premium and HOF, they could use the same two-tank configuration shown in Figure 9. This scenario could have the additional benefit of allowing stations to use HOF as a blendstock for premium before HOF-optimized vehicles are produced, therefore making it readily available to become a certification fuel. Table 7 contains the curtailment strategies that are used in scenario 2 .

Table 7. Barrier Curtailment Strategies Used by Scenario 2

\begin{tabular}{|l|}
\hline Scenario 2 Barrier Curtailment Strategies \\
\hline Remove 85 AKI from high-altitude areas to reduce misfueling-based spark retard \\
\hline First-generation HOFVs are optimized to 91 AKI but tolerant to HOF \\
\hline All new dispensers are E25 compatible \\
\hline Remove 87 AKI E10 once the price differential between premium and regular is minimized \\
\hline Use HOF as a blendstock, rendering it readily available before demand is fully developed \\
\hline
\end{tabular}

\subsection{Scenario 3: Price-Driven Adoption}

Scenario 3 markets HOFVs to drivers who are trying to minimize the total cost of vehicle ownership. ${ }^{20}$ To do so, the first HOFVs to be offered will be the most fuel-efficient models. The high fuel economy combined with the lower price of HOF would result in vehicles with lower cost of operation. Then sequentially less-efficient models will be converted to HOFVs. However, these vehicles do not represent the fastest payback; because they require fewer gallons, it takes longer for the per-gallon fuel savings to accrue.

In this scenario, it is especially important to keep the price of HOF lower than that of gasoline. Policy measures, including but not limited to the RFS, as well as technological and market measures such as improved conversion technologies and economies of scale, might all contribute to lower prices. The number of capital cost grants given to retail stations and RIN prices is explored in Section 6.1. Vehicle subsidies worth $\$ 2,500$ to the driver were also explored in this scenario. Table 8 lists the strategies addressed through scenario 3.

\footnotetext{
${ }^{20}$ Total cost of ownership looks at the vehicle purchase price, fuel costs, maintenance, and insurance over the lifetime of the vehicle.
} 
Table 8. Barrier Curtailment Strategies Used by Scenario 3

\begin{tabular}{|l|}
\hline Scenario 3 Barrier Curtailment Strategies \\
\hline Vehicle rollout from most to least fuel efficient \\
\hline RIN prices increased \\
\hline Retail equipment is subsidized \\
\hline Vehicle subsidy of $\$ 2,500$ given (as alternate scenario) \\
\hline
\end{tabular}

\subsection{Scenario 4: Accelerated Deployment}

Scenario 4 serves as a bookend with the fastest vehicle penetration and HOF adoption. It is meant to stress the HOF production system and infrastructure in the models. This scenario assumes that all new vehicles, starting in MY 2018, are optimized for HOF. Because the average LDV lasts about 16 years (Davis et al. 2014), nearly the entire stock of LDVs will presumably be HOFVs in 2034. This model year might be unrealistic by the point of publication. However, it was chosen to represent a very aggressive market adoption and because model parameters are more concrete when modeling relatively current years. Results may be interpreted as years from current date as an introduction date becomes clearer.

On the retailer side, all new dispensers (about 40,700 dispensers per year) would be HOF compatible. ${ }^{21}$ This dispenser compatibility would make it much cheaper for any retailer that wants to offer HOF in the future. Furthermore, this scenario assumes that the largest $20 \%$ of retailers (with urban and rural areas accounted for separately) are mandated to offer HOF. Such a mandate is how unleaded gasoline was introduced, where urban stations that sold more than 200,000 GPY and rural stations that sold 150,000 GPY were required to sell unleaded (38 FR 1253). There are significant advantages to requiring the largest stations to convert first. They tend to have more money or credit available for the investment, and they also tend to have more USTs that create flexibility for offering HOF without purchasing a new UST. NACS 2014 data show that to target the $20 \%$ largest stations, the threshold should be set at approximately 175,000 GPY.

This scenario assumes that retailers configure the equipment to dispense HOF in a costminimizing way, which means that HOF is more likely E25 instead of E40. It also means that the mandated stores are required to have only one HOF dispenser (or two refueling positions). Although not modeled, ASTs should be considered in this scenario because they are substantially cheaper than USTs. Table 9 shows barrier curtailment strategies tackled by scenario 4.

\footnotetext{
${ }^{21}$ The estimate is based on NACS (2014) data. The average station has 4.05 dispensers; 150,822 total stations * 4.05 $=610,829$ dispensers in the nation. Dispensers are expected to last 15 years, so $1 / 15 * 610,829=40,722$ new dispensers per year.
} 
Table 9. Barrier Curtailment Strategies Used by Scenario 4

\begin{tabular}{|l|}
\hline Scenario 4 Barrier Curtailment Strategies \\
\hline All new vehicles starting in MY 2018 are optimized for HOF \\
\hline All new dispensers ( $39,000 /$ year) would be HOF compatible \\
\hline Mandate or incentivize any station more than 150,000 or 200,000 GPY to sell HOF \\
\hline
\end{tabular}

\subsection{Scenario 5: E51 Intermediary}

E51 bypasses all of HOF's regulatory barriers because it is considered flex fuel and is therefore a registered alternative fuel. It also curtails a substantial number of the simultaneous rollout barriers by using the current 2,950 flex fuel stations (AFDC 2015) and many of the 17.9 million FFVs (Polk 2015). This scenario assumes that HOFVs are optimized to E40 but use E51 sold through the current flex fuel infrastructure until HOF curtails the regulatory barriers and adds new HOF infrastructure. Once the HOF market is established, flex fuel retailers would likely transition to sell HOF instead.

Scenario 5 assumes that all 2,950 flex fuel stations market a flex fuel that is E51. This transition is in the best interest of all parties involved for the following reasons:

- E51 wastes less octane than higher blends of flex fuel, which results in a higher value and more economical use of ethanol. This benefit is true if HOF is used in FFVs and is especially true if used for E40-optimized HOFVs.

- The 17.9 million FFVs currently on the road would likely start using more ethanol fuel if it were E51 (rather than flex fuel) because they would achieve up to $16.4 \%$ better fuel economy. ${ }^{22}$ Similarly, when switching from E10 to E51, FFVs would see only a 7\% penalty in fuel economy instead of a $26 \%$ penalty. Additionally, FFVs may be able to capture some of the additional performance benefits of HOF, resulting in better fuel economy than these energy-based calculations would predict. ORNL is performing tests to see if this is indeed the case.

- This improved fuel economy would likely boost sales at the retailers that have already invested in ethanol-compatible equipment.

- HOFVs that are optimized to E40 would see only a 4\% reduction in fuel economy when using E51 instead of E40, so it is not likely to be a large deterrent.

- The 2,950 flex fuel stations in the United States already have achieved critical mass in numerous regions. Therefore, HOFVs in these areas could drive solely on E51 and HOF.

- Minimizing the ethanol content of flex fuel allows it to be more widely dispersed, and supports a larger market, before demand drives prices up.

\footnotetext{
${ }^{22}$ All fuel economy estimates for FFVs are based on energy density.
} 
Scenario 5 is also particularly suitable to use a fleet-based deployment strategy because so many fleets have embraced FFVs and infrastructure (EIA 2013b). HOF is particularly attractive to police fleets because they can best use its performance benefits. Furthermore, with nearly 200 police fleets reporting flex fuel projects to the Clean Cities program in 2013, they are particularly well positioned to implement this scenario (Johnson and Hettinger 2014). Table 10 highlights the curtailment strategies addressed by scenario 5 .

The Tier 3 final rulemaking states that EPA intends to use E81-83 as the emissions test fuel to represent flex fuel which could complicate emissions test for vehicles intending to use E51.

Table 10. Barrier Curtailment Strategies Used by Scenario 5

\begin{tabular}{|l|}
\hline Scenario $\mathbf{5}$ Barrier Curtailment Strategies \\
\hline Optimize vehicles to HOF, but run them on E51 until HOF infrastructure is rolled out \\
\hline E51 counts as flex fuel, so it bypasses EPA registration, RVP, and certification fuel barriers \\
\hline Uses 2,950 flex fuel stations and 18 million FFVs when coordinating fuels and vehicles \\
\hline Particularly helpful in reducing station costs if HOF is greater than E25 \\
\hline
\end{tabular}

\subsection{Scenario 6: Blender Pumps}

Two large issues when marketing HOF are ethanol creep and the desire to offer E0 to marine and other off-road engines. Blender pumps can solve these problems by providing a wider variety of fuel options. They assure the retailers that they will not have to make further investments if the ideal ethanol blend level is changed. They also assure off-road engine and vintage car owners that they will be able to refuel on E10 or E0 no matter what blends modern cars use. Furthermore, blender pumps offer some flexibility if the optimal HOF blend changes.

Blender pumps are a mature technology that is used in most stations to blend regular and premium gasoline into midgrade. They are increasingly being used for midlevel ethanol blends; about 350 stations own such dispensers produced by three major manufacturers (Clean Cities 2013). As shown in Figure 11, blender pumps can be configured to offer a wide variety of blends and octane levels. They are usually blended from just two USTs, so retailers will not have to invest in new USTs. This configuration is possible because flex fuel, which is one of the blendstocks in a UST, can be anywhere from $51 \%$ to $83 \%$ ethanol. A higher ethanol fuel can also be stored and used to blend flex fuel and the other fuels. For HOF, we recommend a configuration with E10, E15, HOF, and flex fuel. E0 can also be offered if the retailer feels that the off-road sector provides adequate demand and 87 minimum AKI E0 can be obtained. 


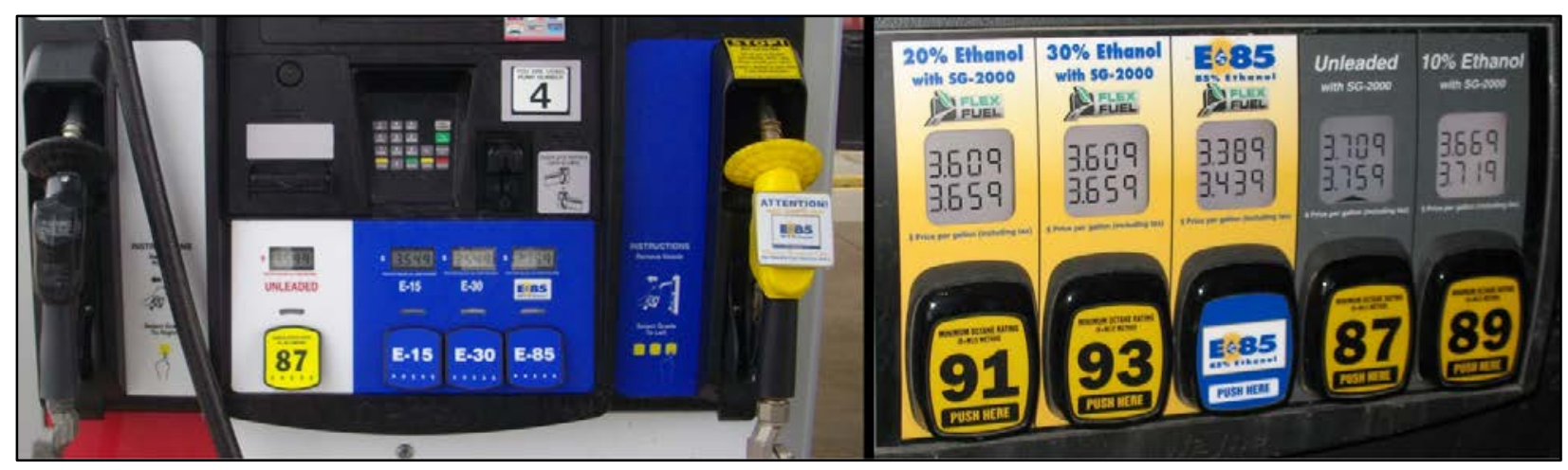

Figure 11. Two fuel configurations at ethanol blender pumps

Source: Southwest Research Institute

Despite their merits, blender pumps will likely increase the chances of customer confusion and misfueling if not properly labeled. Posting the octane of each blend (Figure 11, left) encourages people to use the highest blend their cars can handle. Posted prices will likely have the same effect. Clear labeling must differentiate the vehicles that can use E0 (all engines), E10, E15 (all on-road vehicles MY 2001 and newer), HOF (HOFVs and FFVs) and flex fuel (FFVs). An audio recording would also be helpful, and an RFID system would greatly simplify the refueling process. Table 11 illustrates the barrier curtailment strategies handled through scenario 6.

Table 11. Barrier Curtailment Strategies Used by Scenario 6

\begin{tabular}{|l|}
\hline Scenario 6 Barrier Curtailment Strategies \\
\hline Minimize costs by using existing two tanks \\
\hline Allow for clear gasoline to be sold to off-road engines \\
\hline Signs, recordings, and RFID help reduce misfuelings and confusion \\
\hline
\end{tabular}

\subsection{Scenario 7: Regional Deployment}

As discussed in Section 3.2.1, many aspects of introducing HOF and HOFVs simultaneously can be simplified if done on a regional basis. This strategy allows the nation to focus its resources on a smaller market so that it might achieve critical mass of both supply and demand of HOF. Then the adoption of HOF can expand beyond this stable initial market until it eventually reaches the entire country. Regional deployment also allows the best-prepared regions to adopt HOF first so that the other regions can learn from their case studies before taking on even more difficult barriers. Three regions look particularly promising for this type of deployment: the Midwest, California, and RVP-prepared areas. However, only the Midwest is modeled in Section 6.1.

The Midwest is a promising initial market because most ethanol biorefineries and current ethanol feedstocks (i.e., corn) are located here, which minimizes transportation costs. Furthermore, these states are more ethanol friendly than others. Of all the pro-ethanol state incentives on the books in 2014, nearly 40\% were enacted in Midwest states (AFDC 2014e). This concentration indicates not only an advantageous market for ethanol, but a political system and constituents that support ethanol. Minnesota is the only state to have already approved E20. 
The Midwest has shown to be the most promising market for flex fuel, which could translate to HOF because HOF can build on the ethanol/flex fuel infrastructure and vehicles. NREL recently performed a geographical information system-based analysis that mapped the weighted indicators of supply and demand for the flex fuel market (Johnson and Hettinger 2014). These indicators included (in order of weighting) current flex fuel retail stations, density of FFVs, gasoline prices, pro-ethanol state incentives, and proximity to ethanol refineries. The results, shown in Figure 12, indicate how dominant the Midwest's flex fuel market is. The strength of this market is likely to translate directly to a strong HOF market in the Midwest.

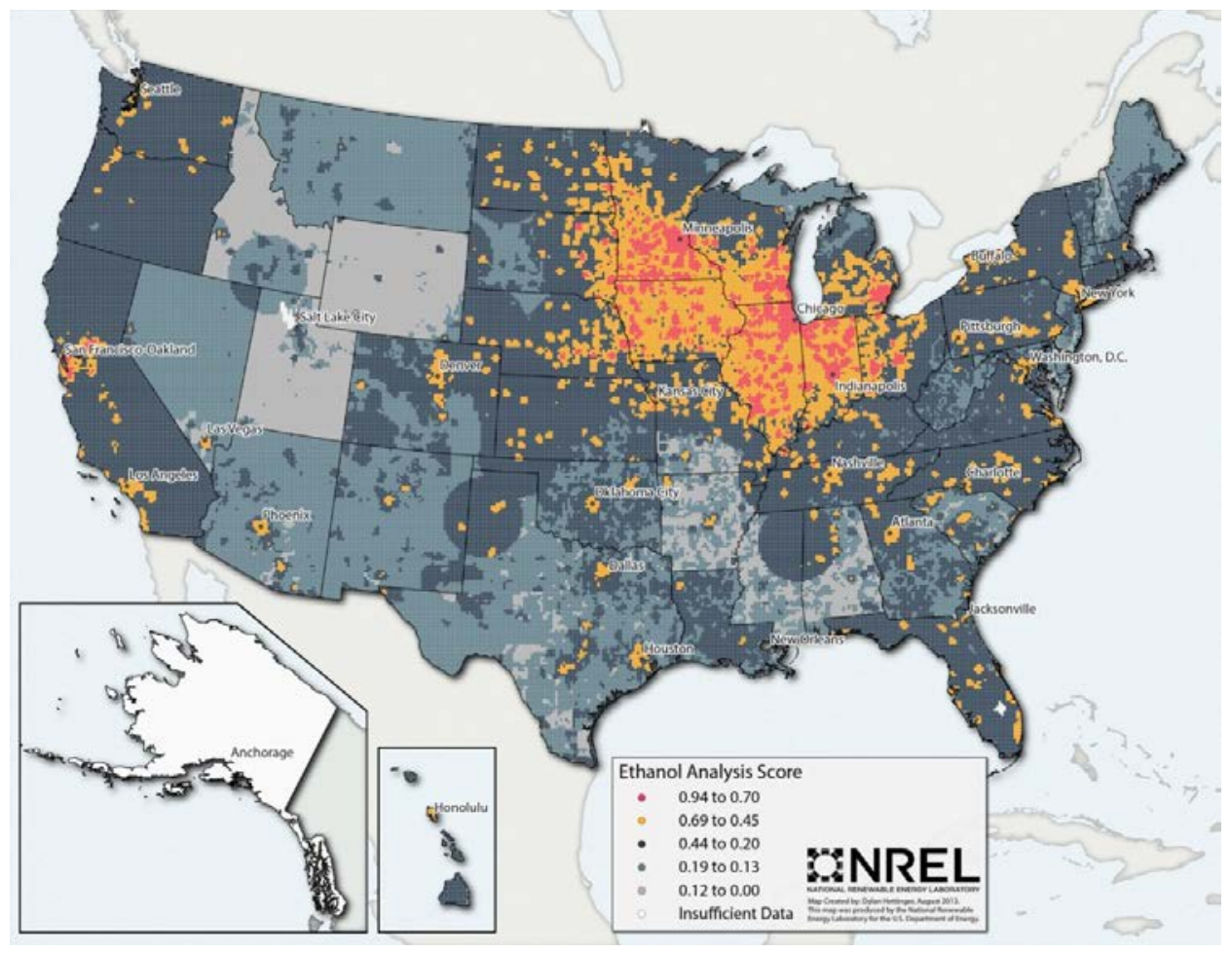

Figure 12. Indicators of a strong supply and demand for flex fuel. This could serve as a direct proxy for indicators of a strong potential HOF market.

Source: Johnson and Hettinger (2014)

California is another area where a regional rollout of HOF could make sense. California has its own unique vehicles and supply chains because it is the only state that is allowed under the Clean Air Act to develop its own emissions standards (Bloomberg BNA 2012). However, Tier 3 emissions standards aim to treat California vehicles the same as those from all other states. Given California's history of vehicle regulations and mandates, it is positioned better than any other state to encourage the sale of HOFVs. Furthermore, Figure 12 shows that the greater San Francisco/Sacramento area and the Los Angeles area already have strong markets for ethanol fuels. These areas could serve as anchor markets, and they are already being connected by healthy markets on Highway 99. However, California is not modeled in the regional scenario of the BSM and BioTrans model runs. Table 12 includes the curtailment strategies addressed by scenario 7. 
Table 12. Barrier Curtailment Strategies Used by Scenario 7

\begin{tabular}{|l|}
\hline Scenario 7 Barrier Curtailment Strategies \\
\hline Could focus on areas where RVP barrier is bypassed \\
\hline Deploy regionally to achieve critical mass quickly for fuels and vehicles \\
\hline Midwest deployment simplifies the fuel distribution infrastructure needed \\
\hline Regional deployment allows for easier coordination of blendstocks \\
\hline Uses large numbers of FFVs and flex fuel stations in Midwest \\
\hline $\begin{array}{l}\text { Many metropolitan service areas can provide full service to an HOFV with } \\
\text { current infrastructure }\end{array}$ \\
\hline
\end{tabular}

\subsection{Scenario 8: Expensive}

Scenario 8 serves as a bookend and was designed to represent the conditions most likely to lead to slow deployment. It does this by assuming that the more expensive equipment will be needed in vehicles and retail stations. HOF is E40 in this scenario because E40 requires more equipment changes than does E25.

This scenario hits many HOF-adoption barriers head on. Therefore, it is a good scenario to test a variety of incentives in the models that can enable HOF adoption despite formidable barriers. These incentives include subsidies to ethanol producers, fuel retailers, vehicle purchasers, and variations on CAFE and RFS.

The incremental cost of HOFVs (meaning the difference between a conventional vehicle and an HOFV) is assumed to be more expensive in this scenario. All the other scenarios assume that the incremental cost is $\$ 100$ just for ethanol tolerance (a conservative estimate based on IBTimes [2010] and Congressional Record [2005]. Those scenarios assume that there is no incremental cost for DI or turbocharging because these are on a trajectory to be offered in nearly all vehicles by the time HOFVs will be adopted (Figure 13). Scenario 8, on the other hand, assumes that gasoline direct injection (GDI) and turbocharging will cost an additional \$355 for HOFVs (Duleep 2011), so the total incremental cost for HOFVs in Scenario 8 is $\$ 455$. 


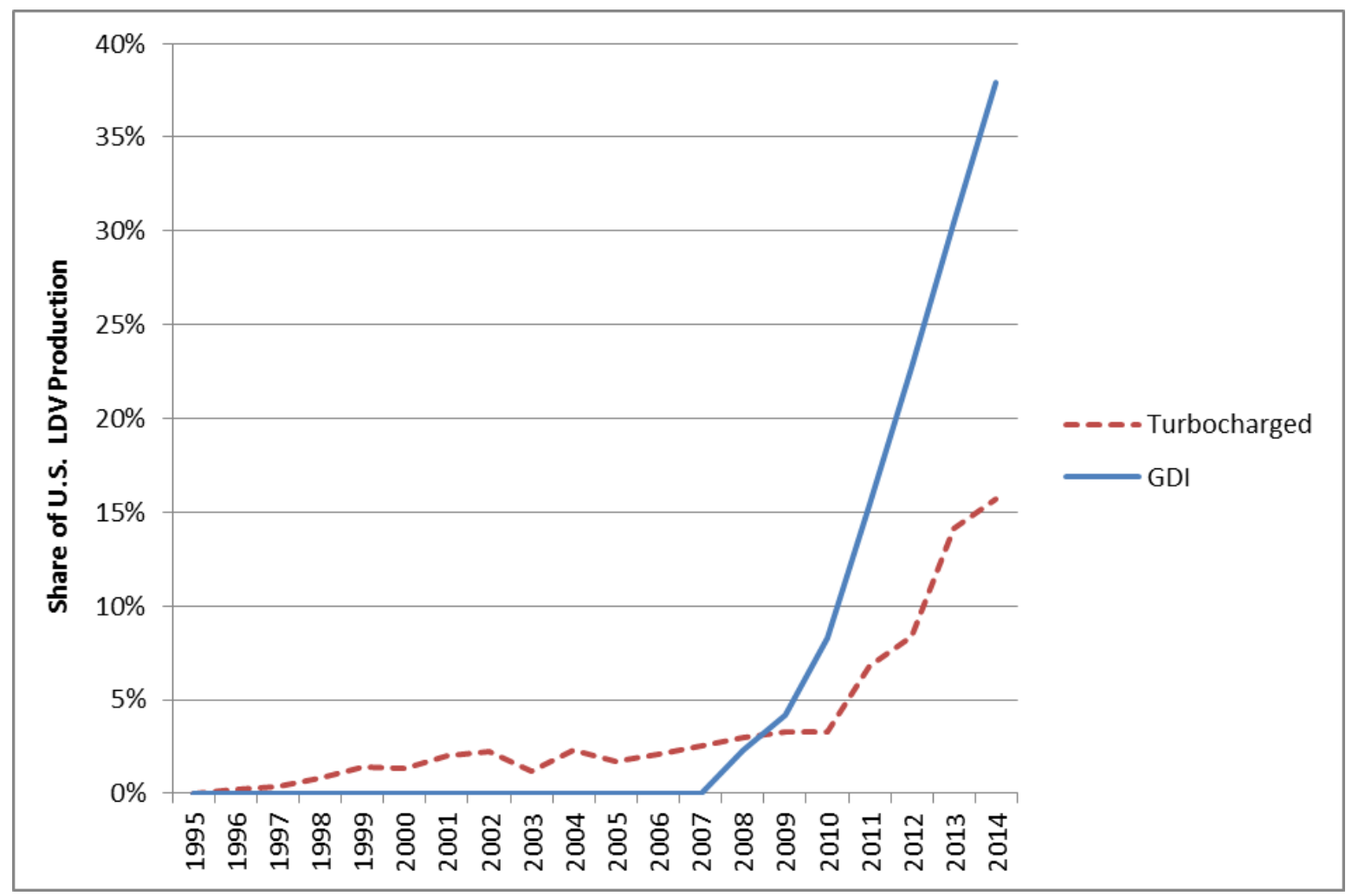

Figure 13. Production share of GDI and turbocharged vehicles

Source: Alson et al. (2014)

Scenario 8 also makes the following assumptions:

- The retailers need to spend more money to sell HOF.

- Each retail station needs to add a UST to serve HOF, which implicitly assumes that the blendstock cannot be optimized to allow the mixing of HOF and E10 into premium E15, as used in other scenarios.

- No midgrade USTs are available for HOF.

- Two E40 dispensers (each with an incremental cost of \$6,500) must be added to ensure quick service.

Table 13 shows the curtailment strategies addressed by scenario 8 .

Table 13. Barrier Curtailment Strategies Used by Scenario 8

\begin{tabular}{|l|}
\hline Scenario $\mathbf{8}$ Barrier Curtailment Strategies \\
\hline Scenario characterized by hitting barriers head on \\
\hline Look at how incentives bump us over the barriers \\
\hline Incremental cost of HOFVs is $\$ 455$ for ethanol tolerance, turbocharging, and DI \\
\hline
\end{tabular}




\section{High-Octane Fuel Vehicle Adoption Modeling}

The impact of HOF on vehicle sales was estimated by ADOPT. The ADOPT model is an LDV consumer choice and stock model developed at NREL and supported by the DOE Vehicle Technologies Office. It estimates technology improvement impacts on U.S. LDV sales, petroleum use, and GHG emissions (Brooker et al. 2015).

The ADOPT model uses a logit function to estimate vehicle sales. Most vehicle makes, models, and trims are included to represent the full market. The logit function estimates their sales based on key attributes including vehicle price, fuel cost, acceleration, range, and usable volume (for either passengers or cargo). The average importance of several attributes changes nonlinearly across its range, and changes with income, as seen in Figure 14. This importance is derived from the observed relationship between vehicle sales (Polk 2015) and demographic factors (U.S. Census 2013). For several attributes, a distribution of importance around the average value is used to represent consumer heterogeneity.

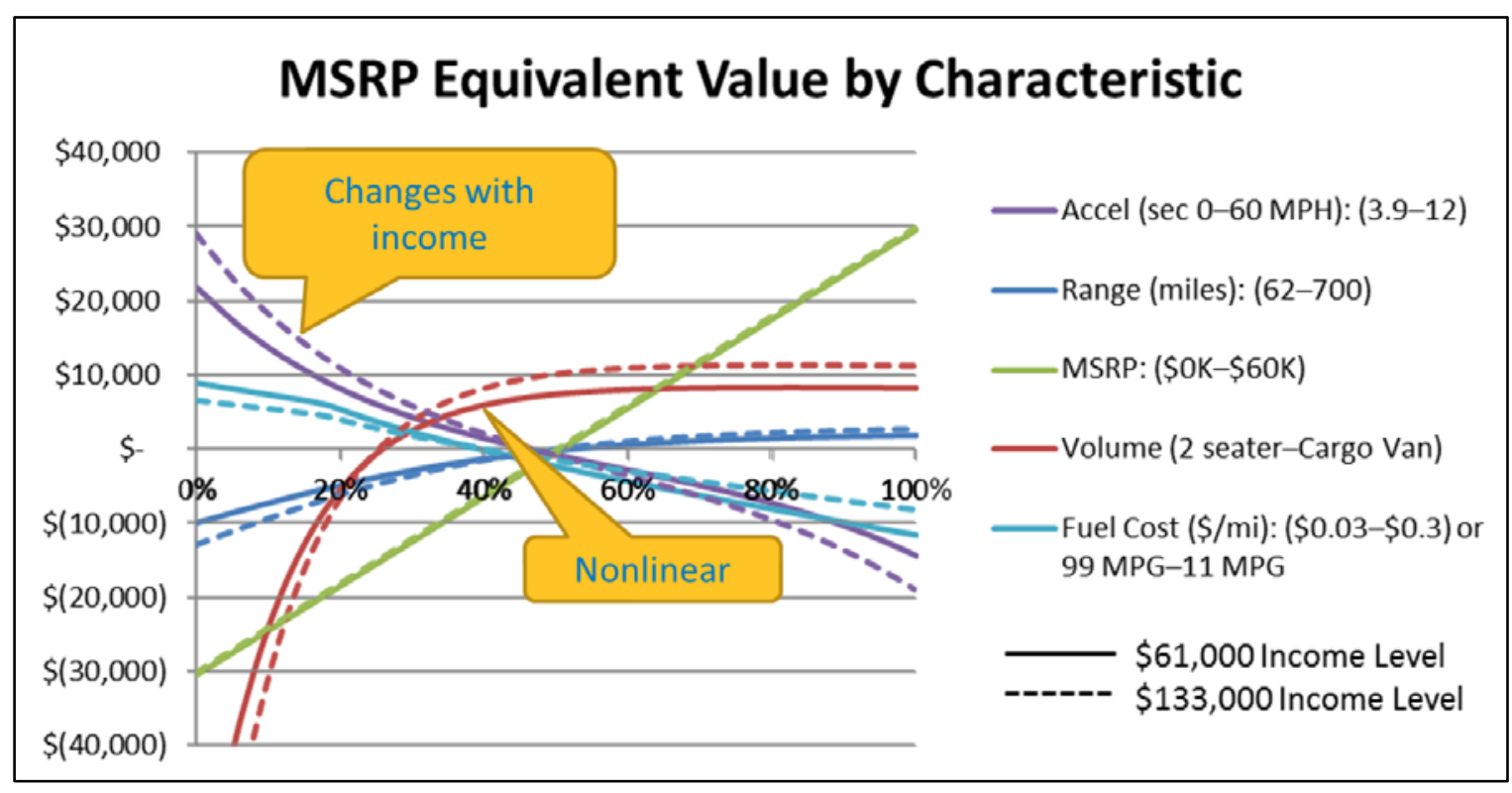

Figure 14. Value of vehicle characteristics by purchaser income

${ }^{*} \mathrm{MSRP}=$ manufacturer's suggested retail price

As discussed in section 3.2.7, there are multiple ways that fuel economy and GHG emissions could be calculated for HOFVs. For this analysis, ADOPT calculated them with an R-factor of 0.96, which is similar to the credit tracked by tailpipe GHG emissions for gasoline vehicles. Future work will explore calculating CAFE impacts via other methods.

The ADOPT model has been extensively validated with historical sales data, matching in key dimensions including sales by fuel economy, acceleration, price, vehicle class, and powertrain across multiple years. A few examples are shown in Figure 15. 


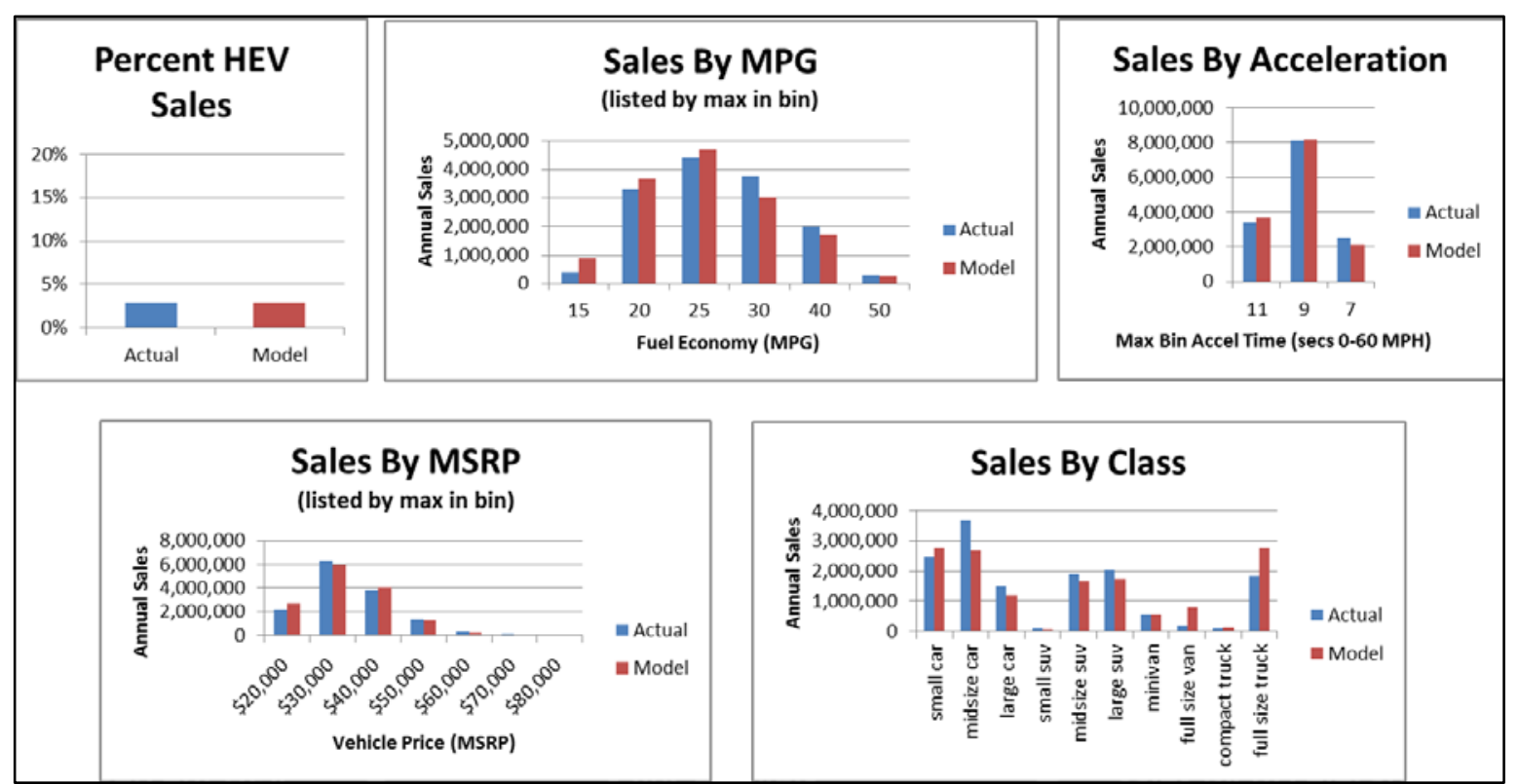

Figure 15. Five means of ADOPT validation through comparison with historical sales data

Vehicle sales were estimated by ADOPT for the given HOF scenario assumptions. Although the scenario definitions have strong implications for sales, vehicle choice still plays a major role. For example, in scenario 1, conventional vehicle models were replaced with HOFVs based on their acceleration. This replacement changes the mix of vehicle model options for consumers, which heavily influences sales. During the transition, however, the sales of those model options are still influenced by the fuel cost and vehicle price differences caused by HOF.

For comparison to the HOF scenarios, a baseline run was completed that assumed no HOF. In this case, the share of HEVs, plug-in HEVs, and all electric vehicles collectively grow to over $40 \%$ of all sales by 2025 . This fleet projection is driven by the need to meet future CAFE. Even with engine downsizing, strong incentives and penalties were required to meet CAFE, which effectively reduced the incremental price of more efficient advanced powertrains and increased their share, as seen in Figure 16. 


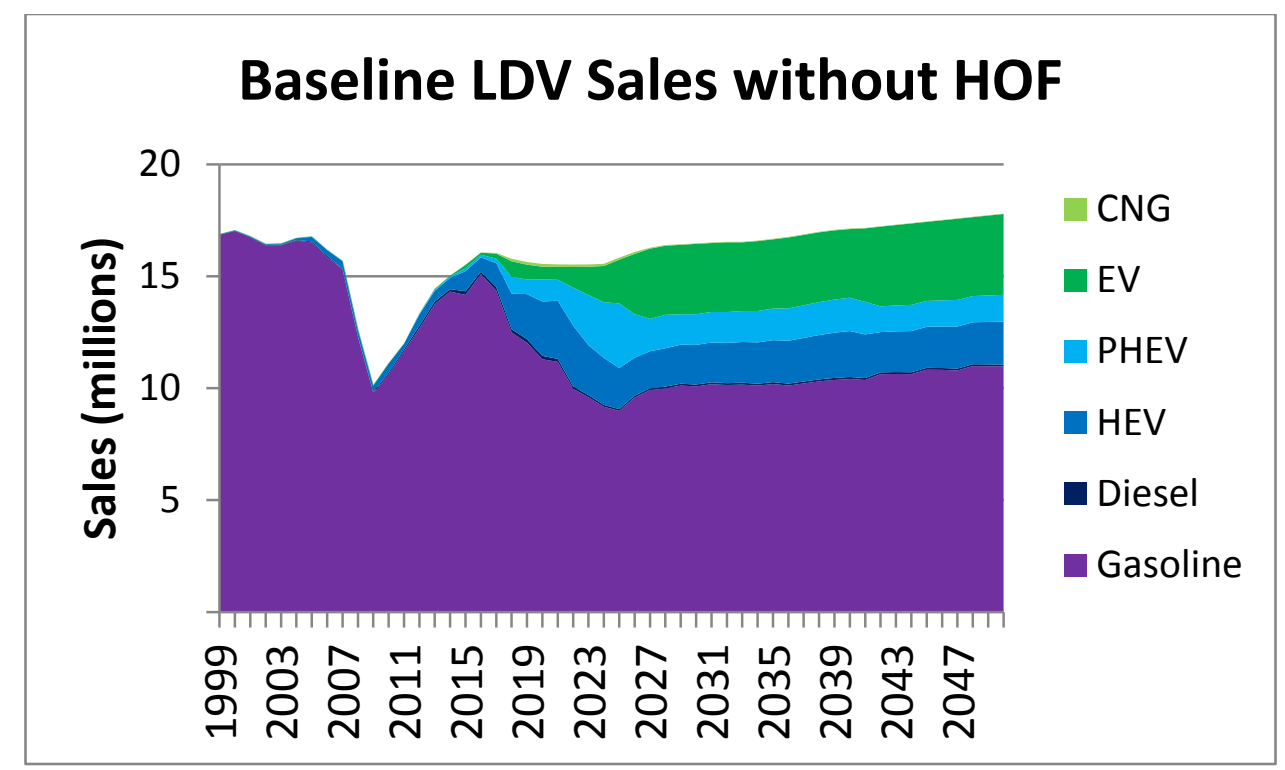

Figure 16. Baseline LDV sales estimates without HOF

Figure 17 shows that HOF led to an even greater diversification of vehicle type. Assuming that HEVs and PHEVs can use HOF and that CAFE accounts for ethanol with an R-factor of 0.96 (which is similar to tailpipe GHG accounting-see Section 3.2.7), HOF allows for the ongoing sales of multiple technologies. The case is quite different if CAFE is calculated as if HOF is an alternative fuel with an $\mathrm{F}$ factor of 1 . In such cases, CAFE is met almost entirely by HOF and the need for other highly efficient powertrains is completely diminished.

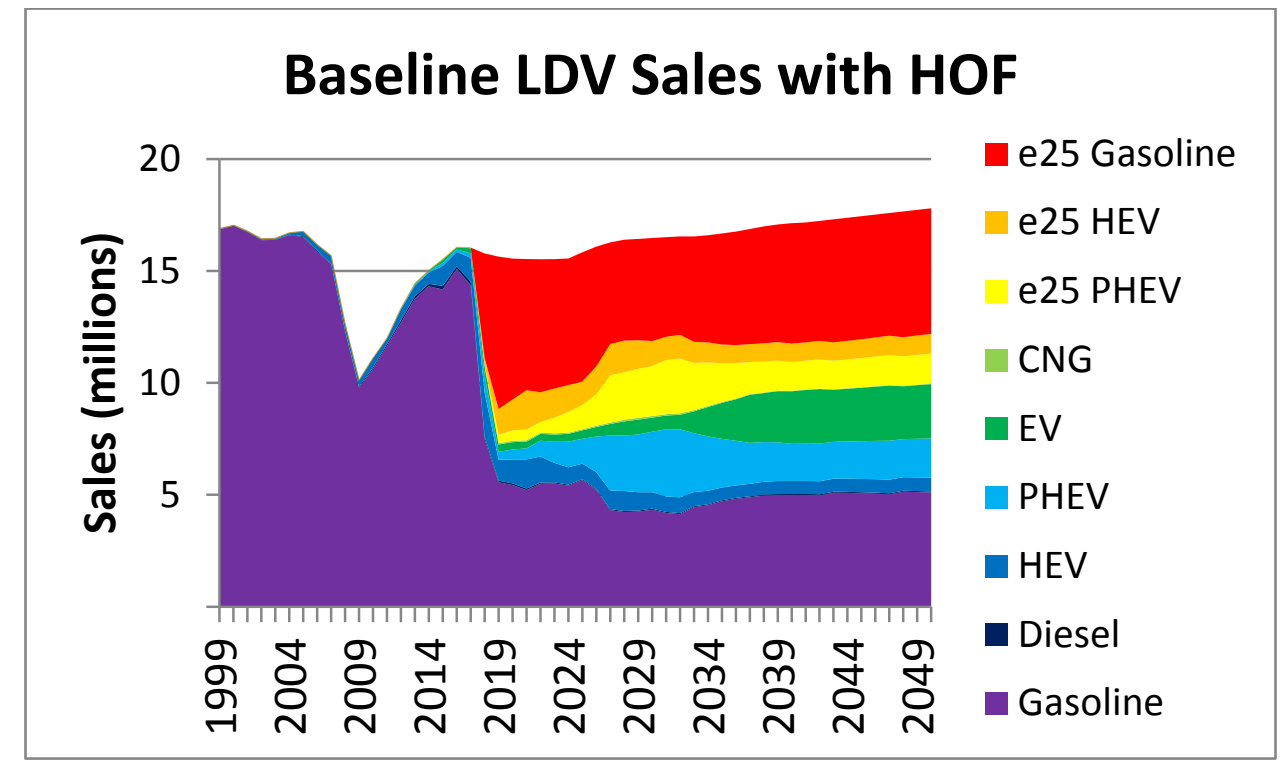

Figure 17. LDV sales estimates under scenarios 2, 5, 6 and 7, where consumer preference and fuel prices shape the adoption of HOFVs using E25 
The sales estimates then feed the vehicle stock model to estimate how many HOFVs will be on the road in a given year. These vehicle market penetration curves, which include HEVs and PHEVs that are optimized for HOF, are shown in Figure 18. One ADOPT scenario was used in multiple deployment scenarios (outlined in Section 4). This is "scen 2,5,6,7" in Figure 18, which represents an unrestrained, undirected adoption of HOFVs based on consumer choice and meeting future CAFE. An additional ADOPT scenario is shown in Figure 18 that was used only as an alternative adoption path in the market-driven scenarios. This is scenario X, where HOFVs are discounted by $\$ 2,500$ from MSRP.

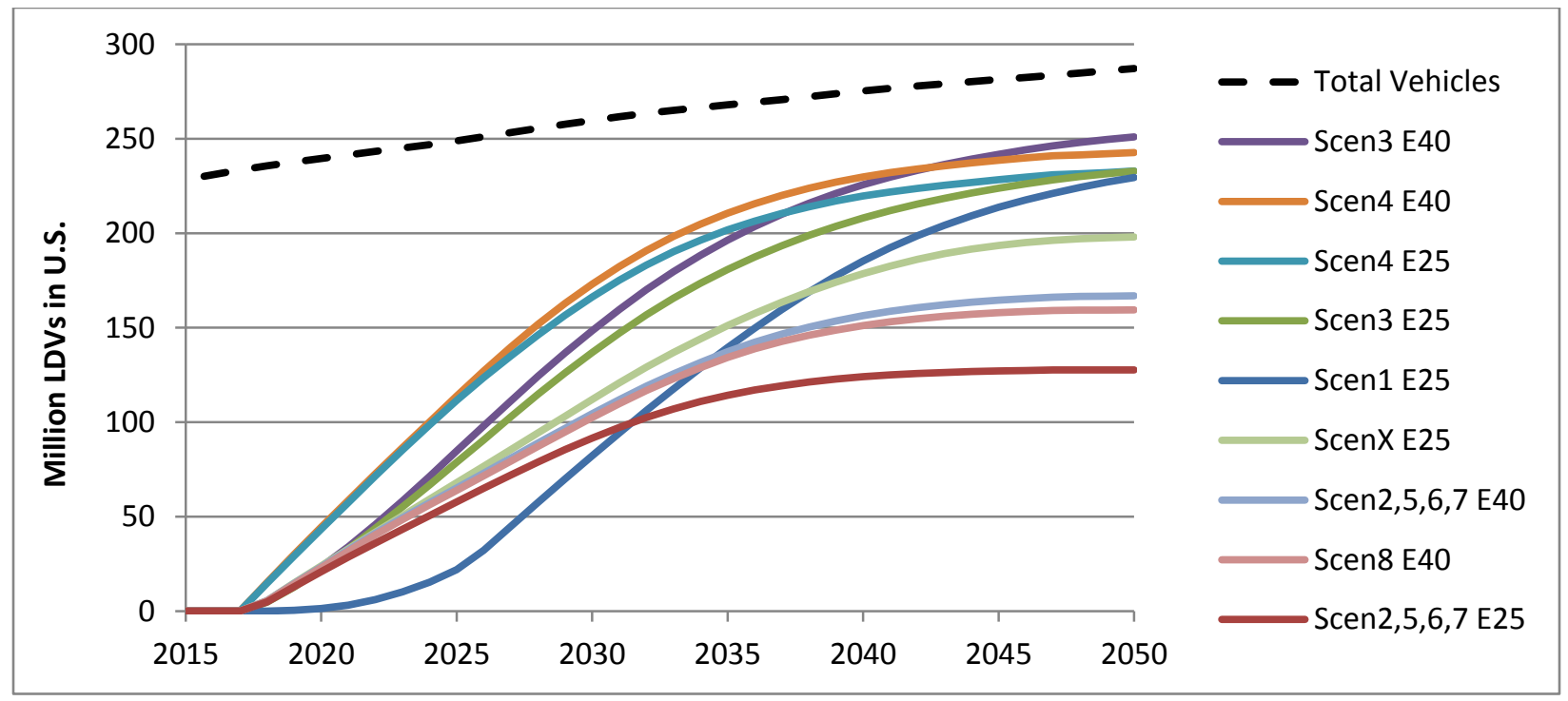

Figure 18. Stock of HOFVs estimated by ADOPT under the various scenarios

The estimated vehicle stock of the various scenarios is shown in Figure 18. For simplicity, the high oil price scenarios and any incompatible or improbable combinations of fuel blend levels within certain scenarios have been removed. This means that Scenarios 1 and X show E25 only, Scenario 8 shows E40 only, and the other scenarios show both blends. All scenarios were started in MY2018 so they could be compared side by side. This early start date would be difficult to achieve, but was chosen because model parameters are more concrete in recent years.

Figure 18 shows that the different scenarios result in an HOFV fleet comprising $43 \%-79 \%$ of the total LDV fleet by 2035 and $44 \%-87 \%$ by 2050 . The difference between these scenarios is caused by a few overlying factors. Within similar deployment strategies, E40 HOFVs sell better than their E25 counterparts because they offer drivers greater fuel cost savings and offer vehicle manufacturers a little more future CAFE benefit. As a result, Scenario 8 (expensive) does not have the least market penetration. However, the increased retailer equipment costs of Scenario 8 are not accounted for until the fuel supply modeling in Section 6.

Scenarios where model conversions are given direction (either most efficient [Scenario 3] or highest acceleration [Scenario 1]) achieve greater penetration than market-driven scenarios because the conventional version of these models is discontinued. Rather than offering new HOFV models in response to consumer demand, the OEMs are being proactive and making new models available. However, Scenario 1 has a delayed penetration because the first vehicle models it offers have very limited production numbers. This is opposite of Scenario 3, where 
HOF is first offered in efficient vehicle models which tend to be produced in larger volumes. The market-driven scenarios offer more models faster than the directed scenarios, but since the HOF version of these models are very similar to their conventional counterparts, they sell at similar levels to one another.

Vehicle price shows a substantial impact on adoption. The $\$ 2,500$ discount offered in Scenario X boosted 2050 penetration 55\% over its counterpart Scenario 2,5,6,7 E25. The additional \$455 that an HOFV costs in Scenario 8 dropped 2050 penetration 5\% below its counterpart Scenario 2,5,6,7 E40.

Scenario 4 (regardless of blend level) is the quickest out of the gates because all new vehicle sales starting in MY 2018 must be HOFVs.

Each scenario was varied by using the AEO reference oil price or its high oil price projection (EIA 2014a). This had very little impact on most scenarios, with the 2050 fleet numbers for high and reference oil prices being within two percent of one another. This result could be because the high gasoline prices led consumers to purchase slightly more efficient vehicles, which reduced the pressure that future CAFE applied to the vehicle manufacturers. In Scenario X (with the $\$ 2,500$ incentive), high oil prices actually decreased HOFV penetration. This could be because the higher fuel costs diluted the effect of the $\$ 2,500$ incentive on the vehicle purchaser.

Furthermore, high oil prices caused more consumers to consider BEVs instead of HOF since the price of HOF rose with oil prices but the price of electricity did not.

If future CAFE treated HOF as an alternative fuel (with $\mathrm{F}=1$ ) instead of accounting according to tailpipe GHG emissions, the average scenario saw 49\% greater penetration of HOFVs by 2050. This was slightly higher for the E25 scenarios than for the E40 scenarios. This is because when CAFE treated HOF as an alternative fuel, E40 vehicles provided virtually all needed CAFE benefits before full penetration in many scenarios.

The vehicle adoption estimates derived in ADOPT were then used as inputs for HOF production and supply modeling. 


\section{High-Octane Fuel Production and Supply Modeling}

Two separate models were used to explore the market adoption scenarios outlined in Section 4. Since the model outputs (e.g., availability of dispensing stations) were not dynamically linked with vehicle inputs (e.g., vehicle sales), the simulations were in many ways a screening exercise to identify scenarios that may warrant additional exploration. The BSM was employed to gain perspective on how the biomass-to-biofuels system might respond to the various infrastructure costs, dispensing station investment strategies and vehicle deployment settings outlined in the market adoption scenarios. The BSM was designed to:

- Analyze and evaluate points of impact.

- Generate market adoption scenarios that address barriers in a variety of ways.

- Identify high-impact levers and bottlenecks to system evolution.

- Instigate focused discussion among policymakers, analysts, and stakeholders.

The BioTrans model was used to analyze issues surrounding market competitiveness and price/quantity outcomes, commercial investment, and consumer choices for fuel. The BioTrans model has an explicit representation of dispensing infrastructure and other durable capital equipment, and uses optimization methodology to generate its results. Therefore, it can be helpful for investigating specific producer/retailer investment or consumer choice-related questions.

The two models were employed to explore the HOF supply chain from slightly different perspectives. The BSM was utilized to identify potential barriers or points of leverage for the new fuel throughout the supply chain (feedstock, conversion facilities, distribution, dispensing stations, and fuel use). The different players made decisions based on economic factors with little knowledge of future conditions. For example, station owners use expectations of future performance that are based on current fuel prices and HOF infrastructure build-out as inputs to the decision around investment in HOF dispensers. The BioTrans model was utilized to look at the evolution of the HOF industry if decision makers at different stages in the supply chain have more insight into the future and can make decisions based on that knowledge. For example, it provided a benchmark of how much HOF the HOFVs would demand in each year and explored how the station owners would respond if they had that knowledge. Using these different perspectives brackets the analysis and adds value by showing the implications of assumptions about information availability on investment and usage behavior at each point along the supply chain.

\subsection{Brief Description of the Biomass Scenario Model}

The DOE Bioenergy Technologies Office and NREL have developed the BSM to investigate the potential dynamics associated with the evolution of a biofuel industry in the United States (Biomass Program 2009). The model uses a system dynamics modeling approach, built on the STELLA software platform (isee systems 2010), to represent the dynamic interactions of the major stages of the biomass-to-biofuel supply chain - feedstock production and logistics, feedstock conversion, and downstream elements (inventory, distribution, dispensing, fuel use, and vehicle fleet). The BSM tracks the development of the biofuel industry over time by 
representing investment in new technologies, competition from petroleum fuels, vehicle demand for biofuels, and implementation of various government policies. As an established methodology for analyzing the behavior of complex, feedback-rich systems, system dynamics focuses on the relationships between and feedback among parts of a system and can facilitate investigation of system bottlenecks, analysis of policies, and diagnosis of unintended consequences (Sterman, Morrison, and Repenning 2003). Extensive analyses have been performed utilizing the model to address the critical role played by system bottlenecks, gasoline pricing, industrial learning, and financing in development of the biofuel industry (Vimmerstedt et al. 2012; Newes et al. 2011; Clark et al. 2013; Vimmerstedt et al. 2013; Vimmerstedt et al. 2015; Newes et al. 2015).

The BSM is designed to be modular, such that each major component (feedstock supply and logistics, feedstock conversion, and downstream) can be simulated in isolation from or in conjunction with other sectors. The feedstock production and logistics sector simulates the production of bioenergy and commodity crops, through farmer decision-making, land allocation dynamics, and new agricultural practices, markets, and prices; it also tracks costs associated with harvesting, collection, storage, preprocessing, and transportation of feedstocks. The feedstock conversion modules capture investment and operation of various conversion pathways, including algae, oil crop, renewable hydrocarbons, starch ethanol, and cellulosic ethanol. The model represents 15 conversion platforms at four production scales. The ethanol produced during conversion is then distributed and consumed as ethanol/gasoline blends such as E10, E15, E25, E40, and flex fuel. The model is geographically stratified, using the ten U.S. Department of Agriculture (USDA) farm production regions (Interagency Agricultural Projections Committee 2007), which allows for region-specific analyses to be performed.

For this analysis, we modified the model to account for an HOF market. Consistent with the purpose of this report as a screening exercise, we made several simplifying assumptions to facilitate the scenario analysis.

- FFV sales stop in 2018.

- Flex fuel phases out as HOFVs enter the system, and E85 equipment is used to retail $\mathrm{HOF}$.

- HOFVs enter the market according to schedule generated by ADOPT.

- HOFVs fuel with regular gasoline (because premium is not differentiated in BSM) until HOF-capable stations become available within a region.

- One hundred percent of HOFVs within a region will fuel with HOF once $20 \%$ of stations in that region have HOF capability (per the logic explained under barrier 1.8).

- Thirty percent of stations have tankage that could be repurposed for HOF.

- Under all but extreme differences (see Appendix A for details), price differentials between HOF and regular gasoline do not affect HOF use.

- Stations have the opportunity to purchase HOF tankage and/or equipment as older equipment reaches the end of its useful life of 25 years. In scenarios 2 and 4, only HOFcapable equipment is available to station owners. In other scenarios, stations base the investment decision on incremental costs and benefits of HOF-capable equipment, relative to traditional equipment. 
For more information on the basic architecture of the HOF area of the BSM, along with associated assumptions and limitations, see Appendix A.

\subsection{System-Level Insights from Biomass Scenario Model Analysis}

The BSM was used to explore the system-level implications of the scenarios outlined in Section 4. Although specific results varied among the scenarios, a set of system-level insights emerged from the analysis. Because the ADOPT scenarios were taken as inputs, there was no feedback between fuel availability and price (derived by BSM) and HOFV purchase. Therefore, the insights contained here do not discuss this area of HOF deployment. The addressable insights are summarized in Table 14 and described in more detail below.

Table 14. Insights on HOF Deployment along the Supply Chain, as Revealed through BSM Simulations, and Relevant Model Assumptions

\begin{tabular}{|c|c|c|}
\hline $\begin{array}{c}\text { Stage in } \\
\text { Supply Chain }\end{array}$ & Finding $^{a}$ & $\begin{array}{l}\text { Model Assumptions That, If Varied, } \\
\text { Could Impact Finding }\end{array}$ \\
\hline Vehicles & $\begin{array}{l}\text { 1. In most scenarios (see Section 4), } \\
\text { ADOPT vehicle trajectories set a } \\
\text { ceiling for total ethanol usage. }\end{array}$ & $\begin{array}{l}\text { - Lack of feedback between ADOPT and } \\
\text { BSM }\end{array}$ \\
\hline Dispensing & $\begin{array}{l}\text { 2. If standard dispensing equipment is } \\
\text { HOF-compatible when older equipment } \\
\text { is replaced, many retailers will offer } \\
\text { HOF. } \\
\text { 3. The cost of HOF-compatible equipment } \\
\text { can constrain dispensing station build- } \\
\text { out and thus, HOF usage. } \\
\text { 4. Different scenarios (see Section 4) } \\
\text { require different levels of incentives to } \\
\text { support build-out of HOF-compatible } \\
\text { equipment. }\end{array}$ & $\begin{array}{l}\text { - HOFV owners purchase HOF even } \\
\text { when HOF price is higher than regular } \\
\text { gasoline price, except in extreme price } \\
\text { cases } \\
\text { - HOF price is a markup on fuel price } \\
\text { paid by station owners } \\
\text { - Station owners replace equipment at } \\
\text { the end of its useful life } \\
\text { - Low degree of foresight in decision- } \\
\text { making among station owners } \\
\text { - If } 20 \% \text { of stations in a region provide } \\
\text { HOF, all HOFVs will exclusively refuel } \\
\text { with HOF }\end{array}$ \\
\hline Conversion & $\begin{array}{l}\text { 5. High levels of HOF dispensing build- } \\
\text { out and resultant HOF usage cause } \\
\text { conversion facility build-out to run into } \\
\text { growth constraints. } \\
\text { 6. The E15 market does not compete with } \\
\text { HOF for ethanol production capacity; } \\
\text { E15 deployment facilitates an earlier } \\
\text { start of build-out for the cellulosic } \\
\text { ethanol industry. }\end{array}$ & $\begin{array}{l}\text { - Only } 25 \text { of conversion facilities can be } \\
\text { built in a year } \\
\text { - Timing and rate of E15 uptake }\end{array}$ \\
\hline Feedstock & $\begin{array}{l}\text { 7. Feedstock availability does not appear } \\
\text { to constrain ethanol production or } \\
\text { consumption. }\end{array}$ & $\begin{array}{l}\text { - Concurrent growth in renewable } \\
\text { hydrocarbon production could lead to } \\
\text { price pressure on feedstock supply, } \\
\text { resulting in constrained ethanol } \\
\text { production }\end{array}$ \\
\hline
\end{tabular}

${ }^{a}$ Finding numbers are linked to the insights explored in the main text of this section.

${ }^{\mathrm{b}}$ See Appendix A for additional explanation and discussion of model assumptions. 
All model simulations assumed a $\$ 0.50 /$ RIN effect, ${ }^{23}$ because of the RIN market that was established through the RFS (U.S. Congress 2007), and that the Biomass Crop Assistance Program was in effect for the entire simulation (USDA 2010). Other than the analysis around fixed capital investment grants for dispensing stations, no other incentives were available in the model simulations.

Finding 1. The rollout of HOFVs sets the ceiling for HOF ethanol consumption levels except in scenarios 2 and 4 (Figure 19), where levels are constrained by biorefinery construction limits (see Finding 5). Because ADOPT scenarios were exogenous inputs to the model, there was no feedback between station availability and vehicle adoption. Therefore, the vehicle demand was unchecked and determined by factors described in Section 5.

Finding 2. If only HOF-compatible equipment is available for purchase when older equipment reaches the end of its useful life (as in scenarios 2 and 4), it makes financial sense for retailers to offer HOF; therefore, retailer participation is not the limiting factor. All new pumps would be able to offer HOF, and retailers would not have to consider whether the investment is in their best interest.

Finding 3. If non-HOF-compatible equipment is available for purchase when older equipment reaches the end of its useful life, the relative costs for HOF equipment are prohibitive; therefore, retailers do not generally choose to install HOF dispensing equipment, ${ }^{24}$ and HOF availability at the retail level becomes the limiting factor. Figure 19 shows that the potential consumption of HOF by HOFVs in the fleet is much greater than the HOF that is available at fueling stations, except for scenarios with relatively small dispensing incremental capital costs (scenarios 1 and 6) or when station owners can purchase only HOF-compatible pumps and tanks (scenarios 2 and 4) where the gap between desired HOF consumption by HOFVs and HOF provided by dispensing stations is much smaller. Current model settings assume that only $30 \%$ of existing stations have repurposable tankage. If $100 \%$ of existing stations are assumed to have repurposable tankage, more station owners choose to invest in HOF equipment for scenarios other than 2 and 4, but the actual HOF demand still lags behind potential consumption. This result suggests that the capital costs for HOF equipment (Table 3) may require HOFV owners to pay a premium for the fuel (as discussed in barrier 1.9). This result is especially true for the E40 cases, where the capital costs are significantly higher than for E25. Scenario 6 has greater investment in infrastructure because blender pumps do not require new tankage. The largest gap in potential and actual HOF ethanol consumption occurs when HOF price is lower than gasoline price (Figures 20 and 23). In these cases (Scenarios 3, 5, 7 and 8), there is little investment in HOF infrastructure, and therefore ethanol refineries, so the HOF price does not change significantly throughout the simulation. This price consistency indicates that the analysis would benefit from further exploration of incentives promoting HOF for retailers versus vehicle purchasers.

\footnotetext{
${ }^{23}$ The RIN effect is not the same as a RIN price, but rather it is the \$/gallon-ethanol-equivalent benefit to biorefineries from the RIN market. The difference between the RIN price and the RIN effect has to do with what player in the supply chain benefits from the RIN.

${ }^{24}$ Appendix A describes the logic behind how station owners decide whether to install RSP equipment.
} 


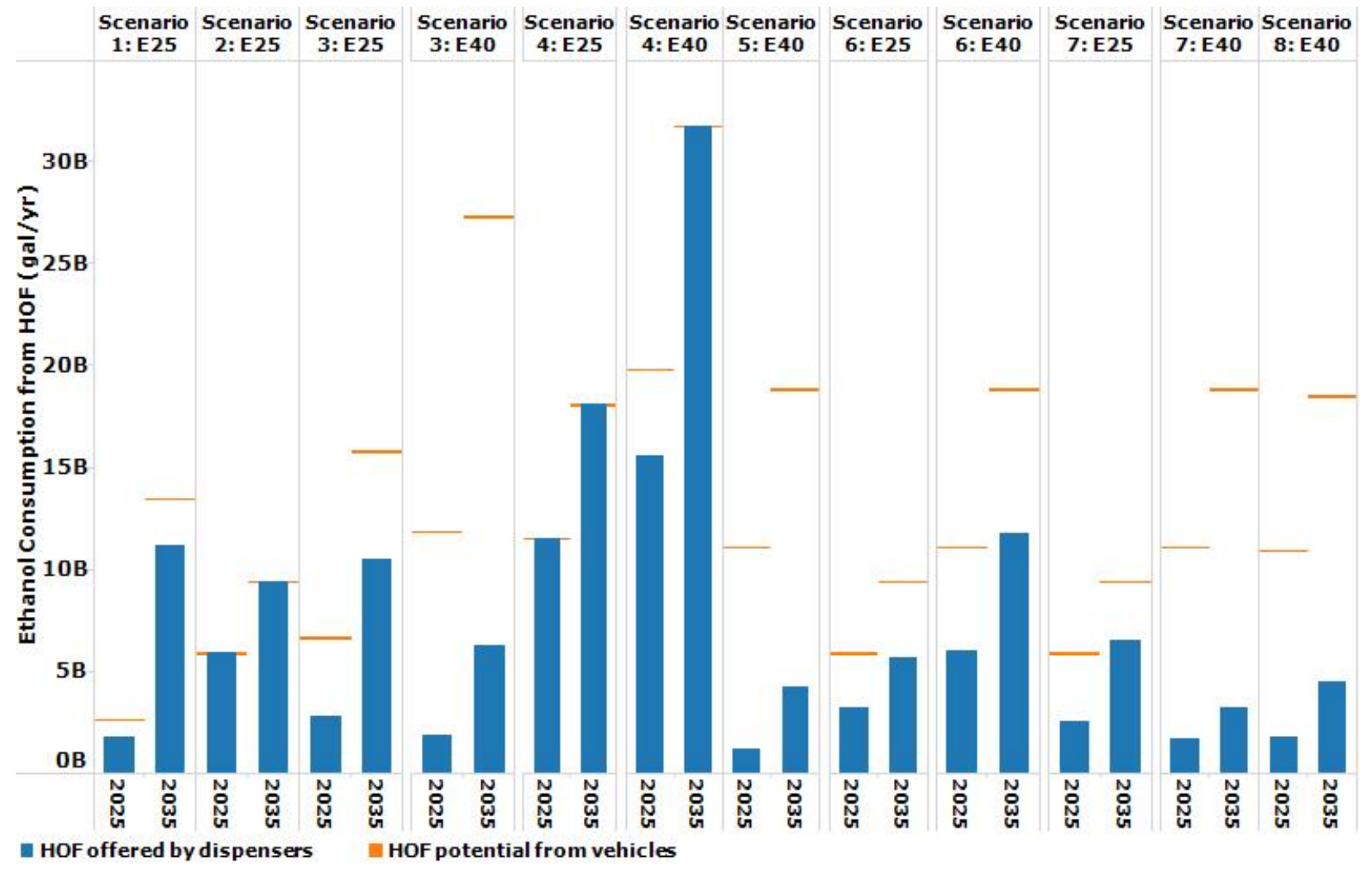

Figure 19. Potential ethanol demand, given vehicle fleet, versus actual ethanol demand from HOF dispensing stations in 2025 and 2035 for all scenarios with different HOF ethanol content, no dispensing station incentives, and no transition from E10 to E15

Finding 4. Some deployment strategies (outlined in Section 4) require higher incentives for dispensing stations to be successful. Table 15 shows how retail-focused incentives can greatly increase the number of dispensing stations installing HOF-compatible equipment, thereby increasing ethanol consumption. For scenarios with an option to install non-HOF equipment (all but scenarios 2 and 4), ethanol consumption could increase by up to $30 \%$ in 2035 with just a $40 \%$ capital cost grant and over $60 \%$ with an $80 \%$ capital cost grant. With an $80 \%$ grant, many scenarios can reach the same level of ethanol production as those where only HOF-compatible equipment is available (scenarios 2 and 4 ).

Finding 5. If dispensing station owners can purchase HOF-compatible equipment only when replacing end-of-life equipment (scenarios 2 and 4), more station owners offer HOF, which drives up demand for ethanol. This elevated demand increases construction of biorefineries, which quickly reach a limit for the number that can be constructed in a year. Based on historical data on maximum construction of starch ethanol refineries and similar industrial facilities, the BSM limits construction of biorefineries to 25 per year (Warner 2014). In the initial years of HOF deployment (2020-2023), this constraint is a limiting factor in ethanol production under all scenarios (left side of Figure 20). For scenarios 2 and 4, the limitation continues throughout the simulation. If the limit on biorefinery construction is increased to 40 per year, this constraint is a less significant limitation for all scenarios. 
Table 15. Ethanol Volumes (Billion Gallons per Year) in 2035 for Each Scenario, with and without Different Levels of Fixed Capital Investment Grants for Dispensing Stations To Install HOF Infrastructure with No Transition from E10 to E15

\begin{tabular}{|c|c|c|c|c|c|}
\hline Scenario & $\begin{array}{l}\text { No } \\
\text { incentives }\end{array}$ & $\begin{array}{l}40 \% \text { grant } \\
\text { for } \\
\text { dispensing } \\
\text { stations }\end{array}$ & $\begin{array}{l}\text { Percent } \\
\text { increase } \\
\text { over no } \\
\text { incentives } \\
\text { case }\end{array}$ & $\begin{array}{l}80 \% \text { grant } \\
\text { for } \\
\text { dispensing } \\
\text { stations }\end{array}$ & $\begin{array}{l}\text { Percent } \\
\text { increase } \\
\text { over no } \\
\text { incentives } \\
\text { case }\end{array}$ \\
\hline $\begin{array}{l}\text { Scenario 1: E25 (replace } \\
\text { midgrade) }\end{array}$ & 16.1 & 18.2 & $12.6 \%$ & 18.4 & $13.9 \%$ \\
\hline $\begin{array}{l}\text { Scenario 2: E25 (raise octane } \\
\text { floor) }\end{array}$ & 16.2 & 16.2 & $0.0 \%$ & 16.2 & $0.0 \%$ \\
\hline $\begin{array}{l}\text { Scenario 3: E25 (price driven } \\
\text { adoption) }\end{array}$ & 16.1 & 17.9 & $11.7 \%$ & 18.0 & $12.2 \%$ \\
\hline $\begin{array}{l}\text { Scenario 3: E40 (price driven } \\
\text { adoption) }\end{array}$ & 15.3 & 19.9 & $30.4 \%$ & 25.8 & $69.1 \%$ \\
\hline $\begin{array}{l}\text { Scenario 4: E25 (accelerated } \\
\text { deployment) }\end{array}$ & 21.1 & 21.1 & $0.0 \%$ & 21.1 & $0.0 \%$ \\
\hline $\begin{array}{l}\text { Scenario 4: E40 (accelerated } \\
\text { deployment) }\end{array}$ & 31.0 & 31.0 & $0.0 \%$ & 31.0 & $0.0 \%$ \\
\hline $\begin{array}{l}\text { Scenario 5: E40 (intermediate } \\
\text { E51) }\end{array}$ & 14.6 & 18.1 & $23.5 \%$ & 22.9 & $56.8 \%$ \\
\hline $\begin{array}{l}\text { Scenario 6: E25 (blender } \\
\text { pumps) }\end{array}$ & 14.4 & 16.4 & $13.8 \%$ & 16.4 & $13.7 \%$ \\
\hline $\begin{array}{l}\text { Scenario 6: E40 (blender } \\
\text { pumps) }\end{array}$ & 20.2 & 23.9 & $18.3 \%$ & 25.1 & $23.8 \%$ \\
\hline $\begin{array}{l}\text { Scenario 7: E25 (regional } \\
\text { deployment) }\end{array}$ & 14.8 & 15.2 & $2.9 \%$ & 15.8 & $6.5 \%$ \\
\hline $\begin{array}{l}\text { Scenario 7: E40 (regional } \\
\text { deployment) }\end{array}$ & 13.9 & 17.3 & $24.4 \%$ & 22.4 & $60.9 \%$ \\
\hline
\end{tabular}

*These scenarios assume that only HOF-compatible equipment is available when it is time to replace end-of-life equipment. 


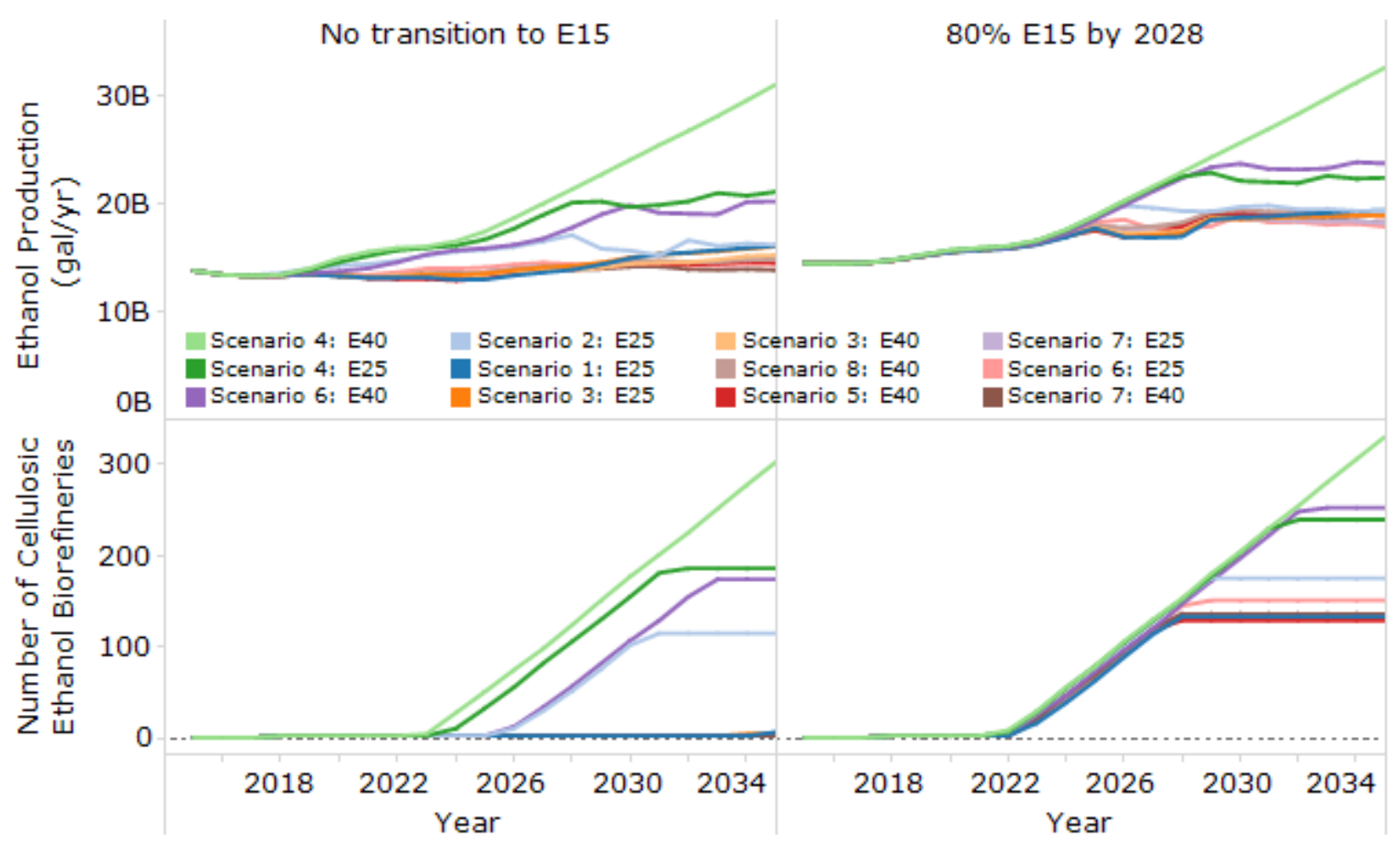

Figure 20. Ethanol production and number of cellulosic ethanol biorefineries from 2015-2035 by market adoption scenario, given different assumptions around E15 deployment with no dispensing station incentives

Finding 6. Deployment of E15 does not greatly impact the introduction of HOF dispensing stations, but it does cause the cellulosic ethanol industry to build refineries in all scenarios and to continue building refining capacity until a later year (right side of Figure 20). The transition of the low-blend ethanol market from E10 to E15 increases the demand for ethanol in later years. However, the E15 market does not compete with HOF for ethanol production capacity. The amount of ethanol consumed by HOF between the two scenarios does not change significantly because the biorefinery capacity can meet the demand for both HOF and E15.

Finding 7. In contrast to construction limitations, feedstock availability does not appear to limit ethanol production even in high-HOF scenarios. The sequencing of feedstock utilization is similar to what we have found with previous BSM analyses containing high-biofuel-demand scenarios (Clark et al. 2013): forest residues are utilized first, followed by the harvesting of crop residues and the establishment of energy crops (Figure 21). [See Lin et al. (2013) for more information on data sources utilized as inputs for the feedstock area of the BSM and Peterson et al. (2013) for more information on the modeling logic contained in the BSM.] 


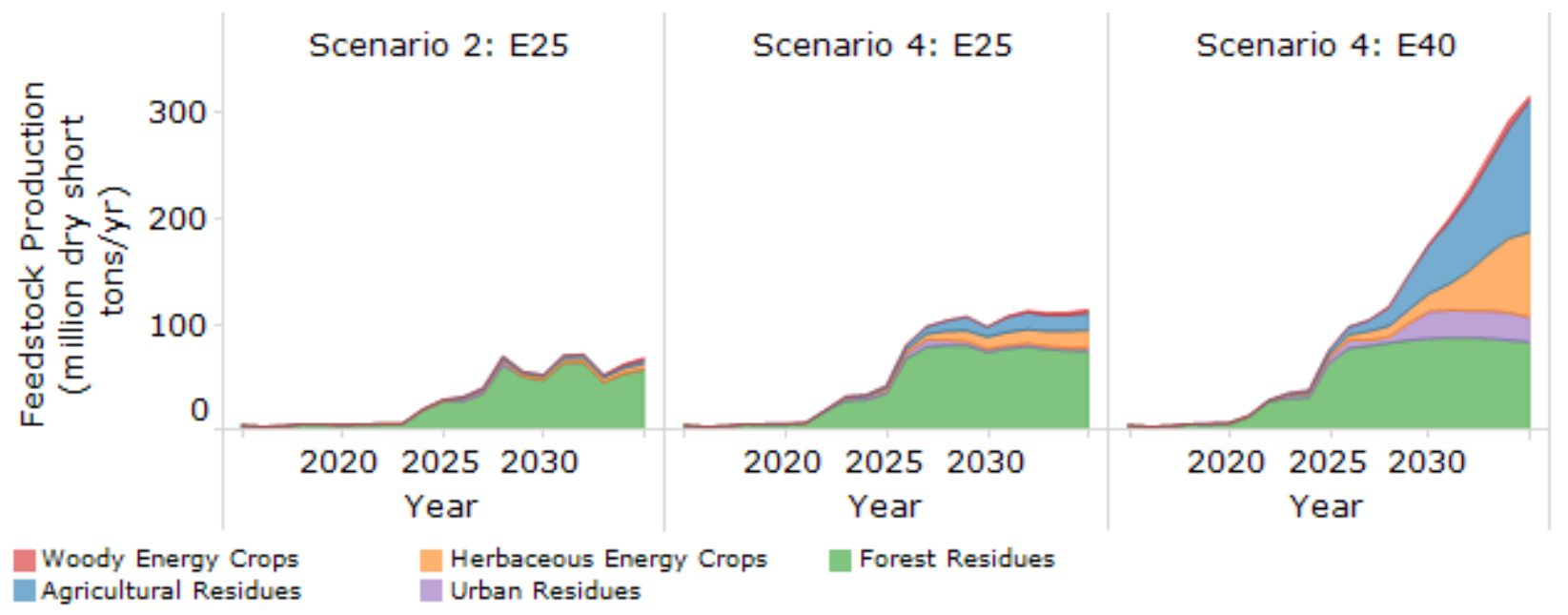

Figure 21. Feedstock production from 2015-2035 by feedstock type for high-ethanol-demand scenarios with no transition from E10 to E15 and no dispensing station incentives

HOF prices vary with scenario but are in the same general range as gasoline prices from the AEO (U.S. Energy Information Administration 2014a). Since HOF has a high gasoline content, prices rise and fall with oil prices (Figure 22). Scenarios with high ethanol consumption (Scenarios 1, 2, 4, and 6) have much higher pump prices than the others because the system is straining to produce enough biorefineries to satisfy demand. If the model assumed greater consumer sensitivity to differences between HOF and gasoline prices, the amount of ethanol demanded in these cases could decrease. However, HOFVs are likely to be limited to HOF and premium gasoline. Therefore, the comparison with regular gasoline comes more into play at the point of vehicle purchase (in the ADOPT scenario) rather than each refueling event.

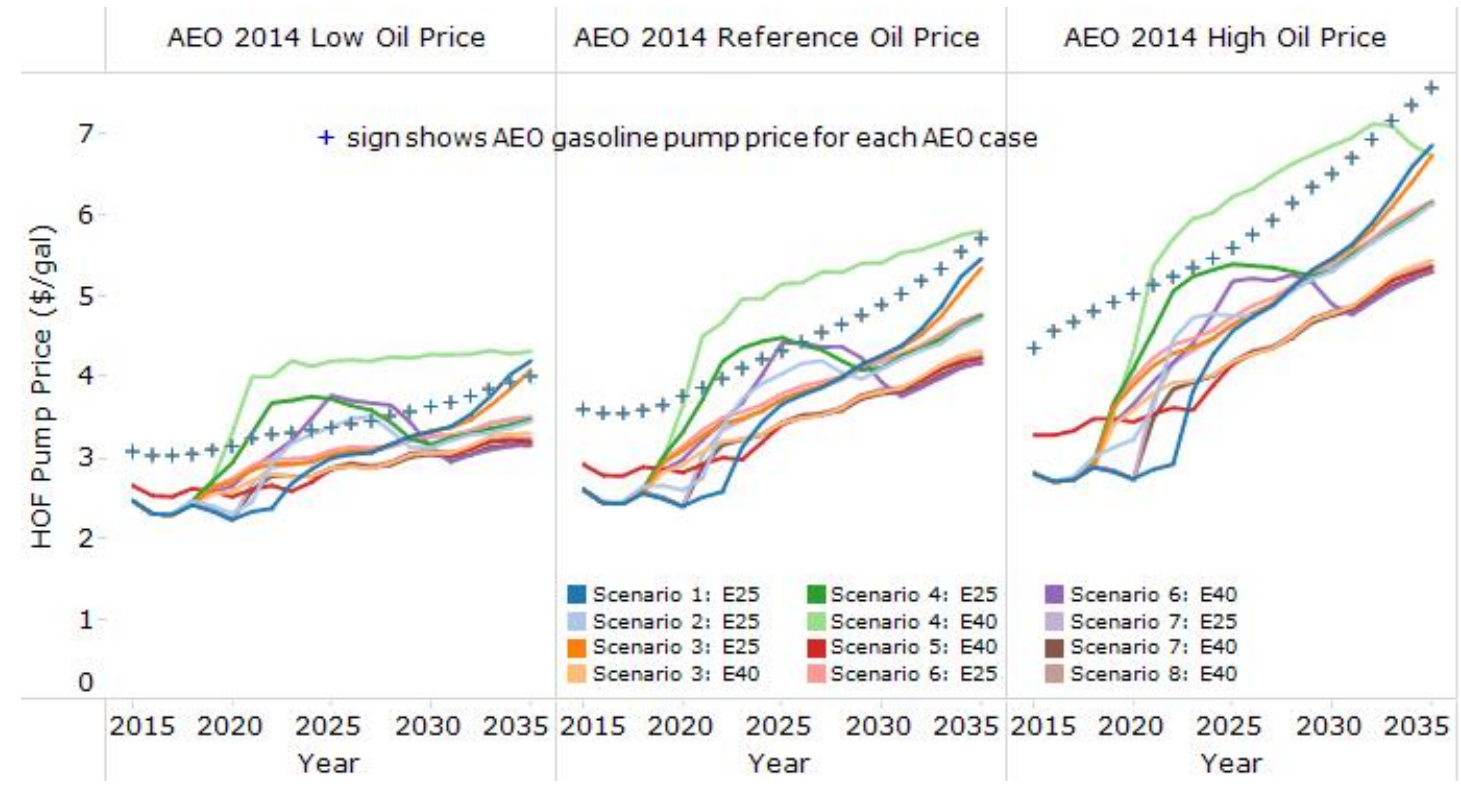

Figure 22. Pump prices by scenario from 2015-2035 for different AEO 2014 oil price cases with no transition from E10 to E15 and no dispensing station incentives 


\subsection{Brief Description of the BioTrans Model}

BioTrans is a partial equilibrium, nonlinear programming model that represents economic markets and activities associated with feedstocks and fuels in the U.S. biofuels supply/demand chain. It combines the biofuel economy model with a simple representation of petroleum fuel supply and an LDV stock submodel to satisfy U.S. demand for passenger road transportation services. BioTrans is a dynamic optimization tool, built using the General Algebraic Modeling System (GAMS), which solves for the market equilibrium by maximizing the sum of consumer and producer surplus over a 30-year period subject to material balance, capacity, and regulatory constraints. Because neither producers nor consumers are assumed to have market power, the value-maximizing solution is also a cost-minimizing competitive market equilibrium. BioTrans can be exercised under either complete or limited foresight assumptions, implying different behavior regarding long-lived decisions such as capital investment.

BioTrans uses census divisions as the unit of spatial disaggregation and depicts a variety of biofuel production pathways from farmgate to pump. Corn, corn stover, switchgrass, and forest residues availability are not endogenously determined in BioTrans. Instead, feedstock supply curves produced by the POLYSYS model as part of the 2011 Billion-Ton Study (DOE 2011) are used. BioTrans depicts the choice among alternative conversion process to turn the biomass feedstocks into ethanol or cellulosic gasoline or diesel. Biofuel production levels are determined endogenously based on market drivers and policy incentives. Once biofuel reaches a wholesale fuel terminal, it is blended with petroleum-based gasoline or diesel and RINs are detached and used to satisfy regulatory obligations. The blends are then shipped to retail stations, and vehicle owners decide which blends to purchase based on relative prices and other attributes (e.g., retail infrastructure availability, fuel mileage). BioTrans focuses on the LDV sector and includes four types of vehicles: conventional gasoline vehicles (distinguishing between those older than MY 2001 and newer ones ${ }^{25}$ ); FFVs (which can consume any blend from E05 to E85); diesel vehicles, and HOFVs. Vehicle choice is not explicitly represented in this round of analysis. Instead, projections of vehicle sales shares are taken from the ADOPT model to compute vehicle stock in BioTrans. For comparability with the BSM cases, the scenarios here also use ADOPT on-road MPGs by vehicle category, and aggregate fuel use by each vehicle category is taken as the reference demand level.

Biorefineries and retail infrastructure (dispensing equipment, USTs, and fuel distribution trucks) are treated as durable capital assets, with upfront fixed costs. For both types of assets, available capacity evolves over time, being decreased each year by depreciation and increased by any new market-based investment, if it is expected to be profitable. The activities that take place using these assets are limited by capacity constraints. Other durable assets (e.g., preprocessing equipment outside of the biorefinery or biomass/biofuel storage facilities) are assumed to be added smoothly in synchrony with the levels of activity needed. Their cost is included in the unit cost associated with those activities.

\footnotetext{
${ }^{25}$ Pre-2001 and post-2001 vehicle vintages are tracked for cases in which E15 is one of the fuel choices.
} 
For this analysis, we modified the model to account for an HOF market. Consistent with the purpose of this report as a screening exercise, we made several simplifying assumptions to facilitate the scenario analysis.

- ADOPT HOFV sales are used to compute vehicle market mix and quantity. Reference travel (VMT) demands by each vehicle category are also made consistent with ADOPT scenario fuel demands and on-road MPGs (average) for each vehicle type. In this way reference fuel use and potential HOF use are matched to the ADOPT scenarios conditions.

- When HOF is not available, HOFVs use premium gasoline as a backup. We assume premium gasoline is always available at stations where HOF is not, but is $8 \%$ more expensive than regular gasoline. Some of the scenarios assume different backup fuels for HOFVs (E15 in Scenario 1 and E51 in Scenarios 5 and 7).

- HOFV owners choose whether to fill up using HOF or premium gasoline. Reference shares are specified over time to benchmark consumer choice. How far vehicle owners will move away from reference shares partly depends on fuel price differentials and how price-sensitive the fuel choice decision is assumed to be. Currently, the assumed HOF reference share increases slowly from 2018 to 2023 and then plateaus at $90 \%$.

- Station owners can change their fuel offerings by refurbishing dispensers and tanks (allowed in some scenarios only), replacing HOF-compatible equipment for E10 equipment at the end of its useful life, or adding new extra dispensing and storing capacity at any time. The equipment life is assumed to be 15 years for dispensers and 30 years for USTs.

- In all scenarios, E25 and E40 dispensers are treated as blender pumps. The former can be used to retail any ethanol blend up to E25; the latter are compatible with any ethanol blend up to E85 and are significantly more expensive, as indicated in Table 3.

- Except in scenario 3 (see Section 4), the RFS2 is assumed to be relaxed or delayed so that the renewable volume obligation does not force into the market biofuel volumes beyond those that make sense based on current demand and competitiveness with petroleum fuels. Relaxing the RFS2 constraint also results in RIN prices remaining at or close to zero.

- The only other established policy incentive currently depicted in BioTrans is the USDA Rural Energy for America Program (REAP), which offers grants for alternative fuel dispensing infrastructure in rural areas.26 However, that program expires in 2016 (i.e., before HOFVs are available). Some of the BioTrans simulations contain additional hypothetical incentives consistent with the descriptions of the scenarios.

- Scenario 3 assumes a 40\% grant on blender pumps and E85 USTs.

\footnotetext{
${ }^{26}$ www.rurdev.usda.gov/SupportDocuments/TX_REAP\%20Flex\%20Fuel\%20Station\%20Owners\%202011.pdf
} 
- Scenario 4 assumes availability of cheaper alternative fuel storage units during the 20182023 period. Those units, whose assumed cost is $45 \%$ of that of a new UST, are meant to represent ASTs.

\subsection{System-Level Insights from BioTrans Scenario Analysis \\ Table 16. Insights on HOF Deployment along the Supply Chain, as Revealed through BioTrans Simulations, and Relevant Model Assumptions}

\begin{tabular}{|c|c|c|}
\hline $\begin{array}{c}\text { Stage In } \\
\text { Supply Chain }\end{array}$ & Finding & $\begin{array}{l}\text { Model Assumptions That, If Varied, } \\
\text { Could Impact Finding }\end{array}$ \\
\hline Demand & $\begin{array}{l}\text { 1. There are large variations in biofuel and ethanol } \\
\text { demand across scenarios. } \\
\text { 2. HOF (especially if it is E25) is not enough to } \\
\text { achieve } 36 \text { billion gal/year of renewable fuel } \\
\text { consumption by } 2025 \text {. The two most aggressive } \\
\text { scenarios achieve it by } 2035 \text {. } \\
\text { 3. Total ethanol consumption tends to be larger in } \\
\text { scenarios where HOF is E40. } \\
\text { 4. By } 2023 \text {, HOFVs generally achieve the } \\
\text { assumed reference share of HOF consumption } \\
\text { (90\%) in most regions regardless of whether } \\
\text { the assumed backup fuel is E10 premium, E15 } \\
\text { or E51. }\end{array}$ & $\begin{array}{l}\text { - HOFV sales rates (limited by } \\
\text { economics and stock turnover in } \\
\text { ADOPT) } \\
\text { - Aggregate vehicle fuel use and } \\
\text { MPG (ADOPT scenarios conform } \\
\text { to AEO, which show steadily } \\
\text { declining LDV fuel use) } \\
\text { - Complete foresight helps } \\
\text { coordinate vehicle and retail } \\
\text { infrastructure availability } \\
\text { - HOFVs achieve equivalent miles } \\
\text { per physical gallon }\end{array}$ \\
\hline Vehicles & $\begin{array}{l}\text { 5. In most scenarios, ADOPT vehicle trajectories } \\
\text { set a ceiling for total ethanol usage. }\end{array}$ & $\begin{array}{l}\text { - Lack of feedback between ADOPT } \\
\text { and BioTrans, in terms of vehicle } \\
\text { choice and fuel infrastructure } \\
\text { deployment }\end{array}$ \\
\hline Dispensing & $\begin{array}{l}\text { 6. There are no bottlenecks in availability of HOF } \\
\text { dispensers to station owners } \\
\text { 7. If available, station owners continue purchasing } \\
\text { some cheap E10 dedicated dispensers (even } \\
\text { though E10 demand is in decline and HOF } \\
\text { dispensers can also be used to satisfy E10 } \\
\text { demand). } \\
\text { 8. Refurbishment is a promising avenue for lower- } \\
\text { cost development of infrastructure, but market- } \\
\text { driven refurbishment of dispensers or USTs } \\
\text { takes place in regions/periods only when the } \\
\text { E10 assets are underutilized. }\end{array}$ & $\begin{array}{l}\text { - Base set of scenarios in BioTrans } \\
\text { assume complete information and } \\
\text { foresight (station owners have the } \\
\text { information that HOFVs will be } \\
\text { introduced in large numbers and } \\
\text { will prefer to use HOF if available). } \\
\text { This also means that the value of } \\
\text { flexibility associated with blender } \\
\text { pumps is imperfectly captured. } \\
\text { - The amount of fuel that is } \\
\text { dispensed on a per-pump and per- } \\
\text { dispenser basis }\end{array}$ \\
\hline Conversion & $\begin{array}{l}\text { 9. Biorefinery introduction rate is a binding } \\
\text { constraint for some of the years in most } \\
\text { scenarios. }\end{array}$ & $\begin{array}{l}\text { - Only } 25 \text { of conversion facilities can } \\
\text { be built in a year. }\end{array}$ \\
\hline Feedstock & $\begin{array}{l}\text { 10. Forest residue is the only feedstock for which, } \\
\text { in some scenarios, } 100 \% \text { of available supply is } \\
\text { used. Total feedstock supply is sufficient for all } \\
\text { scenarios. }\end{array}$ & $\begin{array}{l}\text { - BioTrans uses exogenous } \\
\text { feedstock supply curves based on } \\
\text { POLYSYS. No feedback between } \\
\text { HOF-induced demand for forest } \\
\text { residue and future additional } \\
\text { plantings is represented. However, } \\
\text { supply for each feedstock } \\
\text { responds to price. }\end{array}$ \\
\hline
\end{tabular}


Finding 1. Large variations in biofuel/ethanol demand across scenarios. The market adoption scenarios described in Section 4 resulted in a wide range of projections about ethanol consumption during the 2018-2035 period.

BioTrans equilibrates the fuel market for the four types of LDVs it represents (conventional gasoline, FFVs, HOFVs and diesel). ${ }^{27}$ Figure 23 allows us to explore the fraction of total ethanol demand that corresponds to HOFVs in each of the scenarios. The height of each bar corresponds to the potential ethanol demand in a given scenario (i.e., the ethanol demand that would result from all FFVs, HOFVs, and conventional gasoline vehicles consuming flex fuel, HOF, and E10, respectively, $100 \%$ of the time). ${ }^{28}$ Total potential ethanol demand is somewhat lower in 2035 than in 2025 in some E25 scenarios. In those cases, the reduction in flex fuel consumption potential associated with decline in the FFV fleet is not completely offset by the increase in E25 consumption potential by HOFVs. The gray line on each bar indicates the quantity of ethanol consumption achieved.

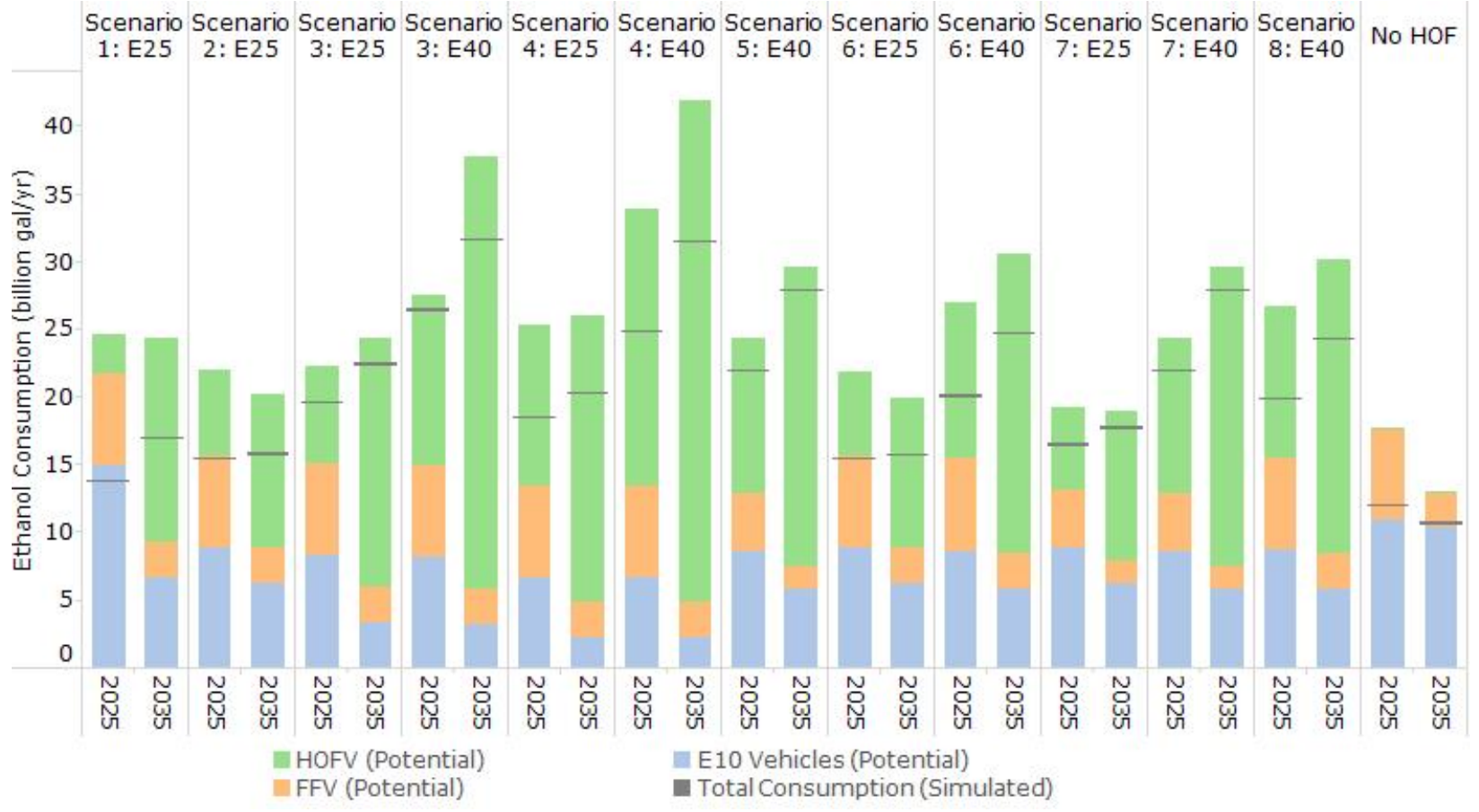

Figure 23. Potential versus simulated total ethanol consumption in 2025 and 2035 (including conventional gasoline vehicles, FFVs, and HOFVs)

In all scenarios where HOFVs are deployed nationally, by 2025, the simulated ethanol demand is higher than if the LDV fleet contained only FFVs and vehicles capable of consuming up to

\footnotetext{
${ }^{27}$ Even though in all scenarios with RSP FFV sales stop in 2017, the 2017 FFV fleet continues consuming E85 afterward. Given the survivability coefficients being used in BioTrans, a small fraction of the 2017 fleet would continue being driven in 2035.

${ }^{28}$ In scenario 1, conventional gasoline vehicles consume a mixture of E10 and E15. In scenarios 5 and 7, E51 replaces E85 in the current E85-compatible infrastructure.
} 
E10/E15 blends. The fraction of the potential ethanol demands depicted in Figure 23 that is actually fulfilled depends on the relative price of gasoline versus ethanol, the availability of HOF and flex fuel, and the relative attractiveness of the fuels vis-a-vis other attributes that shape consumers' decisions (e.g., acceleration, range, perceptions about the energy security and environmental attributes of the fuel blends). For each scenario, the fulfilled fraction of potential ethanol demand is always equal or larger in 2035 than in 2025. This result reflects an increased ability to serve ethanol demand over time as more biorefinery capacity comes online and more of the dispenser and UST infrastructure is replaced with HOF-compatible equipment. It is also a function of the decreasing trend in the fuel cost of each vehicle mile traveled (VMT).

Finding 2. Except for the most aggressive vehicle deployment scenarios, HOF (especially if it is E25) cannot by itself achieve 36 billion gal/year renewable fuel consumption. HOFVs can markedly expand (cellulosic) ethanol use, but to meet the full long-run RFS goals other biofuels are likely still required. Figure 23 shows that potential ethanol demand is below 36 billion gal/year in all but two scenarios in 2025 and 2035. This figure includes potential ethanol demand from all vehicle categories, as a component of E10, flex fuel, and HOF.

The two scenarios with price-driven HOFV adoption (Scenario3: E25 and Scenario3: E40) assume that the initial biofuel blending mandate set forth in EISA 2007 is maintained. As already indicated, the 2022 mandated biofuel blending level is hardly achievable with an ethanol-only pathway. Thus, in those two scenarios, BioTrans also allows for production of cellulosic gasoline and diesel using a pyrolysis conversion pathway. Those drop-in biofuels are much more expensive than cellulosic ethanol but generate more RINs per gallon because of their higher energy content. In 2022, the marginal cost of cellulosic ethanol and cellulosic gasoline at the biorefinery gate in Scenario 3: E40 are \$3.36/gallon and \$7.68/gallon, respectively. Through a combination of corn ethanol, cellulosic ethanol, and pyrolysis-based cellulosic fuel production, as well as sugarcane ethanol imports, the total number of RINs generated in 2022 is 28.6 billion (gallons ethanol equivalent) in the E25 price-driven adoption case and 28.0 billion (gallons) in the E40 price-driven adoption case. The remainder of the RFS2 requirement is fulfilled by borrowing RINs and importing sugarcane ethanol. ${ }^{29}$ All in all, these two cases show that the original RFS2 schedule would be extremely hard and expensive to meet even with HOF deployment.

Finding 3. Substantial ethanol use occurs in many scenarios. Given the HOFV sales from ADOPT, and under stable, predictable conditions, HOFVs achieve a significant fraction of their full potential ethanol use (see Figure 24). Potential ethanol use is based on reference VMT demand by HOFVs if they were to use HOF one-hundred percent of the time. For HOFVs, reference HOF choice share is $90 \%$ after 2023. In BioTrans, HOFV fuel choice shares and total travel demand can vary endogenously from the reference levels. Simulated HOF choice share varies based on relative fuel prices and the retail availability of HOF, and actual VMT demand

\footnotetext{
${ }^{29}$ Given the conversion pathways it represents, BioTrans includes the cellulosic biofuel requirement (16 billion gal/year by 2022) but not the advanced biofuel requirement. It also sets an upper bound of 15 billion gal/year on corn ethanol production. Thus, the RFS2 requirement imposed as a constraint in these two scenarios is 31 billion gal/year in 2022 rather than the total renewable fuel requirement of 36 billion gal/year.
} 
can increase or decrease modestly from reference levels in response to average fuel prices. ${ }^{30}$ The scenario results in Figure 24 reflect the base case conditions where investors and consumers have good information and reliable expectations of future HOF vehicle demand, price and policy conditions (complete foresight). This contributes to smoothing out the vehicle and retail infrastructure availability coordination problems, and encourages infrastructure investment. Figure 24 shows ethanol use in 2025 and 2035, years by which HOF is expected to be substantially available. ${ }^{31} \mathrm{HOF}$ is generally cost-competitive with E10, and certainly lower cost than premium E10, so HOF choice shares are high in most scenarios.

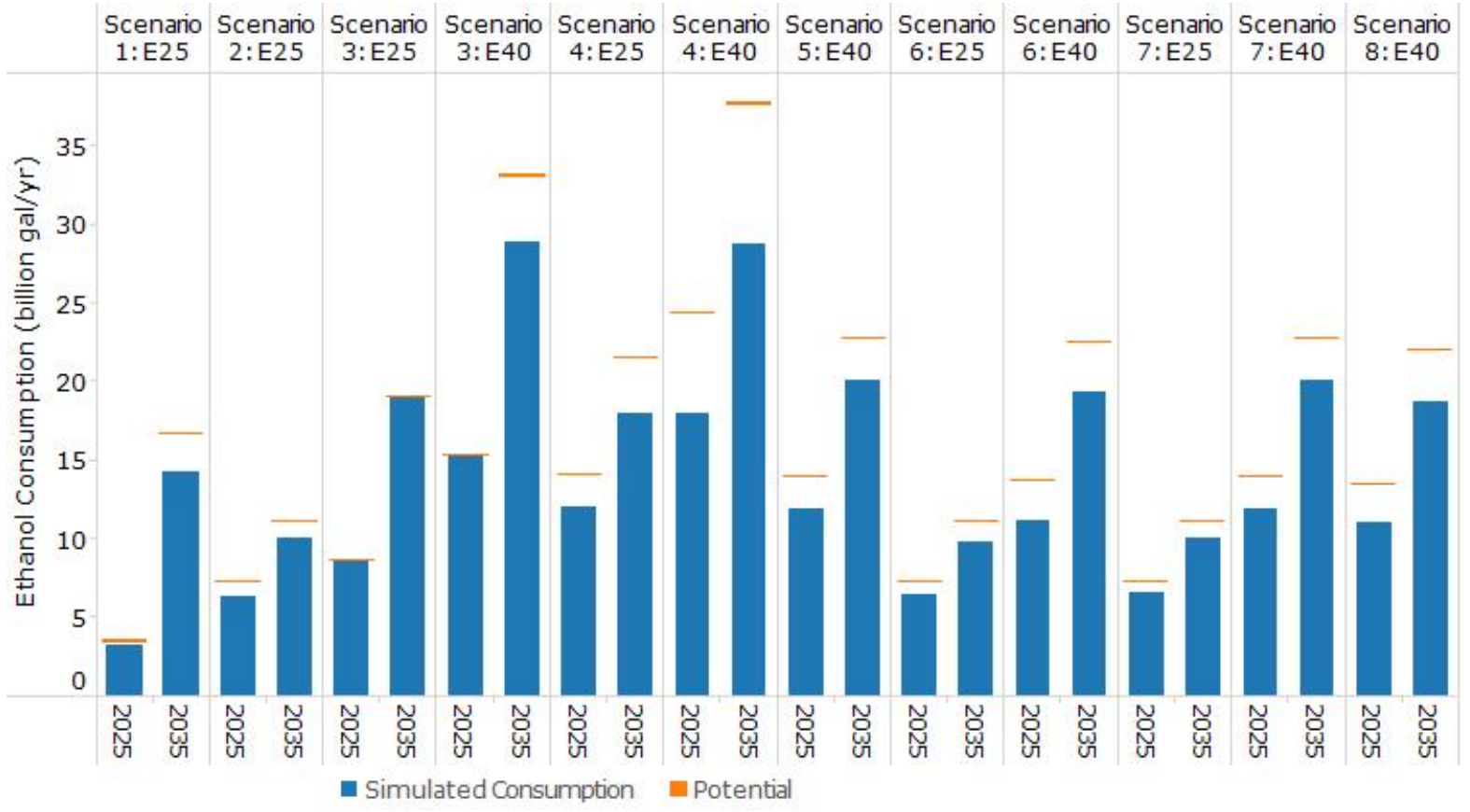

Figure 24. Achieved and potential ethanol consumption by HOFVs for many scenarios in 2025 and 2035

Finding 4. Total ethanol consumption tends to be higher in scenarios where HOF is E40. Figure 24 indicates that only the E40-based scenarios are able to surpass 25 billion gal/year of ethanol consumption. A key assumption, which requires validation through experimental testing of actual vehicles, is that HOFVs experience no mileage penalty (on a physical-gallon basis relative to a conventional vehicle driving on E10) when using HOF. This assumption implies a stronger gain in mileage per gasoline gallon equivalent (gge) when HOF is E40 than when it is E25.

Finding 5. Uncertainty about the future, modeled as limited foresight, suggests somewhat lower levels of achieved HOF and ethanol use. This is more notable in some of the high infrastructure-

\footnotetext{
${ }^{30}$ Absent shocks or variant cases with significant fuel price changes, any endogenous changes in aggregate vehicle fuel demand are typically small, since final demand is price inelastic and prices are near reference prices.

${ }^{31}$ Most research indicates that the effective costs to consumers of limited RSP station- availability rapidly decline to modest levels once RSP retail station availability approaches 15\%-20\%. Thus RSP is "substantially available" for station shares well below $100 \%$.
} 
cost scenarios. But the impact of imperfect foresight is not radical, perhaps since the risks of shocks and sharp changes in policy or fuel prices are not explicitly considered. We investigated the effect of limited foresight on the volume of HOF consumption in variant cases of all of the scenarios. In the limited foresight cases, the model represents agents with a rolling planning horizon ( 6 years at a time with overlap of the last 2 years into the next iteration; i.e., with an opportunity for plan revision after 4 years). Figure 25 shows that limited foresight results in reduced levels of HOF consumption in all but one scenario. Not knowing, for example, the extent to which HOFVs will continue being deployed or the relative prices of gasoline and ethanol more than 4 years out, market participants invest less in the assets necessary to fully satisfy the HOFV fleet. The reduction is small in some cases, but more substantial in four of the E40 cases (with average reductions of $19 \%$ by 2035). The E40 cases involve greater infrastructure investments, for larger ethanol production volumes and more expensive station equipment. If the investors have less reliable information about future market demands and prices, fewer of those investments occur and HOFVs achieve less of their potential biofuel use. ${ }^{32}$ However, the difference between limited and complete foresight is not as great as one might imagine, as long as prices, market conditions, and technological knowledge evolve smoothly, as generally envisioned in AEO and ADOPT projections. ${ }^{33}$

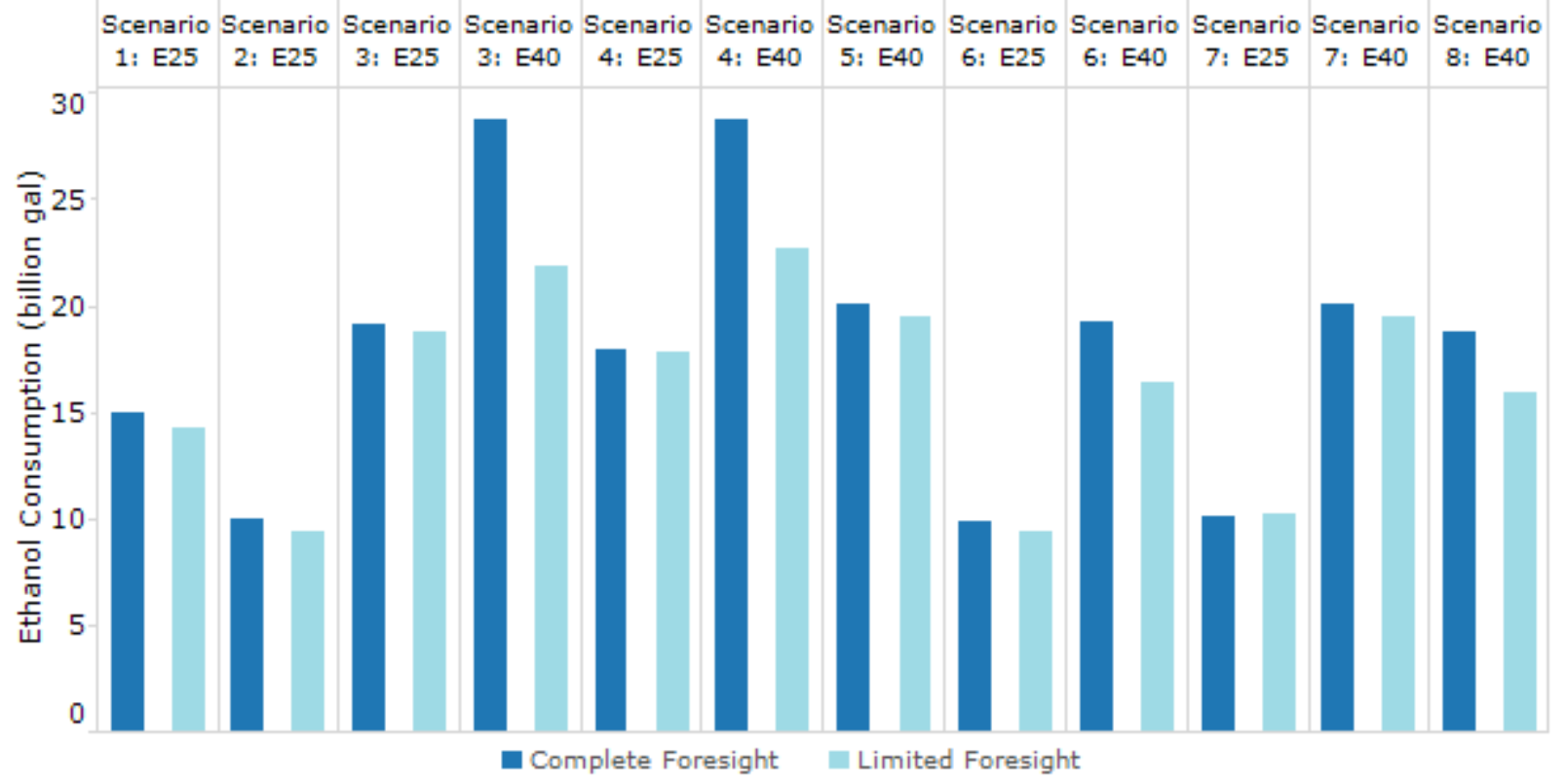

Figure 25. Simulated ethanol consumption by HOFVs (scenarios with complete foresight versus limited foresight)

\footnotetext{
${ }^{32}$ In both the complete foresight and limited foresight cases investors discount future revenues at $16 \%$, a fairly high discount rate that reflects a commonly used barrier rate for private investment.

${ }^{33}$ The role of imperfect foresight and imperfect information is greater in cases of market or policy shocks.
} 
Finding 6. By 2023, HOFVs achieve a large share of HOF consumption, typically close to the $90 \%$ reference share in most regions regardless of whether the assumed backup fuel is E10 premium, E15, or E51. BioTrans benchmarks fuel choice at reference prices by setting reference shares of fuel consumption for vehicle types that can choose across multiple fuels. In the case of HOFVs, reference prices are close to parity and the assumed reference shares start at $15 \%$ in 2018 , smoothly increase up to $90 \%$ in 2023, then staying constant after that. Figure 26 summarizes the HOF share by HOFVs in all scenarios. The only scenario for which the share is lower than $80 \%$ in 2023 is Scenario 4: E40, the one with the largest potential ethanol consumption. This has to do, at least partly, with the inability of the system to build biorefineries at a pace commensurate with the introduction of new HOFVs demanding additional HOF. On the other hand, the only scenarios for which the share is greater than $90 \%$ in 2023 are Scenario 3 (both the E25 and E40 version). The reason for this is that very high and fast HOFV penetration is the need to comply with the RFS-2 requirement. It is thus driven by regulation more than by consumer choice. Post-2022, the shares stay close to the reference $90 \%$ in most scenarios. This reflects the market outcome that E10 and HOF (E25 or E40) price outcomes equilibrate close to one another, given the reference assumption of only moderate price elasticity for fuel choice.

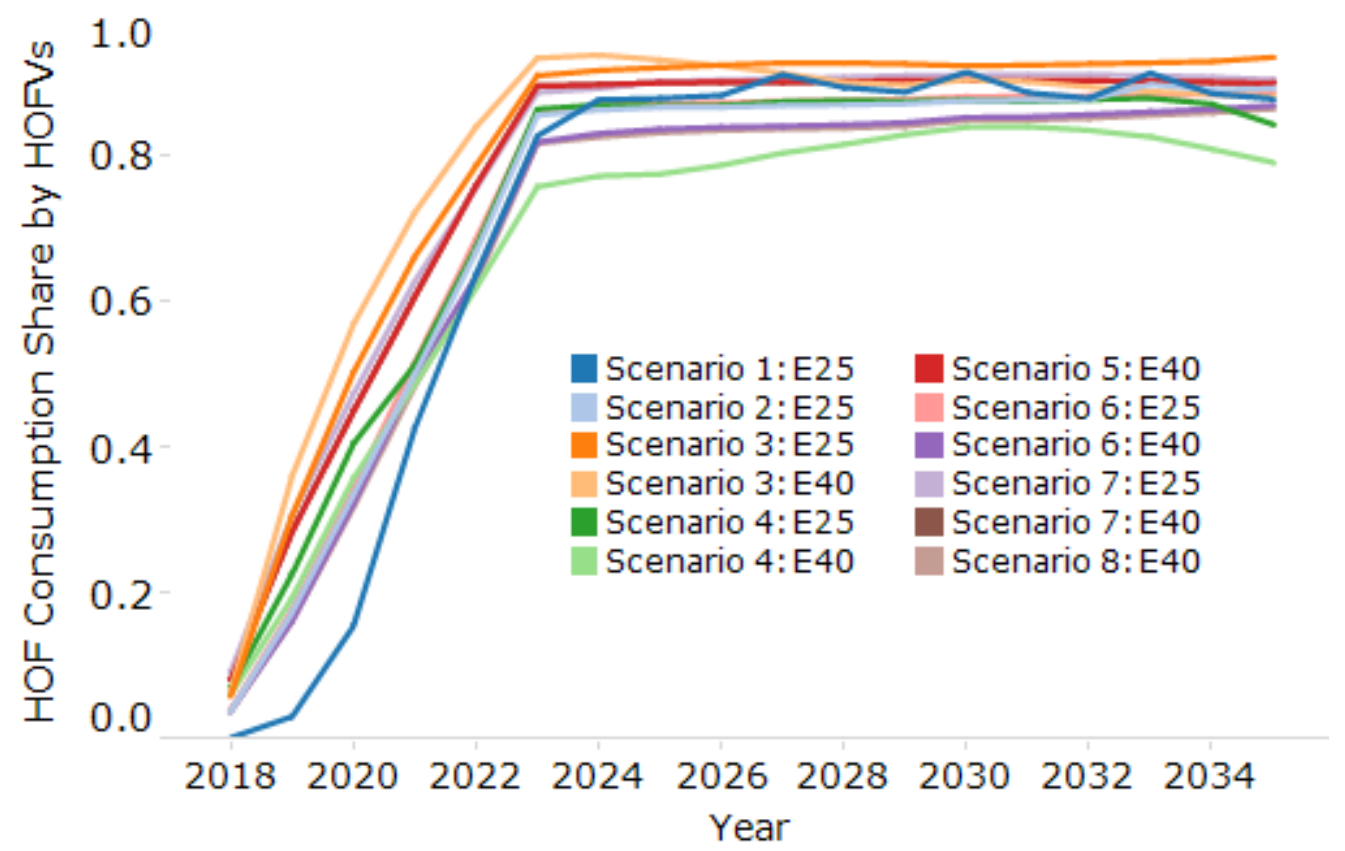

Figure 26. Weighted average HOF consumption share by HOFVs (weights based on regional HOF consumption levels)

Finding 7. In most scenarios, ADOPT vehicle trajectories set a ceiling for total ethanol usage. The results do not yet reflect the full interactions between fuel prices, fuel infrastructure development, and vehicle choice (HOFV demand). The market adoption scenarios discussed in this report envision HOF deployment as a response to exogenous HOFV sales projections (from ADOPT). Thus, they are limited in their representation of the problem of coordinating investments of retail infrastructure, biorefineries, and optimized vehicles. They are useful for pinpointing bottlenecks in upstream parts of the supply chain, and answering questions such as, "Is there enough feedstock?" or "Can enough biorefineries and dispensers be installed to keep with the pace of HOFV introduction based on estimates of productive capacity for building or 
manufacturing those assets?" However, to the extent that BioTrans equilibrium fuel prices and fuel infrastructure development differ from those used in the ADOPT model, the feedback effect of those divergences on vehicle choice and retail deployment decisions cannot be captured with the current modeling setup.

Finding 8. There are no bottlenecks in availability of HOF dispensers to station owners. The maximum number of new dispensers that are allowed each year corresponds to $10 \%$ of the number of dispensers in the initial year. Given that the normal replacement rate for dispensers is $1 / 15$ per year, up to $50 \%$ more new dispensers than are needed for normal replacement each year can be installed. Because overall fuel consumption decreases over time and BioTrans minimizes spare capacity, this constraint is typically not binding during the period of interest (2018-2035). For future analysis, it would be worth checking with retail equipment manufacturers to discern whether the current assumptions about their maximum annual production capacities are too optimistic.

Finding 9. If available, station owners continue purchasing some cheap E10 dedicated dispensers. Absent new incentives, fuel retailers may have insufficient motivation to invest in the needed HOF-compatible equipment. Even knowing that conventional gasoline vehicles will lose market share and that blender pumps allow flexibility in which fuel blends to retail, BioTrans results indicate that retailers would still purchase E10-dedicated dispensers (the cheapest dispenser type). The scenarios that achieve the largest penetration of HOF-compatible dispensers do so because of policy/regulatory decisions. In Scenarios 2 and 6, E10 dedicated dispensers stop being available for sale after 2017 . This "sunset" measure would likely not be taken by equipment manufacturers but result from a regulatory decision. In Scenario 3, a 40\% grant for investment in HOF-compatible dispensers and USTs is available after 2017. This grant makes HOF-compatible retail equipment be cheaper than E10-dedicated equipment. As a result, after year 2020, no additional investment in E10 dispensers takes place in that scenario.

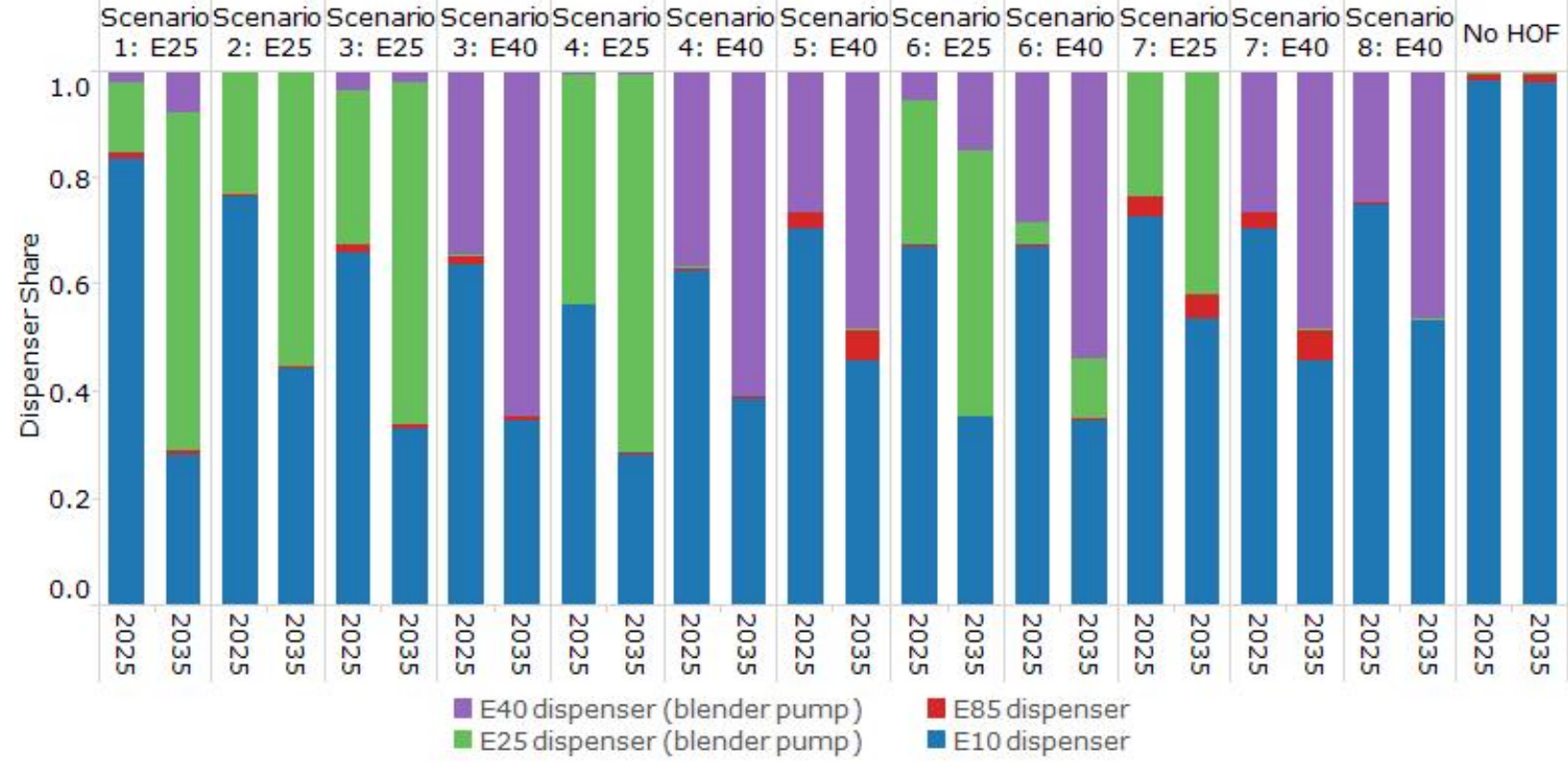

Figure 27. Simulated dispenser shares in 2025 and 2035 
Figure 27 shows that scenarios where HOF is E25 have an increasing fraction of E25 dispensers (compatible with ethanol blends up to E25) from 2025 to 2035. Meanwhile, when HOF is E40 most new dispensers are of the more expensive type, compatible with any ethanol blend up to E85. Nonetheless, E25 and E40 dispensers are being modeled as blender pumps, so a mixture of both is present in many scenarios.

Finding 10. Refurbishment is a promising avenue for lower cost development of infrastructure. It is used in some region-year-scenario combinations in which E10 UST capacity is not fully utilized. Savings associated with the possibility of refurbishment are greater for USTs than for dispensers. The operating life of dispensers is similar to the typical life of an LDV, which means both fleets (dispensers and vehicles) could be turned over in tandem. On the other hand, the lifecycle of USTs is much longer than that of vehicles. Therefore, a strategy where they are replaced only at the end of their useful life leads to slow turnover that would not keep pace with aggressive HOFV scenario deployment. Moreover, USTs are also more expensive than the above-ground infrastructure, so having to install additional units rather than refurbish older ones would make HOF retail infrastructure deployment significantly more expensive.

Figure 28 displays the cumulative (undiscounted) investment in retail infrastructure net of incentives for the various scenarios. The cumulative investment in dispensers and fuel storage tanks from 2018 to 2035 ranges from $\$ 23$ to $\$ 52$ billion. The paths shown in Figure 28 result from subtracting the investment in the no-HOF case from each of the HOF scenarios and they include all types of dispensers and storage tanks (for gasoline and diesel-based fuel blends). Scenarios with HOF deployment lead to higher total retail infrastructure investment than the noHOF case for various reasons. First, the blender pumps needed to retail HOF are more expensive than conventional E10 dispensers. Second, total fuel consumption and, consequently, total retail infrastructure capacity needed is somewhat larger in cases with HOF deployment.

The pattern of investment is remarkably smooth in all cases. Only one of the accelerated deployment cases (Scenario 4: E25) shows a somewhat different timing with a large jump in investment in 2022 (the last year in which installation of cheap ASTs is allowed). With an assumed discount rate of $16 \%$, both the number of tanks and dispensers and the timing of the investment matter for the total (undiscounted) expenditure. A difference in timing partly explains the large gap between total investment in Scenario 4: E25 and Scenario 4: E40. In undiscounted terms, total investment in the E40 case is more than double the investment in the E25 case. In discounted terms, the former is $37 \%$ higher than the latter.

Scenario 3 (price-driven adoption) is the only one in which the purchase of HOF-compatible retail infrastructure is subsidized (with a $40 \%$ grant). Scenario 3 results in the lowest investment cost among those in which HOF is deployed nationally but not in the highest penetration of HOF-compatible dispensers. Penetration is slightly higher (62\% by 2035$)$ in Scenario 4: E25 (accelerated deployment) because, in that case, dedicated E10 and E85 dispensers are no longer available after 2017. In scenarios 6 and 7, the cases in which HOF is E40, result in significantly larger investment costs than their E25 counterparts (30-40\% higher). Not only are E40compatible dispensers more expensive but HOF market share is larger in those two E40 scenarios so the number of dispensers required is also greater. On the other hand, in the pricedriven adoption scenarios (Scenario 3), total investment is the same for E25 and E40 modalities of HOF. 


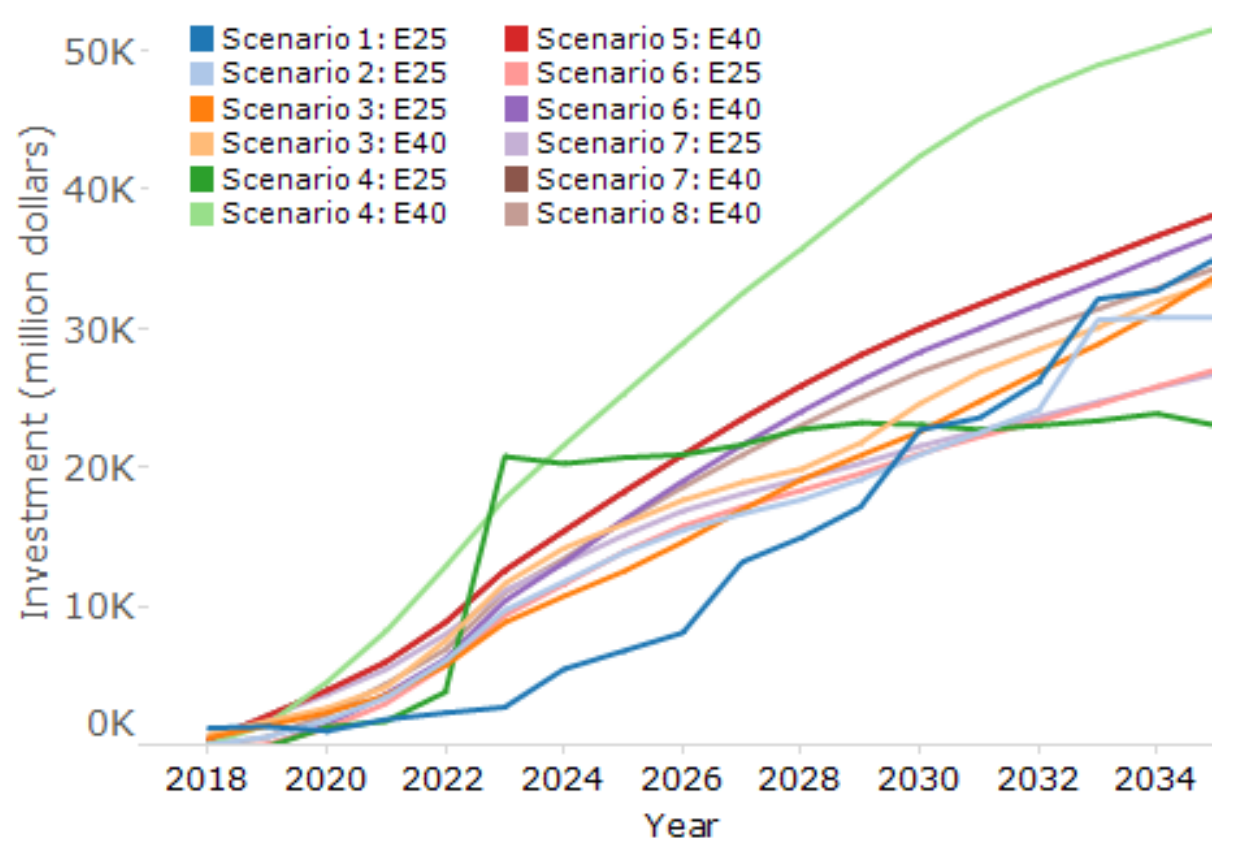

Figure 28. Cumulative investment in retail infrastructure (undiscounted, net of incentives)

Finding 11. Biorefinery introduction rate is a binding constraint for some of the years in most scenarios. The maximum introduction rate for biorefinery capacity was set based on the statistics published by the RFA regarding corn ethanol capacity installed. ${ }^{34}$ Dry mill capacity grew very rapidly for most of the last decade. That growth peaked in 2008 with 31 new corn ethanol plants coming online that year and resulting in the capacity to process an additional 35.75 million dry tons. That number is being used in BioTrans as the maximum biorefinery capacity addition (including corn ethanol and cellulosic ethanol biorefineries) in any given year. Because conversion yields are assumed to grow over time, the biorefinery capacity constraint also grows if expressed in millions of gallons. Table 17 shows, for each scenario, the number of years in the 2018-2035 period in which the biorefinery capacity introduction rate was a binding constraint. Scenarios where HOF is E40 result in the highest levels of ethanol production and, therefore, are those where the upper bound on allowed biorefinery capacity additions is reached more often.

Finding 12. Forest residue is the only feedstock for which, in some scenarios, $100 \%$ of available supply is used. Total feedstock is sufficient for all scenarios. Figure 29 summarizes the feedstock mix used to produce HOF and other ethanol blends in 2 years: 2025 and $2035 .{ }^{35}$ The base of the feedstock supply stack is composed of corn and forest residue. The harvested volume of corn

\footnotetext{
${ }^{34} \mathrm{http}: / / \mathrm{www}$. ethanolrfa.org/pages/statistics

${ }^{35}$ Even though simulated ethanol volumes for Scenario 3: E25 and Scenario 3: E40 are significantly different, the simulated feedstock volumes are approximately the same in the two scenarios. This apparent inconsistency can be explained by the fact that, in Scenario 3, the RFS2 renewable fuel mandate must be met by 2022. In that scenario, it is the regulatory mandate that drives total feedstock volume. Part of the feedstock harvested is used for producing cellulosic gasoline or cellulosic diesel.
} 
remains very stable across years and scenarios because it is limited by the upper bound in corn ethanol production set by the RFS2 (15 billion gal/year) and because corn ethanol production is depicted in BioTrans as a mature technology whose conversion yield will not increase over time. Forest residue is the preferred feedstock used in thermochemical conversion pathways because it produces the cheapest cellulosic ethanol. Remaining biofuel demand is satisfied with a combination of switchgrass and corn stover. By 2035, more than half of U.S. biofuel feedstock is cellulosic in three of the 13 scenarios depicted.

Table 17. Number of Years in Which the Biorefinery Capacity Introduction Rate Is Binding during the Period 2018-2035

\begin{tabular}{|l|l|}
\hline Scenario 1: E25 & 3 \\
\hline Scenario 2: E25 & 0 \\
\hline Scenario 3: E25 & 4 \\
\hline Scenario 3: E40 & 13 \\
\hline Scenario 4: E25 & 0 \\
\hline Scenario 4: E40 & 13 \\
\hline Scenario 5: E40 & 12 \\
\hline Scenario 6: E25 & 10 \\
\hline Scenario 6: E40 & 13 \\
\hline Scenario 7: E25 & 0 \\
\hline Scenario 7: E40 & 12 \\
\hline Scenario 8: E40 & 13 \\
\hline
\end{tabular}

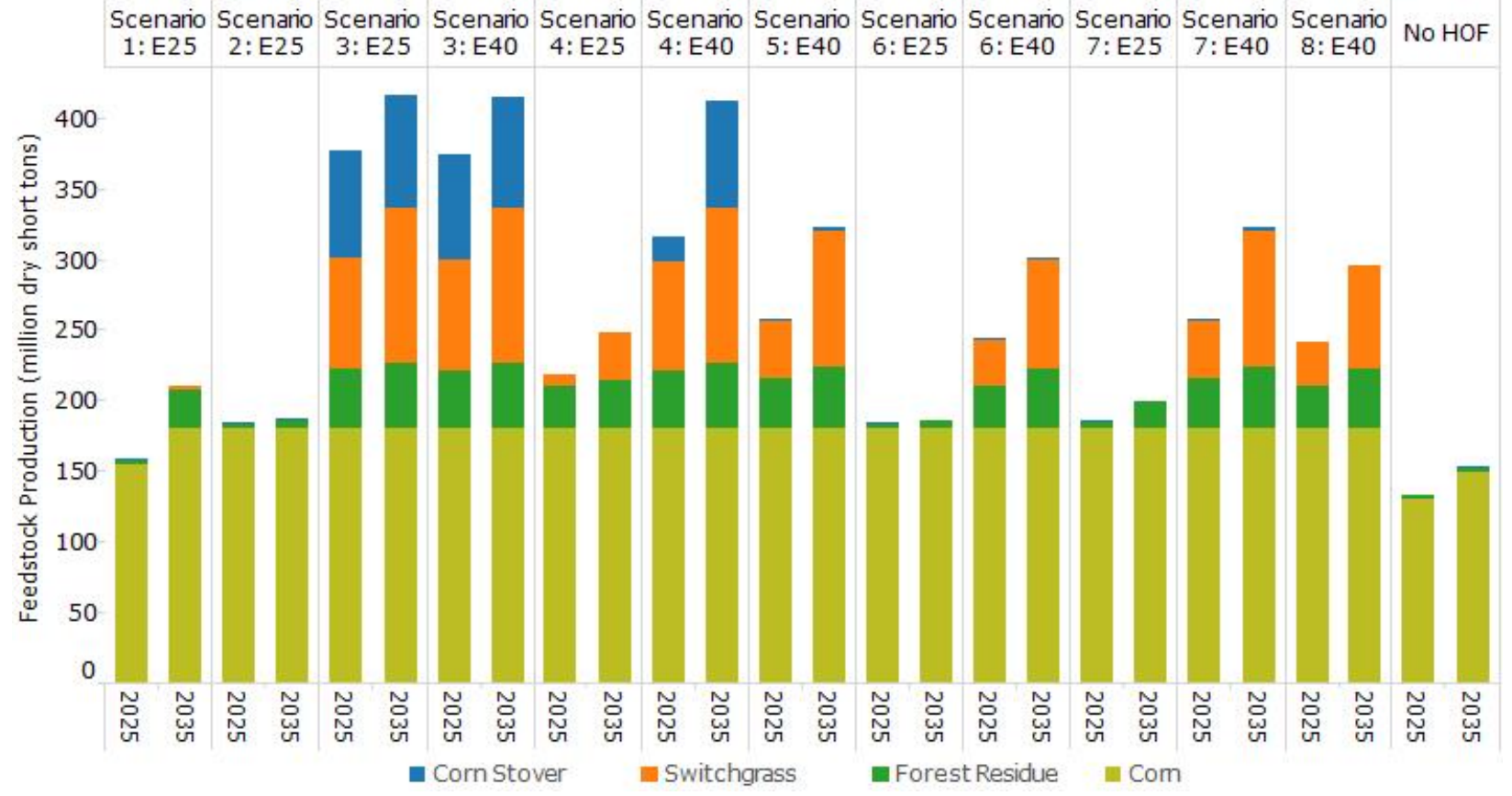

Figure 29. Biofuel feedstock production (2025 and 2035) 


\subsection{Discussion of Differences between Biomass Scenario Model and BioTrans Scenario Analyses}

The BSM and BioTrans models utilize substantially different modeling approaches. BioTrans reflects a competitive market-equilibrium approach: it solves for the biofuel system configuration and operation over a 20-year planning horizon that optimizes consumer benefit net of producer cost. The BSM reflects a system dynamics approach that focuses on the accumulations, flows, and feedbacks that drive the dynamic evolution of the biofuel supply chain. Given these differences, the models approached the question of HOF market evolution in different ways and answered different questions. The BSM analysis focused on how the biomassto-biofuels system would react to a set influx of HOFVs (i.e. potential HOF demand) and the interaction of decision-makers at each stage, whereas the BioTrans model was calibrated to explore a system where biorefinery and retail infrastructure investment pursue, to the extent possible, the socially optimal final fuel mix (given complete information about the evolution of the vehicle fleet and the relative prices of gasoline and ethanol).

Even though the internal logic differed, the analysis revealed a set of system-level insights that were identified by both models:

- The economics behind investment in HOF-compatible dispensing infrastructure may impede the ability of HOFVs to use HOF;

- Biorefinery construction limits may not be able to meet the demand for ethanol from HOFVs in aggressive scenarios;

- Feedstock availability does not appear to constrain ethanol production.

Because of the different modeling approaches employed and, to a lesser extent, because of model data and features in place, we found some differences in specific model output when comparing the results of BioTrans and BSM. Appendix C provides a systematic overview of model features that differ between the two models.

\subsubsection{Potential Fuel Demand}

As was highlighted in Sections 6.2 and 6.3, we worked to coordinate model inputs so that scenario representation in BioTrans and BSM were generally consistent. Potential fuel demand sets a ceiling for sustained use and production of ethanol, and hence for the build out of conversion capacity and for the demand for feedstocks. The two models utilized consistent potential ethanol demand from HOFVs (Figure 30). 


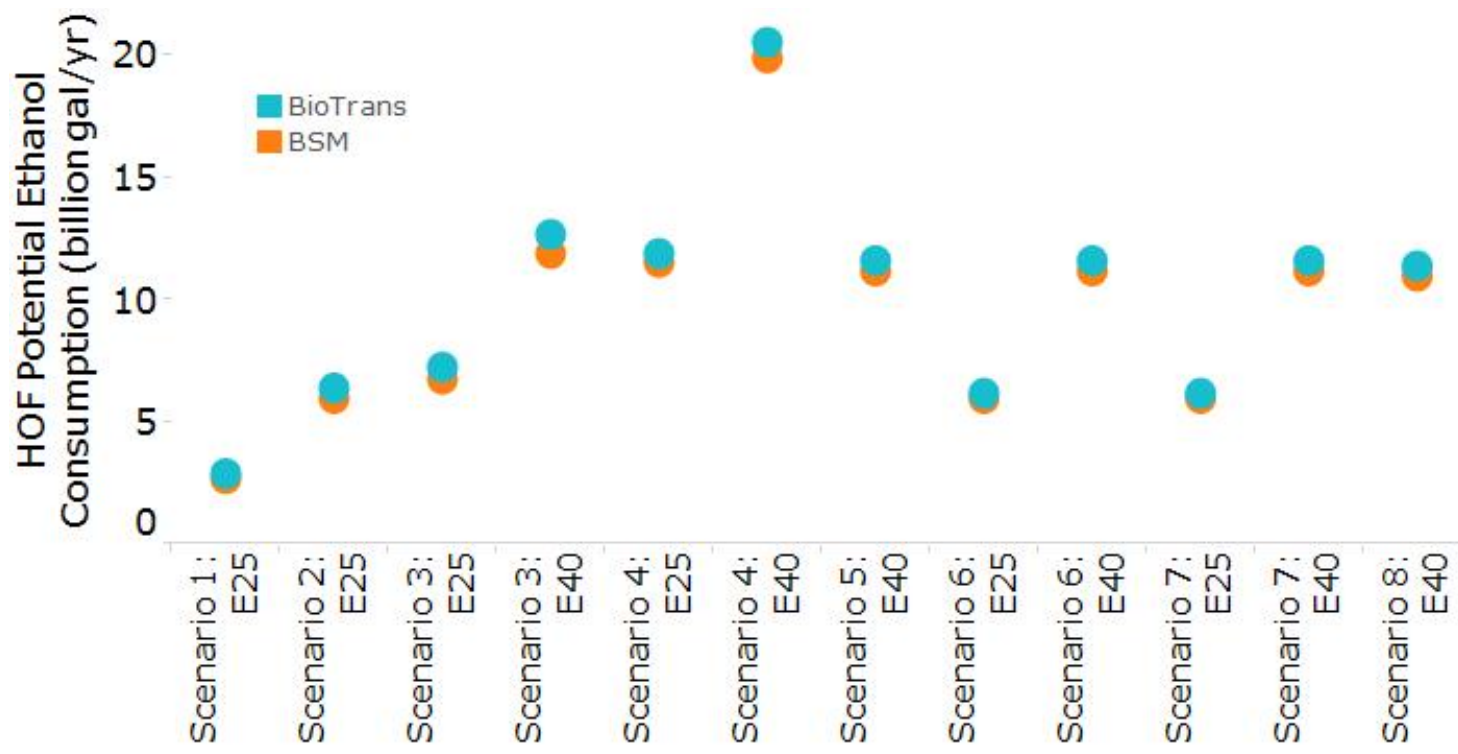

Figure 30. Comparison of the potential HOF ethanol demand in 2025, given vehicle fleet, by scenario for the BSM and BioTrans models

Note that for all scenarios, HOF potential ethanol demand is slightly lower in BSM than in the BioTrans. In both models, potential demand is generated as a product of the number of vehicles, their fuel efficiency, and the number of miles traveled each year. Therefore, differences in potential demand reflect differences in one or more of these drivers. Both the BSM and BioTrans utilized the ADOPT model for vehicle fleet and fuel efficiency projections. However, the BSM calculates VMT based on the age class of vehicles, while BioTrans uses a fleet average that is adjusted upward or downward based on fuel prices.

\subsubsection{Simulated Fuel Demand}

Simulated ethanol consumption from HOFVs was generally higher in BioTrans than in BSM (Figure 31). This difference is to be expected because of how the two models consider station investment decisions and fuel choice. In particular, different assumptions around station owner decisions appear to have the greatest impact on the variations in results (Table 18).

The existence of foresight in the BioTrans model allows station owners to see the price of HOF and predict that HOFV drivers will demand a certain amount of HOF in coming years, given the expected relative prices of $\mathrm{HOF}$ versus premium gasoline. The assumed reference fraction of HOFV demand satisfied by HOF reaches $90 \%$ by 2023 . Therefore, the "demand pull" drives investment in infrastructure to a large extent. ${ }^{36}$ Station owners are assumed to obtain the same margin per unit of fuel sold regardless of the fraction of ethanol included in the blend. ${ }^{37}$ The $\mathrm{BSM}$ is conservative in its representation of station owner investment decisions. The BSM

\footnotetext{
${ }^{36}$ For further explanation around the demand-pull concept, see Appendix C.

37 That margin is exogenously set based on historical data about the differential between retail and wholesale gasoline prices (net of distribution costs).
} 
assumes that the station owner has a limited view into future fuel price and looks at installing HOF pumps as an investment decision based on the net present value (NPV) of installing an HOF pump versus an E10 pump (except in scenarios where refurbishment was an option). The BSM uses a very short payback period, considered to be consistent with a high discount rate, which in turn implies a fairly short-term perspective. Some station owners will begin to invest in new equipment once the NPV of doing so is positive, but $100 \%$ of station owners will not invest until the NPV passes a certain threshold, set at $\$ 10,000$ for these simulations. ${ }^{38}$ The per-unit revenue basis used in BioTrans and BSM may also drive additional investment in infrastructure for the BioTrans simulations (item 4 in Table 18).

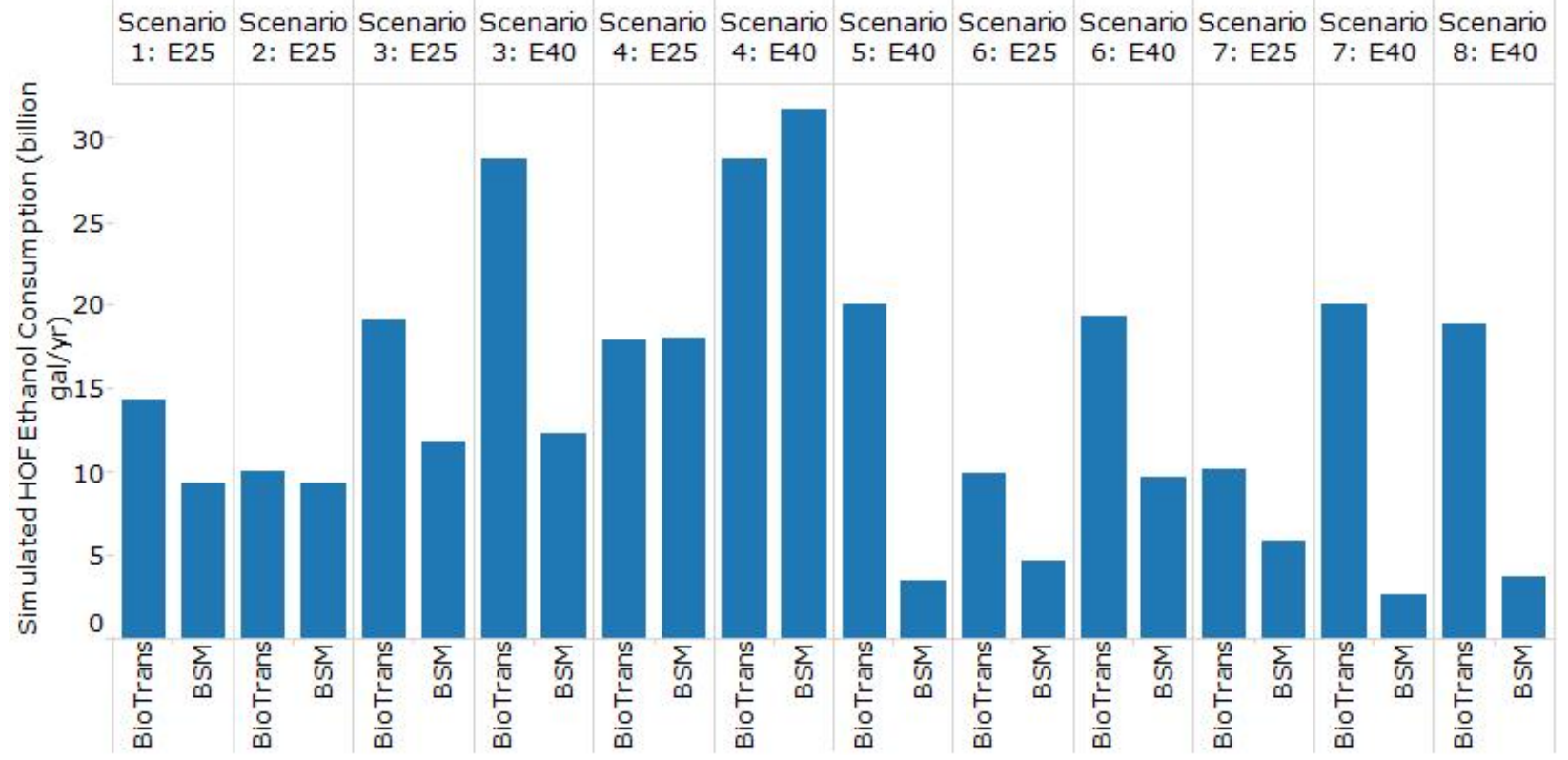

Figure 31. Comparison of the simulated HOF ethanol demand in 2035, given vehicle fleet, by scenario for the BSM and BioTrans models: The differences between the HOF ethanol demand in the two models illustrates the impact of assumptions of a short term NPV-focus (BSM) and a long term social welfare focus (BioTrans).

\footnotetext{
${ }^{38}$ For more information on NPV logic in the BSM, see Appendix A.
} 
Table 18. Differing Logic When Modeling HOF Investment Decisions

\begin{tabular}{|l|l|l|}
\hline Logic Component & \multicolumn{1}{|c|}{ NPV Focus (BSM) } & \multicolumn{1}{|c|}{ Social Welfare Focus (BioTrans) } \\
\hline HOF capital costs & $\begin{array}{l}\text { Capital cost of investment } \\
\text { incorporates all major aspects of the } \\
\text { decision, including potential loan } \\
\text { incurred. Even with high HOF } \\
\text { demand, high capital costs can limit } \\
\text { HOF infrastructure investment. This } \\
\text { is especially true due to the low profit } \\
\text { margins on fuel sales. }\end{array}$ & $\begin{array}{l}\text { The capital costs can be prohibitive if } \\
\text { there is not enough future demand to } \\
\text { make up for the investment. }\end{array}$ \\
\hline $\begin{array}{l}\text { Station owner view } \\
\text { of HOF demand }\end{array}$ & $\begin{array}{l}\text { Station owners only consider HOFVs } \\
\text { currently on the road when making } \\
\text { investment decisions. }\end{array}$ & $\begin{array}{l}\text { Station owner can look ahead from } \\
\text { present to 2040 to take into account } \\
\text { future HOF demand when making } \\
\text { investment decisions. }\end{array}$ \\
\hline $\begin{array}{l}\text { HOFVs demand for } \\
\text { HOF }\end{array}$ & $\begin{array}{l}\text { If HOF is available in a region, 100\% } \\
\text { of HOFVs will use it (unless its price is } \\
\text { significantly higher than E10). }\end{array}$ & $\begin{array}{l}\text { HOFVs are assumed to increasingly } \\
\text { use HOF over time; by 2023, 90\% of } \\
\text { HOFVs will be able to fuel with HOF. }\end{array}$ \\
\hline
\end{tabular}

\subsubsection{Feedstock}

In addition to station investment in the models, the way the BSM and BioTrans determine feedstock supply differs. While BioTrans utilizes POLYSYS supply curves for all feedstock supply, the BSM only uses supply curves for forest residues and urban residues. For energy crops (herbaceous, woody) and agricultural residues, the BSM uses farmer decision logic to determine what crops will be planted and harvested. Due to the delay between planting and harvesting, there is inertia in the supply of these crops. This delay is especially apparent in the difference between 2025 and 2035 in Figure 32. 


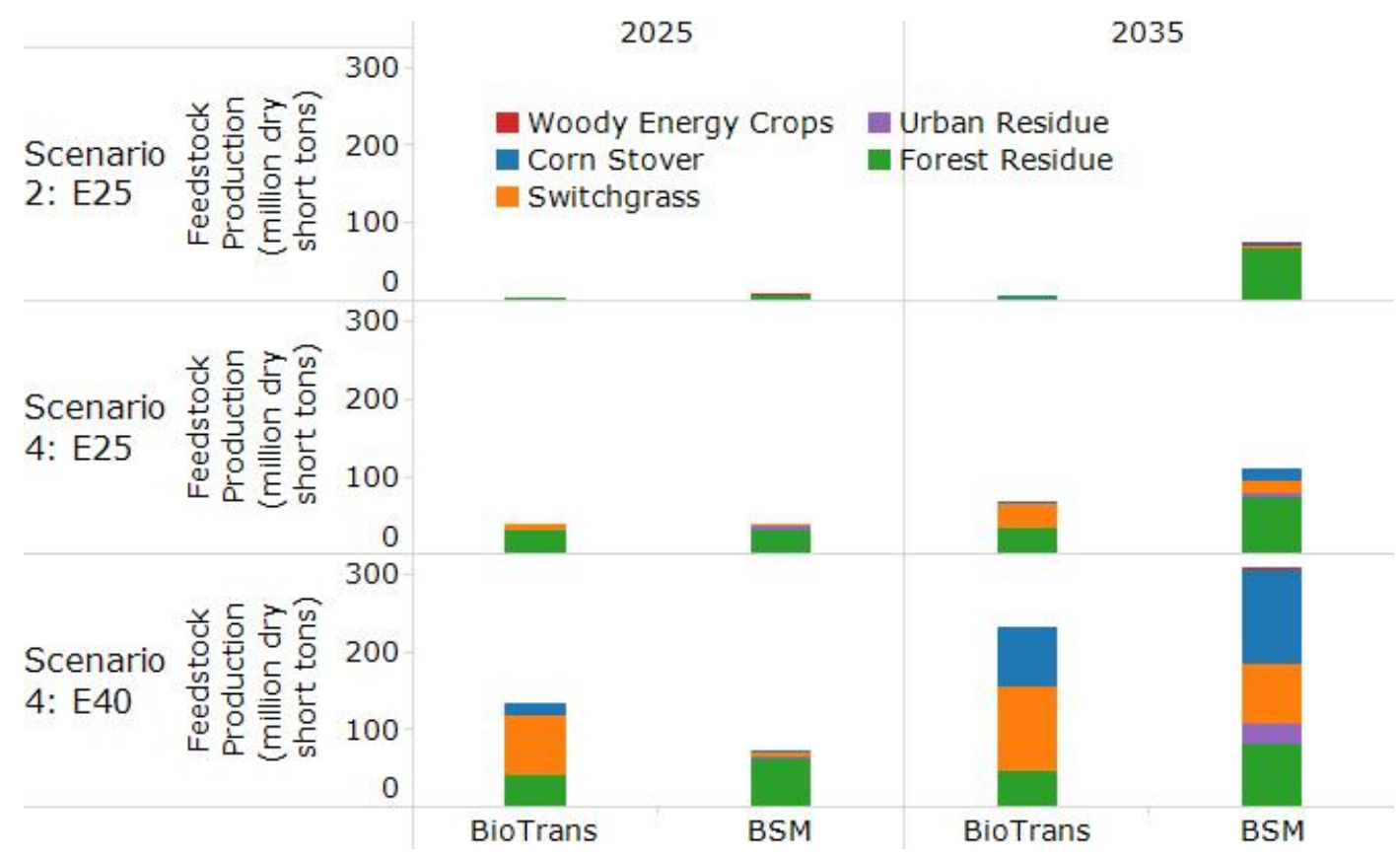

Figure 32. Comparison of the feedstock production by feedstock type from the BSM and BioTrans models for select scenarios in 2025 and 2035: The difference between feedstock production in the two models illustrates the impact of assumptions regarding the dynamism of feedstock supply.

\subsubsection{Scenario Assumptions}

Finally, there were some differences in how the scenarios were modeled. The BioTrans runs assumed that there was a binding RFS in place for Scenario 3. In addition, BioTrans uses E15 rather than premium gasoline as the backup fuel that HOFVs would use if HOF is not available in Scenario 1. In Scenarios 5 and 6, the backup fuel for HOFVs is E51. In the BSM, gasoline is the backup fuel for HOFVs in all scenarios. In addition, BioTrans assumes that once HOFVs are on the road, only blender pumps will be available for purchase in Scenario 6. The BSM assumes that conventional dispensing infrastructure would still be available.

In summary, the model distinctions described above help explain differences in the magnitude of HOF use observed in some scenarios across the two model approaches and highlight the impact of real world behavior (e.g., how decisions about infrastructure investment occur) on the outlook for HOF. However, at this first stage in the formal market analysis of HOF and vehicles, an important result is the broad similarity of system-level insights that is observed, despite the variations in scenario representation and the inherent differences in two model approaches. The main common insights are recapped in the Section 7. 


\section{Conclusions}

The potential benefits that HOF holds for the four key stakeholder groups (drivers, vehicle manufacturers, fuel retailers, and fuel producers) are substantial, but so are the barriers that would have to be curtailed to create a market for HOF. Thirty barriers were defined and 94 potential curtailment strategies were proposed. Complementary strategies were grouped into deployment scenarios that could be simulated in the ADOPT model to estimate HOFV market penetration and in the BSM and BioTrans to explore the potential fuel supply and necessary equipment.

Designing a system that facilitates consistent growth in HOFV stock and in the capacity of the supply chain that will provide HOF to those vehicles is important for the HOF market to develop. The modeling analysis concurs that feedstock availability and cost are not expected to be obstacles to the substantial development of HOF, across all of the scenarios considered. In numerous scenarios, HOF costs are sufficiently competitive that substantial market share is attained - up to 75 billion gallons of E40 or 30 billion gallons of pure ethanol by 2035. This would meet over $60 \%$ of LDV fuel demand in that year, given projections from the ADOPT model. However, all scenarios fell short of $100 \%$ of the fuel demanded by LDVs. The limiting factors affected the eight scenarios in the following pattern.

1. Regulations that have not yet taken HOF into account would be a limiting factor in all of the scenarios. Therefore, most scenarios included the following assumptions in order to allow market adoption:

a. HOF is registered as a fuel and listed as an emissions certification fuel, through one of the curtailment strategies discussed in sections 3.2.6 and 3.2.4, respectively.

b. The RFS is set to increase predictably, so that RIN prices remain within historic levels.

c. Future fuel economy and GHG regulations are set so their accounting systems adequately reward the production of HOFVs.

2. The fuel retailers' investment in HOF equipment is a limiting factor in many scenarios. At varying degrees of market penetration, the economics were not favorable enough for the marginal retailer to invest. This insight was especially true in the simulations where the station owners made investment decisions based more on current economics and less on anticipating high volumes of future demand. The retailers' decision to invest in HOF equipment is no longer the limiting factor if the following elements are in place:

a. The retailer is incentivized to invest through a grant, rebate, or tax credit (per curtailment strategies $1.1 \mathrm{~b}, 1.8 \mathrm{~h}, 1.8 \mathrm{i}$ in Table 4 ). Scenarios where incentives covered $40 \%$ of the investment tended to have greater HOF market penetration, and that penetration was increased even more when $80 \%$ of investment costs were covered.

b. Retail equipment cost is reduced by incentivizing equipment manufacturers, assisting them in their development of equipment, by subsidizing the equipment, or through economies of scale (developed by 1.1a-g). These strategies assume a competitive market where savings to equipment manufacturers result in lower equipment price. Repurposing rather than replacing tanks, dispensers, and other equipment is another way to reduce costs. 
c. Only compatible equipment is sold in advance, which would effectively reduce the upfront cost for retailers that had retired their equipment and replaced it with HOFcompatible equipment even if they didn't intend to sell HOF at the time of equipment replacement $(1.8 \mathrm{c})$.

3. The number of new biorefineries that can be constructed in a year is the limiting factor in scenarios that are not limited by the retail investment barrier, especially in the early years of rapid-growth scenarios. The constraint results in a higher ethanol price, which can subsequently deter the use of HOF. This barrier is adequately curtailed in scenarios where:

a. Enough time passes to allow biorefinery construction to catch up with ethanol demand. This happens around 2025 in applicable cases.

b. Biorefinery construction is performed at an annual rate greater than previously seen in the United States.

4. HOFV adoption is the limiting factor for the two scenarios where adequate retailer investment has been made and biorefinery construction has caught up with demand. The ADOPT model estimated that HOFVs could comprise $43 \%-79 \%$ of the U.S. LDV stock by 2035. The specific level of adoption depended on a number of factors:

a. In general, more HOFVs are adopted if HOF is E40 (rather than E25) because it offers greater fuel cost savings to drivers and a little more future $\mathrm{CAFE} / \mathrm{GHG}$ benefit to vehicle manufacturers under regulations that sufficiently reward such improvements.

b. Proactive vehicle conversion schedules, where entire model lines are converted to HOFVs, resulted in greater estimated HOFV adoption than conversion schedules that merely follow market demand.

c. ADOPT estimated that a $\$ 2,500$ incentive to the driver would significantly increase HOFV adoption.

d. High oil prices had little effect on the estimated rate of HOFV adoption because high gasoline prices led consumers to purchase slightly more efficient vehicles, which reduced the pressure that CAFE applied toward the benefits of HOFVs.

The composition of HOF changes some aspects of the adoption scenarios. Using E40 instead of E25 has the advantage of requiring fewer vehicles to displace the same amount of petroleum but also has the disadvantage of much higher infrastructure investment costs. The BSM and BioTrans utilize different logic when exploring dispensing station investment decisions and demand for HOF, which led to diverging estimates of E25 and E40 consumption. BSM showed lower ethanol consumption in E40 scenarios due to higher capital costs. In contrast, BioTrans showed higher ethanol consumption in E40 scenarios. This was because the reference share of HOF consumption by HOFVs remained the same under both E25 and E40 cases and because endogenous relative prices made large HOF availability optimal to minimize net costs of combined consumers and producers. 


\section{Future Research}

As the first comprehensive market analysis on HOF, this report has raised many questions and uncovered much fertile ground for future research.

\subsection{Integrated Market Analysis}

The work to date relied on separate models for vehicle and fuel markets that were not linked. Further analysis is needed on the interactions between the vehicle and fuel supply stakeholders under various deployments, incentives, and external conditions (e.g., oil prices). Feedbacks need to be added between the vehicle adoption model and the fuel supply and adoption models (most notably for the price of HOF and the extent of fuel infrastructure development). Within a more integrated modeling framework, the range and number of market penetration scenarios can be expanded. Furthermore, robust sensitivity analyses are needed to prioritize methods for overcoming market penetration barriers and improve the accuracy of estimated HOF market impacts on petroleum use.

\subsection{High-Octane Fuel Vehicle Supply and Demand}

The options for how HOFVs and HOF use might be treated under CAFE warrants further analysis, exploring the resulting effects on the size of the HOFV and fuel markets. Such analysis would require further engineering knowledge about the fuel efficiency implications of HOFV optimization. The market scenarios evaluated here assume that HOF and HOFVs can accomplish their goal of greater end-use efficiency (on an energy basis) than conventionally fueled vehicles. Specifically, HOF-optimized vehicles attain "mpg parity" on a miles-per-volumetric gallon basis with similarly advanced gasoline- or E10-fueled vehicles. While this goal is being tested, further market analyses should explore the implications of alternative achieved fuel efficiencies, or performance attributes, of HOFVs.

All the analyses in this study relied on some degree of HOFV compatibility with non-HOF fuels to smooth the early introduction of those vehicles during the period of incomplete HOF retail fuel availability. A better understanding is needed of the importance of this "dual-fuel capability" of HOFVs (e.g., using E10 premium as well as HOF) for HOFV sales, and for HOF sales. This would require improved information about the efficiency and performance of HOFVs using various fuels (HOF, E10 premium, E10 regular, and flex fuel), and the application of the latest relevant insights into consumer fuel choice behavior.

\subsection{Fuel Supply and Retail Outcomes}

Current and potential incentives for deployment of HOF-compatible infrastructure need to be more completely analyzed. In particular, analysis could explore the drivers behind investment in HOF dispensing infrastructure. It may also be useful to distinguish between small single-store operations and large convenience and refueling plazas or stations associated with big-box stores. Further analysis is needed regarding how refueling infrastructure can best be upgraded to HOF compatibility with minimum cost and alteration to normal investment and maintenance patterns, including ASTs. Furthermore, there is a need to research how much benefit fuel retailers see by using HOF to differentiate themselves from their competition. The prospect that retailers might benefit from a higher profit margin with HOF is partially in conflict with the driver's benefit of 
less expensive fuel. The implications of these competing goals needs to be further modeled and understood.

\subsection{Net Benefit Analysis}

Future research should also summarize the costs and benefits of choosing and deploying specific blend levels of HOF. This analysis would help decision makers to determine the mechanically optimal blend and the economically and logistically optimal blend. Discounted cash flow analysis will highlight options for introducing HOF to the market in a way that maximize benefits and minimize costs. Future efforts could also evaluate the relative benefits of HOFs given uncertainties about the major market drivers, including gasoline and biofuel price forecasts, vehicle technological costs, policy changes, and uncertainty about consumer and firm behavior. They should include an assessment of how the benefits of a less expensive fuel might be balanced between fuel producer profits, retailer profits, and consumer savings. 


\section{Glossary}

AKI. Anti-knock index. It is the common octane rating posted on gas dispensers in the United States. It is the average of the research octane number (RON) and the motor octane number (MON).

Flex fuel. A blend of gasoline and anywhere between $51 \%$ and $83 \%$ ethanol by volume.

Knocking. Occurs when an engine is using fuel that is lower octane than it is calibrated to. The fuel then combusts from compression at a nonoptimal time in the four -stroke cycle. This creates a shock wave and metallic "knocking" sound.

MON. Motor octane number. This indicator is increasingly outdated, as performance of modern engines is more closely tied to RON (Chow et al. 2014).

MSRP. Manufacturer's suggested retail price for a vehicle.

Octane. The short form for "octane rating," which is a fuel property that indicates to what degree fuel can be compressed in the piston before spontaneously combusting or "knocking." The greater compression it can endure (indicated by higher the octane rating) enables a higher compression ratio and therefore greater torque. This torque can then be converted into higher performance or higher fuel economy.

RON. Research octane number. It is the octane indicator most closely related to the performance of modern and future engines (Chow et al. 2014).

Spark retard. A strategy by which engine knocking is avoided through a delay in the spark from the spark plug. Most modern cars have this ability programmed in them. This avoids damage to the engine, but significantly reduces torque.

Torque. A measure of rotating force. It is the most basic measure of engine performance. A given amount of engine torque can be preferentially directed toward horsepower, acceleration, towing capacity, or fuel economy. 


\section{References}

AAM. 2011. AAM Summer 2011 U.S. Gasoline Survey.

AFDC. 2009. Kinder Morgan Central Florida Pipeline Ethanol Project. Accessed September 2, 2014: www.afdc.energy.gov/pdfs/km_cfpl_ethanol_pipeline_fact_sheet.pdf.

AFDC. 2014a. Average Retail Fuel Prices in the U.S. Accessed September 25, 2014: www.afdc.energy.gov/data/10326.

AFDC. 2014b. Laws and Incentives Database. Accessed October 27, 2014: www.afdc.energy.gov/laws/search.

AFDC. 2014c. Average Annual VMT and Fuel Economy of Major Vehicle Categories. Accessed July 25, 2014: www.afdc.energy.gov/data/.

AFDC. 2014d. Underwriters Laboratories Ethanol Dispenser Safety Testing-Waivers and Variances. Accessed August 1, 2014: www.afdc.energy.gov/technology_bulletin_0307.html\#waivers.

AFDC. 2014e. Alternative Fuel Station Locator-Supporting Data. Accessed October 27, 2014: www.afdc.energy.gov/data download.

AFDC. 2015. Alternative Fueling Station Counts by State. Accessed June 24, 2015: www.afdc.energy.gov/fuels/stations counts.html.

Alliance of Automobile Manufacturers. 2012. Testimony Opposing Legalized Sale of 85. AKI Octane Gasoline. July 20, 2012 Open Meeting, South Dakota Department of Public Safety. Accessed August 20, 2014: http://dps.sd.gov/documents/allianceofautomobilemfg.pdf.

Alson, J., Hula, A., and Bunker, A. 2014. Light-Duty Automotive Technology, Carbon Dioxide Emissions, and Fuel Economy Trends: 1975 Through 2014. Washington, D.C.: U.S.

Environmental Protection Agency, EPA-420-R-14-023a.

Andersen, V.F., Anderson, J.E., Wallington, T.J., Mueller, S.A., and Nielsen, O.J. 2010. "Vapor Pressures of Alcohol-Gasoline Blends.” Energy \& Fuels 24(6): 3647-3654, doi: $10.1021 / \mathrm{ef} 100254 \mathrm{w}$.

Anderson, J., Wallington, T., Stein, R., and Studzinski, W. 2014. ""Issues with T50 and T90 as Match Criteria for Ethanol-Gasoline Blends." SAE International Journal of Fuels and Lubricants 7(3): 2014, doi:10.4271/2014-01-9080.

Anderson, J.E., DiCicco, D.M., Ginder, J.M., Kramer, U., Leone, T.G., Raney-Pablo, H.E., and Wallington, T.J. 2012. "High Octane Number Ethanol-Gasoline Blends: Quantifying the Potential Benefits in the United States." Fuel 97: 585-594.

Anderson, S.T. 2012. "The Demand for Ethanol as a Gasoline Substitute." Journal of Environmental Economics and Management 63.2: 151-168. 
API. 2010a. "Evaluation of Measures to Mitigate Misfueling of Mid- to High-Ethanol Blend Fuels at Fuel Dispensing Facilities." Washington, DC.

API. 2010b. Determination of the Potential Property Ranges of Mid-Level Ethanol Blends: Final Report. Washington, D.C.

Biomass Program. 2009. 2009 Analysis Platform Review Report: An Independent Evaluation of Platform Activities for FY2008 and FY2009. Washington, DC: U.S. Department of Energy. Accessed October 27, 2014: www.obpreview2009.govtools.us/review/documents/OBP_ANALYSIS_Platform_Review Report_EERE_Standard_Cover_(FINAL_V1).pdf.

Bloomberg BNA. 2012. "EPA Grants California Clean Air Act Waiver To Implement Clean Car Emissions Rules." Daily Environmental Report, December 31, 2012. Accessed August 27, 2014: www.bna.com/epa-grants-california-n17179871622/.

Brooker, A., Gonder, J., Lopp, S., and Ward, J., “ADOPT: A Historically Validated Light Duty Vehicle Consumer Choice Model.” SAE Technical Paper 2015-01-0974, 2015, doi:10.4271/2015-01-0974.

Chow, E., Heywood, J., and Speth, R. 2014. "Benefits of a Higher Octane Standard Gasoline for the U.S. Light-Duty Vehicle Fleet." SAE Technical Paper 2014-01-1961, doi:10.4271/2014-011961.

Clark, C.M., Lin, Y., Bierwagen, B.G., Eaton, M., Langholtz, M.H., Morefield, P.E., Ridley, C.E., Vimmerstedt, L., Peterson, S., and Bush, B.W. 2013. "Growing a Sustainable Biofuels Industry: Economics, Environmental Considerations, and the Role of the Conservation Reserve Program." Environmental Research Letters (8:2), pp. 025016. doi: 10.1088/17489326/8/2/025016.

Clean Cities. 2013. Handbook for Handling, Storing, and Dispensing E85 and Other EthanolGasoline Blends. Accessed October 27, 2014: www.afdc.energy.gov/uploads/publication/ethanol_handbook.pdf.

Clean Cities. 2015. Quarterly Alternative Fuel Price Reports. Accessed June 2, 2015: www.afdc.energy.gov/fuels/prices.html.

Congress.gov. 2014. H.R.1214 - Domestic Fuels Protection Act of 2013. Accessed July 11, 2014: https://beta.congress.gov/bill/113th-congress/house-bill/1214.

Congressional Record. 2002. 148 Cong. Rec. 9, S485 (2002), citing a draft EPA staff report, Supply Analysis of S. 950-The Reformulated Fuels Act of 2001.

Congressional Record. 2005. Senate Vol. 151, Pt. 19, p. 25766.

Davis, S., Diegel, S., and Boundy, R. 2014. Transportation Energy Data Book, edition 33. ORNL-6990.

Diamond, D. 2009. “The Impact of Government Incentives for Hybrid-Electric Vehicles: Evidence from U.S. States.” Energy Policy 37(3): 972-983. 
DOE. 2011. U.S. Billion Ton Update: Biomass Supply for a Bioenergy and Bioproducts Industry. Accessed January 20, 2015: https://bioenergykdf.net/content/billiontonupdate.

Duleep, G. 2011. Comparison of Vehicle Efficiency Technology Attributes and Synergy Estimates (Subcontract Report). Golden, CO: National Renewable Energy Laboratory. NREL/SR-6A20-47806.

EERE. 2015. Integrated Biorefineries. Accessed August 21, 2015: www.energy.gov/eere/bioenergy/integrated-biorefineries

EIA. 2011. Growth Slows in U.S. Ethanol Production and Consumption. Accessed September 20, 2014: www.eia.gov/todayinenergy/detail.cfm?id=3070.

EIA. 2013a. Date of Switch to Summer-Grade Gasoline Approaches. Accessed September 22, 2014: http://www.eia.gov/todayinenergy/detail.cfm?id=11031.

EIA. 2013b. Alternative Fuel Vehicle Data. Accessed August 27, 2014: www.eia.gov/renewable/afv/users.cfm\#tabs charts-2.

EIA. 2014a. Annual Energy Outlook 2014: With Projections to 2040. DOE/EIA-0383(2014). Washington, DC: U.S. Department of Energy. Accessed February 2, 2015: www.eia.gov/forecasts/aeo/pdf/0383(2014).pdf.

EIA. 2014b. Weekly Retail Gasoline Prices. Accessed September 12, 2014: www.eia.gov/dnav/pet/pet_pri_gnd_dcus_r20_m.htm.

EPA. 2011. Regulation To Mitigate the Misfueling of Vehicles and Engines with Gasoline Containing Greater Than Ten Volume Percent Ethanol and Modifications to the Reformulated and Conventional Gasoline Programs; Final Rule. Federal Register. Accessed September 16, 2015: www.gpo.gov/fdsys/pkg/FR-2011-07-25/pdf/2011-16459.pdf.

EPA. 2012a. Fuel Economy and Greenhouse Gas Exhaust Emissions of Motor Vehicles. 40 CFR 600. www.gpo.gov/fdsys/pkg/CFR-2012-title40-vol31/pdf/CFR-2012-title40-vol31-part600.pdf

EPA. 2012b. "EPA and NHTSA Set Standards to Reduce Greenhouse Gases and Improve Fuel Economy for Model Years 2017-2025 Cars and Light Trucks" EPA-420-F-12-051.

EPA. 2014a. Control of Air Pollution from Motor Vehicles: Tier 3 Motor Vehicle Emission and Fuel Standards Rules and Regulations. Office of the Federal Register. Accessed September 29, 2014: www.gpo.gov/fdsys/pkg/FR-2014-04-28/pdf/2014-06954.pdf.

EPA. 2014b. Guide on Federal and State Summer RVP Standards for Conventional Gasoline Only. Accessed July 21, 2014: www.epa.gov/otaq/fuels/gasolinefuels/volatility/standards.htm.

EPA. 2014c. Regulation of Fuels and Fuel Additives: RFS Pathways II, and Technical Amendments to the RFS Standards and E15 Misfueling Mitigation Requirements; Final Rule. Federal Register. Accessed September 29, 2014: www.gpo.gov/fdsys/pkg/FR-2014-0718/pdf/2014-16413.pdf. 
EPA. 2015. "EPA Proposes Renewable Fuel Standards for 2014, 2015, and 2016, and the Biomass-Based Diesel Volume for 2017.” Washington, D.C.: U.S. Environmental Protection Agency. Accessed June

2015: www.epa.gov/oms/fuels/renewablefuels/documents/420f15028.pdf.

EPA and NHTSA. 2012. 2017 and Later Model Year Light-Duty Vehicle Greenhouse Gas Emissions and Corporate Average Fuel Economy Standards. Federal Register. Accessed September 16, 2015: www.federalregister.gov/articles/2012/10/15/2012-21972/2017-and-latermodel-year-light-duty-vehicle-greenhouse-gas-emissions-and-corporate-average-fuel.

Fuels Institute. 2014. Consumers and Alternative Fuels: Economics Are Top of Mind. Accessed August 20, 2014: www.fuelsinstitute.org/ResearchArticles/ConsumersandAlternativeFuels.pdf.

Gallagher, K.S., and Muehlegger, E. 2011. "Giving Green To Get Green? Incentives and Consumer Adoption of Hybrid Vehicle Technology." Journal of Environmental Economics and Management 61(1): 1-15.

Gilbarco. 2013. "Bluetooth 4.0 Payment Comes to the Forecourt." Convenience Store Advisor. Accessed January 5, 2014: http://c-storeadvisor.gilbarco.com/2013/10/bluetooth-4-0-paymentscomes-to-the-forecourt/.

Greene, D.L. 1998. "Survey Evidence on the Importance of Fuel Availability to Choice of Alternative Fuels and Vehicles.” Energy Studies Review 8(3): 215-231.

Greene, D.L., Leiby, P.N., James, B., Perez, J., Melendez, M., Milbrandt, A., Unnasch, S., and Hooks, M. 2008. Analysis of the Transition to Hydrogen Fuel Cell Vehicles \& the Potential Hydrogen Energy Infrastructure Requirements (S. McQueen, ed.). Oak Ridge, TN: Oak Ridge National Laboratory. ORNL/TM-2008/30.

Greenhouse, J. 2011. "E15: Cracking the RVP Nut.” Ethanol Producer Magazine. Accessed July 17, 2014: www.ethanolproducer.com/articles/8222/e15-cracking-the-rvp-nut.

GREET. 2013. GREET model version 1_2013. Accessed September 26, 2014: https://greet.es.anl.gov/.

GREET. 2014. GREET model version 1_2014. Accessed September 17, 2015: https://greet.es.anl.gov/.

Han, J., Elgowainy, A., Wang, M., and DiVita, V. 2015. Well-to-Wheels Greenhouse Gas Emission Analysis of High-Octane Fuels with Various Market Shares and Ethanol Blending Levels. Argonne National Laboratory.

Havranek, T., Irsova, Z., and Janda, K. 2012. "Demand for Gasoline Is More Price-Inelastic Than Commonly Thought.” Energy Economics 34(1): 201-207.

Higgins, T. 2014. "Octane Number Outlook." Presentation to the 2014 SAE High Octane Fuels Symposium. 
Hirshfeld, D., Kolb, J., Anderson, J., Studzinski, W., and Frusti, J. 2014. "Refining Economics of U.S. Gasoline: Octane Ratings and Ethanol Content." Environmental Science \& Technology 48(19): 11064-11071.

Hochhauser, A.M., Benson, J.D., Burns, V.R., Gorse, R.A., Koehl, W.J., Painter, L.J., and Rutherford, J.A. (1993). "Fuel Composition Effects on Automotive Fuel Economy-Auto/Oil Air Quality Improvement Research Program (No. 930138). SAE Technical Paper.

IBTimes. 2010. “GM Seeking More U.S. Ethanol Fueling Stations.” Accessed October 27, 2014: www.ibtimes.com/gm-seeking-more-us-ethanol-fueling-stations-373411.

INEOS. (2013). INEOS Bio Provides Operational Update. Accessed September 30, 2014: www.ineos.com/businesses/ineos-bio/news/ineos-bio-provides-operational-update-/.

Interagency Agricultural Projections Committee. 2007. USDA Agricultural Projections to 2016. U.S. Department of Agriculture. Accessed October 27, 2014: www.ers.usda.gov/media/197549/oce20071_1_.pdf.

isee systems. 2010. "STELLA: Systems Thinking for Education and Research Software." Accessed October 27, 2014: www.iseesystems.com/softwares/Education/StellaSoftware.aspx.

Johnson, C., and Melendez, M. 2007. E85 Retail Business Case: When and Why To Sell E85 (Technical Report). National Renewable Energy Laboratory, NREL/TP-540-41590.

Johnson, C., and Singer, M. 2014. Clean Cities 2013 Annual Metrics Report (Technical Report). Golden, CO: National Renewable Energy Laboratory, NREL/TP-5400-62838.

Johnson, C., Hettinger, D. 2014. Geography of Existing and Potential Alternative Fuel Markets in the United States (Technical Report). Golden, CO: National Renewable Energy Laboratory, NREL/TP-5400-60891.

Klier, T., and Linn, J. 2013. "Fuel Prices and New Vehicle Fuel Economy-Comparing the United States and Western Europe." Journal of Environmental Economics and Management 66.2: $280-300$.

Koseki, K. (2014). "Well-to-Wheels Analysis of Higher Octane Ratings and Ethanol Content for Future U.S. Gasoline." Presentation to the SAE High Octane Fuels Symposium. Washington, D.C.

Leone, T.G., Olin, E.D., Anderson, J.E., Jung, H.H., Shelby, M.H., and Stein, R.A. 2014. "Effects of Fuel Octane Rating and Ethanol Content on Knock, Fuel Economy, and CO2 for a Turbocharged DI Engine (No. 2014-01-1228).” SAE Technical Paper.

Lin, Y., Newes, E., Bush, B., Peterson, S., Stright, D. 2013. Biomass Scenario Model v2.0 Documentation: Data and References (Technical Report). Golden, CO: National Renewable Energy Laboratory, NREL/TP-6A20-57831. Accessed October 27, 2014: www.nrel.gov/docs/fy13osti/57831.pdf.

Liu, C., and Greene, D.L. 2014. "Consumer Choice of E85: Price Sensitivity and Cost of Limited Fuel Availability.” Transportation Research Board 93rd Annual Meeting. No. 14-3875. 
McCormick, R., Chupka, G., Christensen, E., Ratcliff, M., Burton, J., Alleman, T., Fouts, L., and Sindler, P. 2014. Increasing Biofuel Deployment and Utilization through Development of Renewable Super Premium. Milestone Completion Report. Golden, CO: National Renewable Energy Laboratory.

MDOC. (2014). 2014 Minnesota E85 + Mid-Blends Station Report. Accessed July 25, 2014: http://mn.gov/commerce/energy/images/E-85-Fuel-Use-Data.pdf.

Medich, C. 2012. EMV Migration-Driven by Payment Brand Milestones. Smart Card Alliance. Accessed December 17, 2014: www.emv-connection.com/emv-migration-driven-by-paymentbrand-milestones/.

Melaina, M., Bremson, J., Solo, K. 2013. "Consumer Convenience and the Availability of Retail Stations as a Market Barrier for Alternative Fuel Vehicles.” Golden, CO: National Renewable Energy Laboratory, NREL/CP-5600-56898. Presented at the 31st USAEE/IAEE. www.nrel.gov/docs/fy13osti/56898.pdf.

Milpied, J., Jeuland, N., Plassat, G., Guichaous, S., Dioc, N., Marchal, A., and Schmelzle, P. (2009). "Impact of Fuel Properties on the Performances and Knock Behaviour of a Downsized Turbocharged DI SI Engine-Focus on Octane Numbers and Latent Heat of Vaporization (No. 2009-01-0324).” SAE Technical Paper.

Moriarty, K., Theiss, T., and Kass, M. 2014. Increasing Biofuel Deployment and Utilization through Development of Renewable Super Premium: Infrastructure Assessment (Technical Report). Golden, CO: National Renewable Energy Laboratory, NREL/TP-5400-61684.

NACS. 2014. State of the Industry Report: Highlights of the Convenience Store Industry's 2013 Performance. National Association of Convenience Stores.

National Academy of Sciences. 2013. Transitions to Alternative Vehicles and Fuels. The National Academies Press. Washington, D.C.

Newes, E., Bush, B., Peck, C. and Peterson, S. 2015. "Potential Leverage Points for Development of the Cellulosic Ethanol Industry Supply Chain.” Biofuels, doi: 10.1080/17597269.2015.1039452.

Newes, E., Inman, D., and Bush, B. 2011. "Understanding the Developing Cellulosic Biofuels Industry through Dynamic Modeling." dos Santos Bernardes, Marco Aurélio, ed. Economic Effects of Biofuel Production, Rijeka, Croatia: InTech; pp. 373-404. Accessed June 26, 2013: www.intechopen.com/books/economic-effects-of-biofuel-production/understanding-thedeveloping-cellulosic-biofuels-industry-through-dynamic-modeling.

Nicholas, M.A., Handy, S.L., and Sperling, D. (2004). "Using Geographic Information Systems to Evaluate Siting and Networks of Hydrogen Stations." Transportation Research Record 1880: $126-134$.

Oladosu, G., Kline, K, Leiby, P., Uria-Martinez, R., Davis, M., Downing, M., and Eaton, L. 2012. "Global Economic Effects of U.S. Biofuel Policy and the Potential Contribution From Advanced Biofuels.” Biofuels 3703-3723. 
Peplow, M. 2014. Cellulosic Ethanol Fights for Life. Nature 507(7491): 152.

Peterson, S., Newes, E., Inman, D., Vimmerstedt, L., Hsu, D., Peck, C., Stright, D., and Bush, B. 2013. "An Overview of the Biomass Scenario Model." Presented at the 31st International Conference of the System Dynamics Society in Cambridge, MA. Accessed October 27, 2014: www.systemdynamics.org/conferences/2013/proceed/index.html.

POET. 2014. First Commercial-scale Cellulosic Ethanol Plant in the U.S. Opens for Business. Accessed September 30, 2014: http://poetdsm.com/pr/first-commercial-scale-cellulosic-plant.

Polk. 2015. Database of U.S. Light-Duty Vehicle Registrations in the US, as of December 31, 2014.

RFA. 2014. RFA Congratulates Quad County Corn Processors on Iowa's First Gallon of Cellulosic Ethanol. Accessed September 30, 2014: www.ethanolrfa.org/news/entry/rfacongratulates-quad-county-corn-processors-on-iowas-first-gallon-of-cell/.

SC Fuels. 2014. RFID Fuel Management. Accessed October 27, 2014: www.scfuels.com/services/fleet-card-services/rfid-fuel-management.

Searle, S., Sanchez, F.P., Malins, C., and German, J. 2014. Technical Barriers to the Consumption of Higher Blends of Ethanol. The International Council on Clean Transportation. Accessed October 27, 2014: http://bipartisanpolicy.org/sites/default/files/files/ICCT_Ethanol.pdf.

Setiawan, W., and Sperling, D. 2001. "Premium Gasoline Overbuying in the US: ConsumerBased Choice Analysis." University of California Transportation Center.

Sluder, C.S., and West, B.H. 2013. Preliminary Examination of Ethanol Fuel Effects on EPA's $R$-Factor for Vehicle Fuel Economy (Technical Report). Oak Ridge, TN: Oak Ridge National Laboratory. ORNL/TM-2013/198.

Sluder, C.S., West, B., Butler, A., Mitcham, A. et al. 2014. "Determination of the R Factor for Fuel Economy Calculations Using Ethanol-Blended Fuels over Two Test Cycles." SAE International Journal of Fuels and Lubricants 7(2): 551-562, doi:10.4271/2014-01-1572.

Speth, R.L., Chow, E.W., Malina, R., Barrett, S.R., Heywood, J.B., and Green, W.H. 2014. "Economic and Environmental Benefits of Higher-Octane Gasoline." Environmental Science \& Technology 8(12): 6561-6568

Splitter, D.A., and Szybist, J.P. (2014). "Experimental Investigation of Spark-Ignited Combustion with High-Octane Biofuels and EGR. 2. Fuel and EGR Effects on Knock-Limited Load and Speed." Energy \& Fuels 28(2): 1432-1445.

Stein, R., Anderson, J., and Wallington, T. 2013. "An Overview of the Effects of EthanolGasoline Blends on SI Engine Performance, Fuel Efficiency, and Emissions." SAE International Journal of Engines 6(1), doi:10.4271/2013-01-1635. 
Sterman, J., Morrison, B., and Repenning, N. 2003. "System Dynamics for Business Policy." MIT OpenCourseWare, Sloan School of Management, University. Accessed April 5, 2010: http://ocw.mit.edu/OcwWeb/Sloan-School-of-Management/15874Fall2003/CourseHome/index.htm.

Sunoco. 2015. Sunoco Racing Fuels Shopping Website. Accessed August 17, 2015: www.sunocoracingfuels.com/en/shop.

Supreme Court. 2007. MASSACHUSETTS, et al., PETITIONERS v. ENVIRONMENTAL PROTECTION AGENCY ET AL. Argued November 29, 2006. Decided April 2, 2007.

Swedberg, C. 2013. "Datatronic Uses RFID to Drive Down Fuel Loss." RFID Journal. Accessed July 24, 2014: www.rfidjournal.com/articles/view?10889/2.

Tao, L., Schell, D., Davis, R., Tan, E., Elander, R., and Bratis, A. 2014. NREL 2012 Achievement of Ethanol Cost Targets: Biochemical Ethanol Fermentation via Dilute-Acid Pretreatment and Enzymatic Hydrolysis of Corn Stover (Technical Report). Golden, CO: National Renewable Energy Laboratory. NREL/TP-5100-61563.

U.S. Congress. 1992. Energy Policy Act. H.R. 776. Accessed September 21, 2015: http://thomas.loc.gov/cgi-bin/query/z?c102:H.R.776.ENR:

U.S. Congress. 2005. Energy Policy Act. 42 USC §13201. Accessed September 21, 2015: www.gpo.gov/fdsys/pkg/PLAW-109pub158/pdf/PLAW-109publ58.pdf

U.S. Congress. 2007. Energy Independence and Security Act of 2007. Accessed October 27, 2014: www.gpo.gov/fdsys/pkg/BILLS-110hr6enr/pdf/BILLS-110hr6enr.pdf.

U.S. Court of Appeals (2013). API vs EPA, On Petition for Review of Final Agency Action of the United States Environmental Protection Agency. Accessed September 29, 2014: www.cadc.uscourts.gov/internet/opinions.nsf/A57AB46B228054BD85257AFE00556B45/ \$file/12-1139-1417101.pdf.

U.S. Department of Transportation, and NHTSA. 2012. "Summary of Fuel Economy Performance." Washington, DC.

USA Today. 2013. "Vacationers, Beware: Bad Gas Can Damage Your Car." Accessed October 27, 2014: www.usatoday.com/story/money/cars/2013/05/29/bad-gasoline-low-octane-too-muchethanol $/ 2369579 /$.

USDA. 2010. Biomass Crop Assistance Program; Proposed Rule. 7 CFR Part 1450.

Vimmerstedt, L., Bush, B., and Peterson, S. 2012. "Ethanol Distribution, Dispensing, and Use: Analysis of a Portion of the Biomass-to-Biofuels Supply Chain Using System Dynamics." PLoS ONE (7:5. doi: 10.1371/journal.pone.0035082).

Vimmerstedt, L.J., Bush, B.W., and Peterson, S. 2013. "Effects of Deployment Investment on the Growth of the Biofuels Industry." Golden, CO: National Renewable Energy Laboratory. http://dx.doi.org/10.2172/1118095. 
Vimmerstedt, L.J., Bush, B.W., Hsu, D.D., Inman, D., and Peterson, S.O. 2015. "Maturation of Biomass-to-Biofuels Conversion Technology Pathways for Rapid Expansion of Biofuels Production: A System Dynamics peHOFective." Biofuels, Bioprod. Bioref., 9: 158-176. doi: 10.1002/bbb.1515.

Wang, M.Q.; Han, J.; Haq, Z.; Tyner, W.E., Wu, M.; Elgowainy, A. (2011). "Energy and Greenhouse Gas Emission Effects of Corn and Cellulosic Ethanol With Technology Improvements and Land Use Changes.” Biomass and Bioenergy 35: 1885-1896.

Warner, E. (2014). "Limits to Annual Growth in the Number of Biorefineries - Analysis of Existing Literature and Development of Biomass Scenario Assumptions." Memo to Laura Vimmerstedt. 


\section{Appendix A: Biomass Scenario Model: High-Octane Fuel-Specific Model Logic and Assumptions}

Downstream modules within the BSM have been modified to represent scenarios around evolution of the HOF market. Modifications were made to the following modules:

- Dispensing Station Module

- $\quad$ Pricing and Inventory Module (PIM)

- Fuel Use Module

- Vehicle Module.

Changes to logic and assumptions are described below. For a comprehensive description of the BSM, please refer to Peterson et al. (2013).

\section{Dispensing Station Module}

Investment in HOF-capable tankage and equipment. The BSM contains a simple structure to represent investment in flex fuel capable tankage and dispensing equipment. The core structure in the Dispensing Station Module addresses the movement of stations among three states (see Figure A-1):

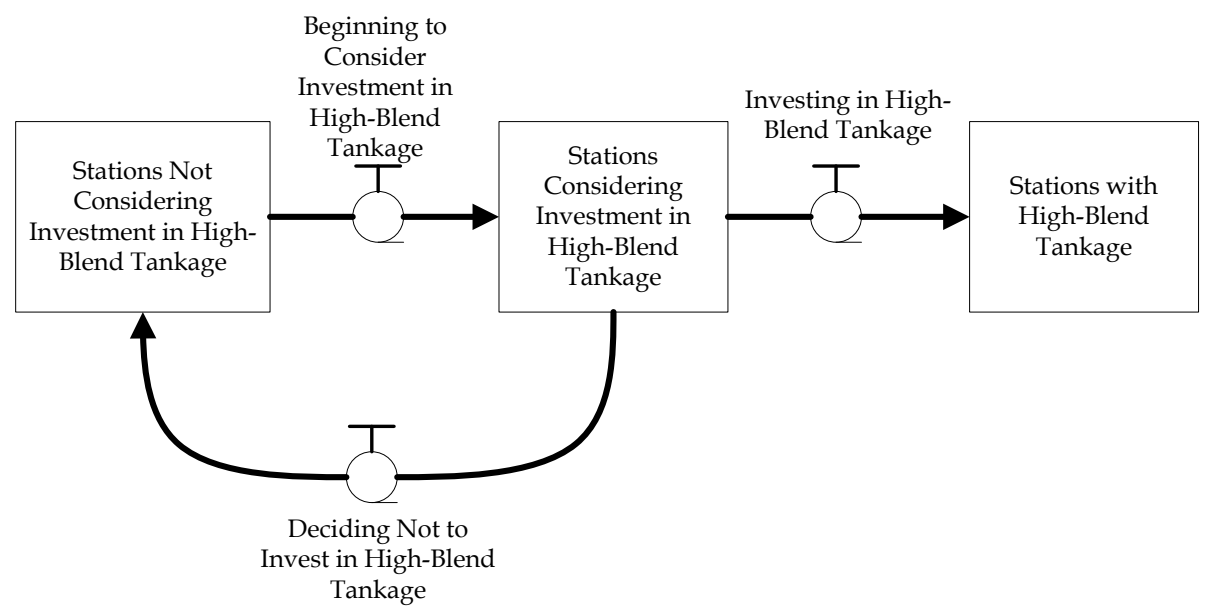

Figure A-1. BSM decision logic around investment in flex fuel dispensing stations

We adapt this structure to represent build-out of HOF-capable tankage and/or equipment. Three changes were involved:

- Movement from "not considering" to "considering" investment in tankage and equipment. In non-HOF versions of the model, the movement from "not considering" to "considering" is driven by development of upstream distribution and logistics capacity. As distribution capacity for high-ethanol-blend fuels increases within a region, a larger fraction of stations within the region have potential to invest in high-blend fuels. Stations that do not invest in high-blend equipment cycle back to "not considering," and then move back to the "considering" status on annual basis. The HOF version of the model 
removes this constraint imposed by upstream distribution and logistics capacity. The rate of movement cycling from "not considering" to "considering" is set to reflect the lifetime of station equipment.

- Relationship between net present value (NPV) and investment in tankage and equipment. In the model, investment in tankage and equipment is determined by the NPV of the investment. For stations considering investment, increasing values of NPV result in a larger fraction investing. In the non-HOF version of the model, $100 \%$ of stations will invest when the NPV reaches $\$ 100,000$. In contrast, the HOF version of the model uses a significantly lower threshold. This threshold was chosen based on the following considerations:

- Cycling of stations from "not considering" to "considering" is much less frequent in the HOF version of the model. As a result, stations have fewer opportunities to decide whether to invest in HOF. A lower threshold helps to account for this less frequent cycling of stations.

- Informal discussions with convenience store owners indicate that many station owners use a payback period of roughly 3 years to trigger investment in tankage and equipment. Analysis of BSM, using different capital cost inputs, and using calculated values for NPV and incremental revenues, yield payback curves in which a $\$ 10,000 \mathrm{NPV}$ is roughly consistent with a payback period of 3 years (see Figure A-2).

- Introduction of HOF station coverage concept. In the non-HOF version of the BSM, station coverage refers to the fraction of stations within a region that are capable of dispensing flex fuel. We modify this concept in the HOF version of the model to account for the penetration of HOFVs and subsequent dispensing of HOF by stations that have previously invested in HOF equipment. This phase-in of HOF station coverage can be triggered either by the penetration of HOFVs within a region or by time considerations.

- Forward-looking concept. The BSM uses a very short payback period, considered to be consistent with a high discount rate, which in turn implies a fairly short-term peHOFective. The BSM has limited incremental traffic logic for first-movers, but it does not make a significant impact on results. The BSM does not incorporate forecasts for potential HOF consumption or for prices. 

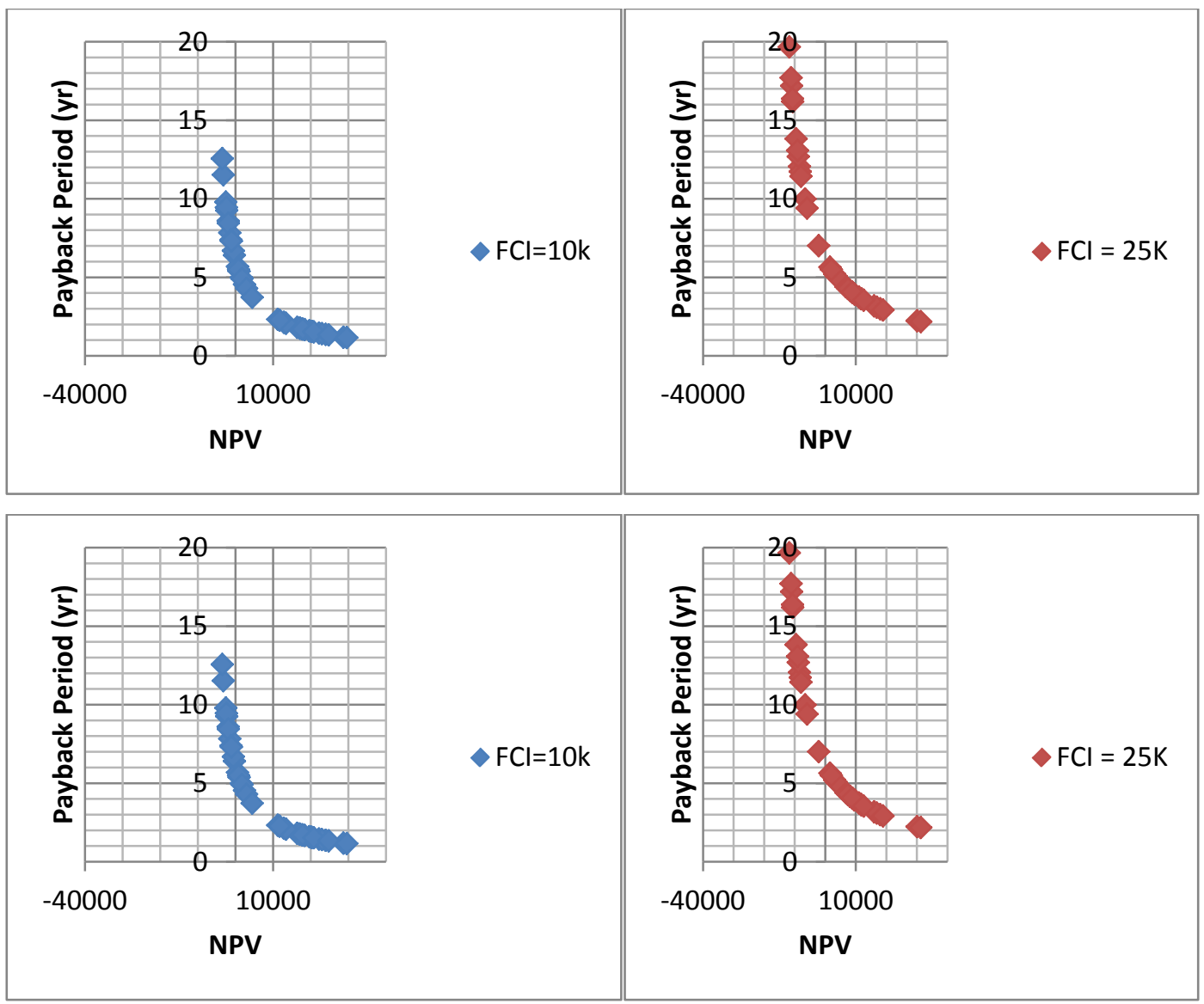

Figure A-2. Payback period versus NPV for different levels of fixed capital investment

\section{Fuel Use Module}

- Structure to account for E51 high-blend consumption by HOFVs. In general, HOFVs are assumed to fuel with E10 until HOF is available at dispensing stations. However, scenario 5 is different. In this case, HOFVs fuel with E51 (flex fuel) until HOF (E40) is available. Eventually all flex-fuel stations switch to E40, as FFVs are phased out of the fleet.

- Structure to account for relationship between station coverage and HOF usage. In adding this structure, we modified the relationship between station coverage and highblend usage that was used in non-HOF versions of the model. The new relationship has a rapid growth in HOF usage by HOF-capable vehicles. This relationship saturates at $100 \%$ when roughly $20 \%$ of stations are HOF-capable (see barrier 1.8 ).

- Structure to account for extreme-condition price feedback to HOF usage. In the nonHOF model, a logit function is used to calculate high-blend market share by FFVs. In the HOF model, uncertainties around price feedback caused us to simplify our approach to price feedbacks. Under all but extreme conditions, price differentials between HOF and regular gasoline must be greater than $20 \%$ before they begin to affect HOF use. 


\section{Vehicle Module}

HOFV deployment. In non-HOF versions of the model, we use AEO scenarios to drive vehicle influx. For the HOF analyses, all vehicle scenarios (new vehicle sales and associated fuel economy) were taken directly from the ADOPT model at a national level. These scenarios were then used as inputs to the BSM and disaggregated into the 10 USDA regions using U.S. Census population data. VMT were calculated using AEO 2012 data. In addition, we assume that HOFVs would experience an efficiency penalty when using regular gasoline (see Barrier 1.1).

\section{Pricing and Inventory Module}

- HOF pricing. In non-HOF versions of BSM, flex fuel retail pricing is based on a weighted average of gasoline and ethanol wholesale prices. Retail pricing algorithms for HOF are unknown. For these analyses, we assume that station owners simply apply a constant markup on fuel price when setting the HOF price for consumers.

- Assumed timing and rate of E15 uptake. It is uncertain how the market will act in the future around E15. The BSM is able to set the ethanol content of gasoline or transition between different percentages. For the scenario contained in this report, we assumed a transition from 100\% E10 in 2011 to $80 \%$ E15 in 2028; however, the input assumptions could be changed to satisfy alternative scenarios.

\section{Other Modules}

Concurrent growth in renewable hydrocarbon production could lead to price pressure on feedstock supply, resulting in constrained ethanol production.

For the scenarios contained in this report, feedstock supply was not a binding constraint on ethanol production. However, with a relaxation of the maximum number of biorefineries capable of being constructed in a year, feedstock supply could become a major factor in production limitations. The BSM also assumes that any cellulosic feedstock could be utilized to produce cellulosic biofuels. If the model were modified to show a preference for certain feedstocks by specific conversion technologies, constraints on feedstock supply could become more apparent. 


\section{Appendix B: Biomass Scenario Model: Explicit Values Included in Net Present Value Logic}

Peterson et al. (2013) includes a diagram of the structure of the BSM's NPV calculations. In general, the logic considers major types of revenue and expense that help to determine station investment. We have included a model with this paper that shows the logic around NPV (BSM NPV.STM). It is built in the STELLA software, which can be downloaded at www.iseesystems.com. 


\section{Appendix C: BioTrans: High-Octane-Fuel-Specific Model Approach and Assumptions}

BioTrans represents all the stages of the biofuel supply chain, from farmgate to pump. This nonlinear, dynamic mathematical programming model solves for the optimal biofuel industry configuration and operation over a long-run (30-year) planning horizon. The model solution provides a complete picture of the biofuel supply chain for each census division and each year in the period 2010-2040. BioTrans can be implemented under either complete or limited foresight assumptions. The objective function maximizes the sum of consumer and producer surplus. Maximizing surplus in the assumed context of competitive markets also implies minimizing the cost of providing the equilibrium volume of final fuel to LDVs. This type of model is well suited to account for interactions among all the variables considered, to explore the cost, performance, and flexibility tradeoffs between various biofuel production pathways, and to simulate a variety of policy and market fundamentals scenarios. ${ }^{39}$

A clear understanding of the representation of investment activities in BioTrans is important for interpreting the results presented in the body of this report. Biofuel production and fuel retailing are the two capacitated activities for which investment is explicitly depicted in BioTrans. Given the algorithms used to solve BioTrans, investment must be represented as a continuous variable expressed in millions of dry tons (for biorefineries) or gallons (for retail infrastructure) of capacity. This means that the associated investment cost must also be expressed in $\$ /$ dry ton or \$/gallon.

Biorefineries have a set daily nameplate capacity, which can be easily translated into an annual capacity and used to convert total plant cost into a \$/dry ton metric. On the other hand, annual dispenser or UST capacity (maybe throughput is a better word) is not a straightforward concept. The number of gallons sold from each dispenser depends on station configuration and location as well as fuel industry logistics (see Table C-1). The physical maximum number of gallons that could be sold from a single dispenser is not a useful concept because no dispenser is designed with the expectation of being operated 24/7. The capacity value currently used in BioTrans is based on the peak fuel sales volume observed in recent years (which corresponds to 2007).

\footnotetext{
${ }^{39}$ A document containing more detailed description of BioTrans structure and components can be obtained from the authors upon request.
} 
Table C-1. Station Configurations

\begin{tabular}{|c|c|c|c|c|c|}
\hline \multirow[b]{2}{*}{$\begin{array}{l}\text { Dispenser Throughput } \\
\text { (region R) }\end{array}$} & \multirow{2}{*}{$=$} & \multicolumn{4}{|c|}{ Total Gasoline Sales Volume, 2007, region $\mathrm{R}$} \\
\hline & & $\begin{array}{l}\text { Number of } S \\
\text { in regio }\end{array}$ & $\begin{array}{l}\text { tations } \\
\mathrm{R}\end{array}$ & $x$ & $\begin{array}{c}\text { Number of Dispensers } \\
\text { per Station }\end{array}$ \\
\hline $\begin{array}{l}\text { UST Throughput } \\
\text { (region R) }\end{array}$ & $=$ & UST Size & $x$ & & $\begin{array}{c}\text { Number of } \\
\text { Refills per Year }\end{array}$ \\
\hline $\begin{array}{l}\text { Tank Truck Throughput } \\
\text { (region R) }\end{array}$ & & Tank Size & $x$ & & $\begin{array}{l}\text { Number of } \\
\text { liveries per Year }\end{array}$ \\
\hline
\end{tabular}

The average number of refills per year for USTs and the number of deliveries per year for tanker trucks are chosen so that the current fleet of USTs and trucks could supply the 2007 total gasoline sales volume. Once all the throughputs are calculated, the cost per unit (i.e., per dispenser, UST, or truck) can be translated into a cost per gallon. An important caveat is that the cost per gallon currently used in BioTrans implies use at 2007 levels. Therefore, simulated costs should be interpreted as a lower bound on what the cost would be if average sales per dispenser are lower than those in 2007.

The rest of this appendix focuses on the specific changes made to BioTrans to depict HOF scenarios. Given the current assumption that HOF is blended at the retail station by mixing E10 and E85 in adequate fractions, all changes correspond to the most downstream portion of the supply chain: retail infrastructure, transportation services demand and vehicle stock evolution.

\section{Retail Infrastructure Refurbishment}

In non-HOF versions of the model, the annual change in retail capacity available reflects one of three possible scenarios:

- If retail station owners replace each year the fraction of the fleet of dispensers, USTs, and trucks that is depreciated, total capacity stays constant.

- If retail station owners invest in more capacity than what is needed to replace the depreciated fraction of the fleet, total capacity increases.

- If retail station owners invest in less capacity than what is needed to replace the depreciated fraction of the fleet, total capacity decreases.

In the HOF version of BioTrans, a fourth possible course of action is depicted in some scenarios (Scenario 1, 2, 4, and 6): changes in the mix of dispensers, USTs, and trucks by refurbishing some of the dedicated E10 assets to make them compatible with HOF. Refurbishment is represented as a conversion activity in which the inputs are E10 dispensers, E10 USTs, or E10 tank trucks and the outputs are E25 blender pumps, E85 USTs, or E85 tank trucks, respectively. The cost per gallon of the conversion is based on the refurbishment costs spelled out in Table 3 and the assumed capacity per dispenser, UST, or truck. An upper bound of 50\% is used on the percentage of the starting fleet that can be refurbished over the planning horizon. Observed levels of refurbishment in the set of scenarios discussed in this report never reached that upper bound. 


\section{Vehicle Miles Traveled Demand}

One of the changes associated with the representation of HOF and HOFVs has been the change in demand units from gges to VMT. In non-HOF versions, BioTrans depicts three ethanol fuel blends (E10, E15 and E85) and the assumption is that vehicles obtain the same mileage per gge regardless of which of those blends they use. Therefore, the exact same solution should result by depicting demand in gges or in VMT. With HOFVs, the correspondence between the energy content of fuel blends and the mileage they produce breaks down. HOFVs obtain a higher mileage per gge when they use HOF as their fuel. Thus, if demand were expressed in units of fuel, the full advantages of HOF for HOFVs would not be acknowledged.

\section{Vehicle Stock}

In non-HOF cases, BioTrans combines AEO 2014 regional vehicle sales projections with a starting year regional stock (based on Polk and AEO data) to assemble projections of regional vehicle stock over the planning horizon. In the HOF cases, national HOFV sales are taken from ADOPT.

Mileage per gge for the fleet is constructed as a weighted average of the mileage achieved by vehicles of all different vintages included in each year's stock.

\section{Reference Fuel Quantities and Prices}

In non-HOF versions of the model, projected E10 and flex fuel quantities and prices from AEO 2014 are used as reference fuel quantities and prices and they are allocated across the various vehicle types using simple rules:

- All flex fuel is consumed by FFVs (and implies a reference share of flex fuel consumption by FFV owners).

- The rest of fuel demand by FFVs is E10.

- The E10 left after allocation to FFVs is consumed by conventional light-duty cars and trucks.

Because vehicle stock and total fuel demand projections are taken from the same source, the fuel allocated to each vehicle type implies the VMT assumed in AEO 12,500/year for all vehicle types. The endogenous solution coming out of BioTrans can differ from the reference shares because demand is elastic. Moreover, for vehicle types that can choose across multiple fuels, a binomial logit framework is used to represent their decision process.

Introducing HOF creates a challenge for benchmarking demand because HOF is not part of the NEMS model in which AEO projections are based. In HOF scenarios, reference fuel quantities are taken from ADOPT. Reference fuel prices for E10 and flex fuel still come from AEO. The reference fuel price for HOF is constructed as a weighted average of the prices of E10 and flex fuel with weights based on their respective volumetric fractions. Since HOF is blended at the pump, it is modeled as a mixture of E10 and flex fuel rather than pure gasoline and ethanol. 


\section{Appendix D: Brief Overview of Biomass Scenario Model and BioTrans Approaches To Modeling the Biomass-to-biofuel Supply Chain}

The different modeling approaches utilized by the BSM and BioTrans are highlighted in Table D-1, along with the potential for model results to diverge.

Table D-1. Comparison of Key Model Characteristics for the BSM and BioTrans Models

\begin{tabular}{|c|c|c|c|c|c|}
\hline $\begin{array}{l}\text { Stage in } \\
\text { Supply } \\
\text { Chain }\end{array}$ & Feature & BSM Representation & BioTrans Representation & $\begin{array}{c}\text { Potential for } \\
\text { Differences in Model } \\
\text { Output }\end{array}$ & Notes \\
\hline \multirow{4}{*}{$\begin{array}{l}\text { Feedstock } \\
\text { Production } \\
\text { and } \\
\text { Logistics }\end{array}$} & Regionality & $\begin{array}{l}10 \text { USDA-based } \\
\text { production regions. }\end{array}$ & $\begin{array}{l}\text { Census Division-level } \\
\text { aggregated from county- } \\
\text { level information from } \\
\text { POLYSYS. }\end{array}$ & & $\begin{array}{l}\text { Differences in regional units } \\
\text { complicate comparison of } \\
\text { regional results. All results in } \\
\text { the report are presented at the } \\
\text { national level. }\end{array}$ \\
\hline & $\begin{array}{l}\text { Market } \\
\text { representati } \\
\text { on }\end{array}$ & $\begin{array}{l}\text { Dynamic competition } \\
\text { between multiple uses of } \\
\text { land (e.g., residue, } \\
\text { herbaceous crops, } \\
\text { woody crops, commodity } \\
\text { crops). }\end{array}$ & $\begin{array}{l}\text { Feedstock supply curves }{ }^{40} \\
\text { for multiple feedstocks } \\
\text { drawn from POLYSYS; } \\
\text { feedstock price is marginal } \\
\text { cost along those curves. }\end{array}$ & $\begin{array}{l}\text { Phased development of } \\
\text { feedstock sources in } \\
\text { BSM; more uniform } \\
\text { development of feedstock } \\
\text { resources in BioTrans } \\
\text { (which omits some } \\
\text { delays). }\end{array}$ & $\begin{array}{l}\text { Scenarios } 2 \text { and } 4 \text { show } \\
\text { differences in feedstock mix } \\
\text { under roughly commensurate } \\
\text { overall feedstock demands. }\end{array}$ \\
\hline & $\begin{array}{l}\text { Producer } \\
\text { behavioral } \\
\text { assumptions }\end{array}$ & $\begin{array}{l}\text { Feedstock production } \\
\text { based on behavioral } \\
\text { assumptions around } \\
\text { farmer adoption of new } \\
\text { practices. }\end{array}$ & $\begin{array}{l}\text { POLYSYS supply curves } \\
\text { reflect optimization of } \\
\text { agricultural income. }\end{array}$ & $\begin{array}{l}\text { To the extent that farmer } \\
\text { adoption rates in the } \\
\text { BSM are different to } \\
\text { those in POLYSYS, there } \\
\text { will be differences in the } \\
\text { rate of introduction of } \\
\text { feedstocks. }\end{array}$ & \\
\hline & $\begin{array}{l}\text { Delays and } \\
\text { system } \\
\text { inertias }\end{array}$ & $\begin{array}{l}\text { Multi-year development } \\
\text { and production periods } \\
\text { for herbaceous and } \\
\text { woody feedstocks. }\end{array}$ & $\begin{array}{l}\text { Feedstock production } \\
\text { depends upon yearly } \\
\text { supply curve. }\end{array}$ & $\begin{array}{l}\text { Under high feedstock } \\
\text { demands, there is a more } \\
\text { uniform mix of feedstocks } \\
\text { in BioTrans than in BSM. }\end{array}$ & \\
\hline
\end{tabular}

${ }^{40}$ Supply curves come from a POLYSYS scenario with a biomass price of $\$ 50 /$ dry ton and baseline yield growth rate. 


\begin{tabular}{|c|c|c|c|c|c|}
\hline $\begin{array}{l}\text { Stage in } \\
\text { Supply } \\
\text { Chain }\end{array}$ & Feature & BSM Representation & BioTrans Representation & $\begin{array}{c}\text { Potential for } \\
\text { Differences in Model } \\
\text { Output }\end{array}$ & Notes \\
\hline & Yields & $\begin{array}{l}\text { Initial crop yields, yield } \\
\text { growth assumptions } \\
\text { derived from POLYSYS. }\end{array}$ & $\begin{array}{l}\text { Feedstock supply curves } \\
\text { drawn from POLYSYS } \\
\text { reflect yields. }\end{array}$ & $\begin{array}{l}\text { No significant differences } \\
\text { to be expected from this } \\
\text { dimension of model } \\
\text { assumptions. }\end{array}$ & \\
\hline & $\begin{array}{l}\text { Forest } \\
\text { residue } \\
\text { supply } \\
\text { curves }\end{array}$ & $\begin{array}{l}\text { POLYSYS-based supply } \\
\text { curves for forest } \\
\text { residues and urban } \\
\text { residues. }\end{array}$ & $\begin{array}{l}\text { POLYSYS-based supply } \\
\text { curves for forest residues. }\end{array}$ & $\begin{array}{l}\text { Although the actual data } \\
\text { used differs, the } \\
\text { methodology is the same. }\end{array}$ & \\
\hline \multirow{5}{*}{$\begin{array}{l}\text { Feedstock } \\
\text { Conversion, } \\
\text { Ethanol } \\
\text { Production, } \\
\text { Import }\end{array}$} & $\begin{array}{l}\text { Maximum } \\
\text { construction } \\
\text { starts }\end{array}$ & $\begin{array}{l}\text { Assumed max } \\
\text { construction starts of } 25 \\
\text { ( } 2000 \text { ton/day) facilities } \\
\text { each year. (18 million } \\
\text { dry ton/year new } \\
\text { capacity max). } \\
\text { Capacity becomes } \\
\text { available after } \sim 3 \text { year } \\
\text { construction and startup } \\
\text { period. }\end{array}$ & $\begin{array}{l}\text { Assumed max investment } \\
\text { of } 35 \text { million dry tons/year } \\
\text { of capacity, allows varying } \\
\text { sized plants; limit is } \\
\text { calibrated to max historical } \\
\text { investment in dry mill } \\
\text { industry (2008). } \\
\text { Capacity becomes } \\
\text { available the year in which } \\
\text { the investment happens. }\end{array}$ & $\begin{array}{l}\text { The maximum amount of } \\
\text { conversion capacity (in } \\
\text { dry tons/year) that can be } \\
\text { introduced each single } \\
\text { year is almost twice as } \\
\text { large in BioTrans than in } \\
\text { BSM. }\end{array}$ & $\begin{array}{l}\text { Even so, in several scenarios, } \\
\text { both BioTrans and BSM } \\
\text { outputs hit limits of assumed } \\
\text { maximum construction starts. }\end{array}$ \\
\hline & $\begin{array}{l}\text { Starch } \\
\text { ethanol } \\
\text { Industry }\end{array}$ & $\begin{array}{l}\text { Mature starch industry } \\
\text { limited to } 15 \text { billion } \\
\text { gallons per year; actual } \\
\text { production of starch } \\
\text { ethanol based on } \\
\text { cost/price dynamics. }\end{array}$ & $\begin{array}{l}\text { Upper bound on corn } \\
\text { ethanol production (15 } \\
\text { billion gallons per year) } \\
\text { based on the RFS2 limit to } \\
\text { corn ethanol RINs. }\end{array}$ & $\begin{array}{l}\text { Most (in BioTrans) or all } \\
\text { (in BSM) of the growth in } \\
\text { ethanol production } \\
\text { associated with satisfying } \\
\text { HOF demand comes from } \\
\text { cellulosic ethanol } \\
\text { industry. }\end{array}$ & \\
\hline & $\begin{array}{l}\text { Nth plant } \\
\text { techno- } \\
\text { economics }\end{array}$ & $\begin{array}{l}\text { Derived from design } \\
\text { reports. }\end{array}$ & $\begin{array}{l}\text { Derived from design } \\
\text { reports. }\end{array}$ & & \\
\hline & $\begin{array}{l}\text { Learning } \\
\text { curve }\end{array}$ & Endogenous. & Exogenous schedule. & $\begin{array}{l}\text { Potential for differences } \\
\text { in process yield and other } \\
\text { techno-economic metrics. }\end{array}$ & $\begin{array}{l}\text { BSM is currently better suited } \\
\text { to explore questions regarding } \\
\text { learning curves. }\end{array}$ \\
\hline & $\begin{array}{l}\text { Ethanol } \\
\text { import from } \\
\text { foreign } \\
\text { sources }\end{array}$ & Yes. & $\begin{array}{l}\text { Yes (advanced sugarcane } \\
\text { ethanol). }\end{array}$ & & \\
\hline
\end{tabular}




\begin{tabular}{|c|c|c|c|c|c|}
\hline $\begin{array}{l}\text { Stage in } \\
\text { Supply } \\
\text { Chain }\end{array}$ & Feature & BSM Representation & BioTrans Representation & $\begin{array}{c}\text { Potential for } \\
\text { Differences in Model } \\
\text { Output }\end{array}$ & Notes \\
\hline \multirow{4}{*}{$\begin{array}{l}\text { Downstream } \\
\text { infra- } \\
\text { structure }\end{array}$} & $\begin{array}{l}\text { Tankage/eq } \\
\text { uipment } \\
\text { investment } \\
\text { units }\end{array}$ & Discrete stations. & $\begin{array}{l}\text { Dispensing capacity } \\
\text { (expressed in millions of } \\
\text { gallons) implying a number } \\
\text { of dispensers and stations. }\end{array}$ & & \\
\hline & $\begin{array}{l}\text { Basis for } \\
\text { replacing } \\
\text { pumps }\end{array}$ & $\begin{array}{l}\text { Fraction of capacity at } \\
\text { end of useful life } \\
\cdot \quad \sim 1 / 25 \text { of stations/yr } \\
\text { No creation of new } \\
\text { capacity }\end{array}$ & $\begin{array}{l}\text { Fraction of capacity that is } \\
\text { at end of useful life } \\
\cdot \quad 1 / 15 \text { of dispensers/yr } \\
\cdot \quad 1 / 30 \text { of UST/yr } \\
\text { Potential to refurbish } \\
\text { dedicated E10 dispensers } \\
\text { and USTs into HOF- } \\
\text { compatible assets before } \\
\text { they reach the end of their } \\
\text { useful life (select } \\
\text { scenarios) } \\
\text { Potential to create new } \\
\text { capacity }\end{array}$ & $\begin{array}{l}\text { Small potential for } \\
\text { divergence in output }\end{array}$ & Basis for replacing pumps \\
\hline & $\begin{array}{l}\text { Capital cost } \\
\text { basis for } \\
\text { NPV } \\
\text { calculation }\end{array}$ & $\begin{array}{l}\text { Capital cost of } \\
\text { investment } \\
\cdot 30 \% \text { equity / } 70 \% \\
\text { loan / } 7 \% \text { interest rate } \\
\cdot \quad 15 \% \text { discount rate }\end{array}$ & $\begin{array}{l}\text { Capital cost of investment } \\
\cdot 16 \% \text { discount rate }\end{array}$ & $\begin{array}{l}\text { Minimal divergence } \\
\text { BSM may understate } \\
\text { capital component of } \\
\text { NPV relative to BioTrans } \\
\text { because BioTrans does } \\
\text { not include loan } \\
\text { assumption. }\end{array}$ & $\begin{array}{l}\text { Capital cost basis for NPV } \\
\text { calculation }\end{array}$ \\
\hline & $\begin{array}{l}\text { HOF volume } \\
\text { basis for } \\
\text { investment } \\
\text { decision }\end{array}$ & $\begin{array}{l}\text { Volume based on HOF- } \\
\text { capable vehicles } \\
\text { existent at each time } \\
\text { step } \\
\text { No foresight }\end{array}$ & $\begin{array}{l}\text { Volume based on } \\
\text { reference share that } \\
\text { saturates at } 90 \% \text { after } \\
2022 \\
\cdot \text { Look ahead from } \\
\text { present } 6 \text { years in limited } \\
\text { foresight (variant) cases }\end{array}$ & $\begin{array}{l}\text { High potential for } \\
\text { divergence between BSM } \\
\text { and BioTrans. } \\
\text { BSM NPV calculation } \\
\text { based on current state of } \\
\text { vehicle system in vehicles } \\
\text { and usage; foresight }\end{array}$ & $\begin{array}{l}\text { HOF volume basis for } \\
\text { investment decision }\end{array}$ \\
\hline
\end{tabular}




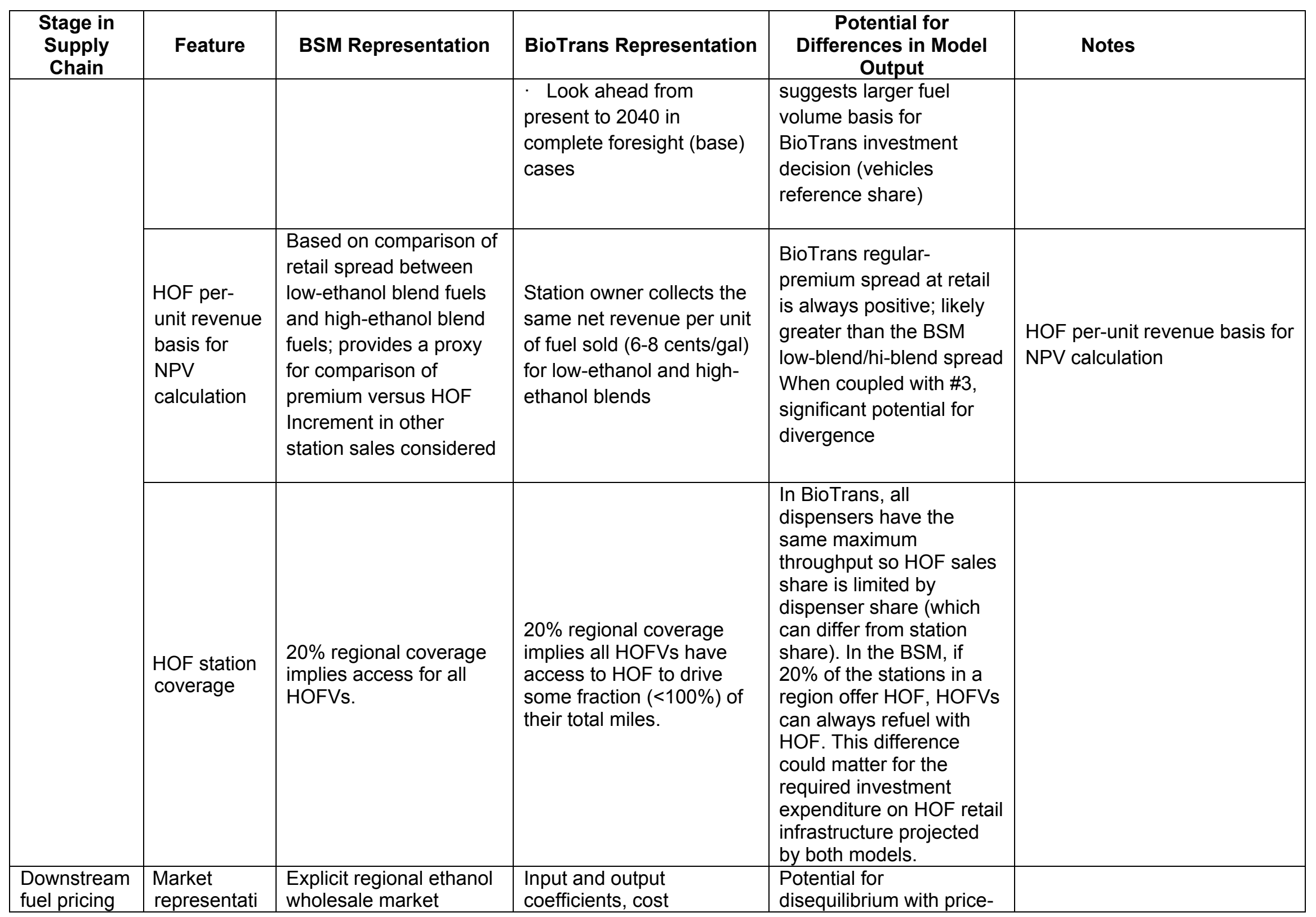




\begin{tabular}{|c|c|c|c|c|c|}
\hline $\begin{array}{l}\text { Stage in } \\
\text { Supply } \\
\text { Chain }\end{array}$ & Feature & BSM Representation & BioTrans Representation & $\begin{array}{c}\text { Potential for } \\
\text { Differences in Model } \\
\text { Output }\end{array}$ & Notes \\
\hline \multirow[t]{3}{*}{ and fuel use } & on & $\begin{array}{l}\text { (production, inventory, } \\
\text { consumption, pricing). }\end{array}$ & parameters. & $\begin{array}{l}\text { inventory oscillations in } \\
\text { wholesale ethanol market } \\
\text { in the BSM. }\end{array}$ & \\
\hline & $\begin{array}{l}\text { Retail } \\
\text { pricing }\end{array}$ & $\begin{array}{l}\text { Cost + markup } \\
\text { formulation: cost is } \\
\text { based on combination of } \\
\text { ethanol cost and } \\
\text { gasoline cost delivered } \\
\text { at retail. Ethanol cost } \\
\text { reflects endogenously } \\
\text { determined wholesale } \\
\text { prices. Gasoline cost is } \\
\text { based on AEO } 2014 \text { and } \\
\text { fixed markup percentage } \\
\text { is then applied. }\end{array}$ & $\begin{array}{l}\text { Price reflects marginal } \\
\text { cost of all upstream } \\
\text { activities needed to deliver } \\
\text { the final fuel blends; price } \\
\text { will differ from marginal } \\
\text { cost if capacity and/or } \\
\text { regulatory constraints are } \\
\text { binding; markup applied to } \\
\text { E10 premium fuel } \\
\text { consumption by HOFVs. }\end{array}$ & $\begin{array}{l}\text { Price of final fuels in the } \\
\text { BSM is based } \\
\text { endogenously } \\
\text { determined gasoline and } \\
\text { ethanol prices. Price of } \\
\text { final fuels in BioTrans is } \\
\text { endogenous based on } \\
\text { market equilibration } \\
\text { (maximizes the sum of } \\
\text { producer and consumer } \\
\text { surplus in competitive } \\
\text { market). }\end{array}$ & \\
\hline & VMT & $\begin{array}{l}\text { VMT based on vintage } \\
\text { class of vehicle and is } \\
\text { derived from AEO } 2012 .\end{array}$ & $\begin{array}{l}\text { VMT demand reference } \\
\text { number }(\sim 12.5 \mathrm{~K} \text { per } \\
\text { vehicle-year) based on } \\
\text { AEO } 2014 .\end{array}$ & $\begin{array}{l}\text { In BioTrans, since the } \\
\text { market for VMT is } \\
\text { explicitly represented } \\
\text { (elastic demand curve), } \\
\text { vehicle owners can } \\
\text { choose to move away } \\
\text { from the reference VMT } \\
\text { and implied fuel use/fuel } \\
\text { mix if fuel costs change. }\end{array}$ & $\begin{array}{l}\text { Potential difference in specific } \\
\text { results in BSM vs BioTrans. }\end{array}$ \\
\hline
\end{tabular}




\section{Appendix E: Overview of the Literature and Empirical Analysis of the Role of Ethanol in the Gasoline Market}

This section provides a brief summary of the recent literature on high-octane market studies, consumer vehicle and fuel choice behavior, and a preliminary empirical analysis of gasoline market data.

\section{Potential Benefits of High-Octane Fuels}

Speth et al. (2014) estimated the potential economic and environmental benefits of higher octane gasoline based on engine and drive cycle simulations. They proposed a specific scenario in which the United States adopts RON standards of 92 for regular and 98 for premium gasoline. Vehicle manufacturers would then introduce new vehicles that would require the 98 RON gasoline. They estimate that fuel savings of $2 \%-5 \%$ are possible with the higher compression ratio of vehicles required to use the $98 \mathrm{RON}$ gasoline, depending on whether engines are downsized or naturally aspirated or turbocharged. The Speth et al. (2014) study identified ethanol as a potential source of higher octane but did not address the various energy contents of ethanol or the regulatory conditions for the proposed scenario. Hirshfeld et al. (2014) evaluated the refinery economics of producing high-octane fuels with different ethanol blend levels using a linear programming refinery model. Their results imply that E10, E20, and E30 gasoline and RON standards of 95 to 101 can be produced for additional average refinery costs of $\$ 0.01-$ $\$ 0.10 /$ gallon, depending on the combination of ethanol blend level and RON. For a given ethanol content the additional cost increases with the RON standard, and for a given RON standard the cost decreases with the ethanol content. They also estimate that crude oil use and emissions in refineries would be reduced by about 3\%. The analysis suggested that producing E20 and E30 gasoline pools would incur lower refining costs relative to E85 because the "octane give-away" in E85 can be fully utilized in producing BOBs for E20 or E30.

\section{Overview of the Literature on Consumer Fuel Choice and Sensitivity to Prices}

Setiawan and Sperling (2001) investigated the sensitivity of the demand for different gasoline grades using data for the 1980s and 1990s. During this period the demand for premium gasoline in the United States accelerated from 12\% in 1983 to $30 \%$ in 1989 . The study found considerable "overbuying" of premium gasoline during this period, and suggested that the demand for different gasoline grades is highly elastic. About $29 \%$ of respondents to a survey use premium fuel all the time and about $14 \%$ more than half the time. However, only about $22 \%-30 \%$ of these respondents cited vehicle requirement as the reason for using premium fuel. A model of willingness to pay for premium fuel based on the survey data found that on average consumers are willing to pay $\$ 0.04-\$ 0.08$ more per octane number. However, this estimate was considered to be high due to the survey bias usually associated with stated values data. Income was found to be only weakly associated with premium fuel purchase. Greene (1989) used data from the early 1980s with an econometric model of fuel choice and also found that consumer choices are highly elastic to fuel prices, with a value of high as -10 at $50 \%$ market share. The findings also suggest that consumers are willing to pay $\$ 0.05-\$ 0.10$ /gallon or $\$ 0.01-\$ 0.02$ per octane number for premium fuels. The rapid increase in premium consumption during the $1980 \mathrm{~s}$ was attributed to the increasing number of turbocharged and fuel-injected vehicles that required premium fuels at the time. 
More recently a number of papers have analyzed the demand for ethanol as a substitute for gasoline. Anderson (2012) estimated household demand for flex fuel as a substitute for E10 using a model that linked the ethanol demand curve to the distribution of household willingness to pay for ethanol. Results of the model with data for Minnesota imply an flex fuel own-price elasticity of negative 3-3.8, and a gasoline price elasticity of 2.3-3.2. Other findings include a $0.05 \%-0.10 \%$ increase in flex fuel sales volumes for a $1 \%$ increase in the number of FFVs. flex fuel buyers also learned quickly about new stations so that sales at new stations increase from about $50 \%-100 \%$ of capacity within 2 months. Liu and Greene (2014), using data from Minnesota, North Dakota, and Iowa, found that the long-run own-price elasticity of flex fuel choice is in the range of -6 to -7 at a price level of $\$ 3.25 /$ gallon. They also found that the penalty for limited fuel availability decreases from $\$ 1.2$ /gallon at $1 \%$ availability to $\$ 0.25 /$ gallon at $5 \%$, and drops to zero at more than 15\%. Salvo and Huse (2013) use data from Brazil to evaluate the sensitivity of switching between gasoline and sugarcane ethanol, and found that roughly $20 \%$ of motorists would switch to ethanol when the gasoline price is $20 \%$ higher than ethanol in gasoline equivalent terms. They also found considerable consumer heterogeneity in fuel choice behavior implying the need to account for consumer price and non-price preferences in introducing new vehicles/fuels. Du and Carriquiry (2013) concluded that when consumers have the ability to choose freely between ethanol and gasoline the relative prices of the fuels converge to the longrun equilibrium, and that the dynamics of prices depend on several market determinants, such as feedstock prices, policies, and composition of the vehicle fleet.

A recent survey of consumers by the Fuels Institute (Fuels Institute 2014) described the perspectives of consumers on E15 and flex fuel ethanol-blend fuels. The survey found that although $78 \%$ of respondents drive 2001 or newer vehicles, only $20 \%$ are very or somewhat familiar with E15. Of those with 2001 or newer vehicles $48 \%$ would consider E15 at the same price as gasoline (assumed to be E10), and the rest at a $\$ 0.05$ discount to gasoline. About $6 \%$ of respondents own FFVs, and about $43 \%$ of these have purchased flex fuel $(25 \%$ more often than E10). Availability was an important issue, with $73 \%$ willing to buy more flex fuel if available. Pricing was also important because 59\% of FFV owners view flex fuel to be more expensive or the same price as E10. A chart of monthly average volume per station versus the flex fuel discount showed volumes varied by up to $50 \%$ for discounts of $10 \%-20 \%$, which supports the high price elasticity highlighted from the literature. However, this comparison does not account for other factors behind month-to-month variation in fuel demand.

\section{Overview of the Literature on Vehicle-Fuel Choice}

HOF-tuned vehicles running on HOFs are expected to have fuel efficiencies comparable to conventional vehicles running on regular gasoline. However, HOF-tuned vehicles are unlikely to run with equal efficiency on regular or premium gasoline. As a result, HOFV manufacturers would be faced with a tradeoff between using the higher octane rating of HOFs to improve fuel economy and other vehicle performance characteristics. The potential extent of this tradeoff depends on consumers' perspective on the value of efficiency and performance in purchase decisions, and the relative efficiency and performance of HOF-tuned vehicles to other vehicles on the market. A few studies in the literature have evaluated the combined impact of fuel prices, vehicle fuel economy, and other characteristics on consumer decisions. Klier and Linn (2013) compared the effects of fuel prices on the fuel economy of new vehicles in Europe and the United States using monthly data for 2002-2007 on prices, registrations and sales, model-fuel 
type (gasoline and diesel), taxes, and consumer preferences. Results show that increases in fuel prices lead to a reallocations of vehicle purchases from lower efficiency toward higher efficiency groups, and that the U.S. vehicle market is more sensitive to fuel prices than the European market. The findings correspond to an elasticity of fuel economy to fuel prices of 0.06 in the United States and 0.03 in the Europe, which are characterized as short-run, monthly estimates. In a related paper Klier and Linn (2010) also examined the relationship between vehicle fuel economy and weight, length, engine size, and number of cylinders. Results from this analysis found that an increase in the price of gasoline causes a decrease in the market shares of vehicle models that have large engines. Burke and Nishitateno used annual data from 1995 to 2008 for 132 countries to evaluate worldwide gasoline consumption. In addition to a long-run price elasticity of gasoline demand of between -0.2 and -0.5 they found that higher gasoline prices cause consumers to buy more fuel-efficient vehicles with an elasticity of +0.2 . The recent Fuel Institute Survey (Fuels Institute 2014) also found that of the $48 \%$ of respondents likely to buy a new car in the next 3 years $80 \%$ identified purchase and fuel costs as important drivers of vehicle purchase decisions. Safety, handling, and fuel and engine type were ranked as important by about $50 \%$ of respondents, whereas performance and passenger capacity were ranked as important by $40 \%$ of respondents.

\section{Empirical Gasoline Market Modeling and the Role of Ethanol}

A preliminary analysis of the market data was performed to obtain quantitative insights into the role of recent increases in ethanol blend rates on the U.S. gasoline market, as a starting point for evaluating the potential benefits of HOFs. Questions for the analysis include:

- What are the effects of increases in the ethanol blend rate on the price or cost of each gasoline grade?

- How does the demand for each gasoline grade respond to own- and other- prices?

- What are the direct and indirect gasoline demand effects of ethanol?

- Why is there little uptake of flex fuel?

- What are the potential contributions of alternative options, such as the HOF, for increasing ethanol in the U.S. gasoline pool?

- What other potential market factors would determine the increase in ethanol use?

Gasoline and other market data, mostly at the Petroleum Administration for Defense District (PADD) level, were obtained from various sources. The following data were obtained from the EIA. Monthly prime supplier sales to local distributors and retailers or end users are used as a measure of gasoline demand, and retail gasoline prices as a measure of prices. Data on net refiner inputs, including ethanol, crude oil, and other inputs, were obtained for the analysis of the determinants of gasoline prices. Annual historical data on the shares of vehicles by technology type were compiled from supplements to the AEO forecasts at the census region level, but were assigned to PADDS. Ethanol prices are the monthly Nebraska Rack price series. State-level quarterly income data were obtained from the Bureau of Economic Analysis. Prices and income data were deflated using the U.S. consumer price index. Figure E-1 shows the change in ethanol inputs by refiners and blenders by PADD, as well as real ethanol and refinery oil acquisition prices between 1994 and 2014. Although these data are not at the ideal level of detail for 
understanding the market effects of recent changes in ethanol use in the United States, the analysis provides preliminary insights into the how ethanol has affected the U.S. gasoline market, and its implications for higher future higher ethanol use.

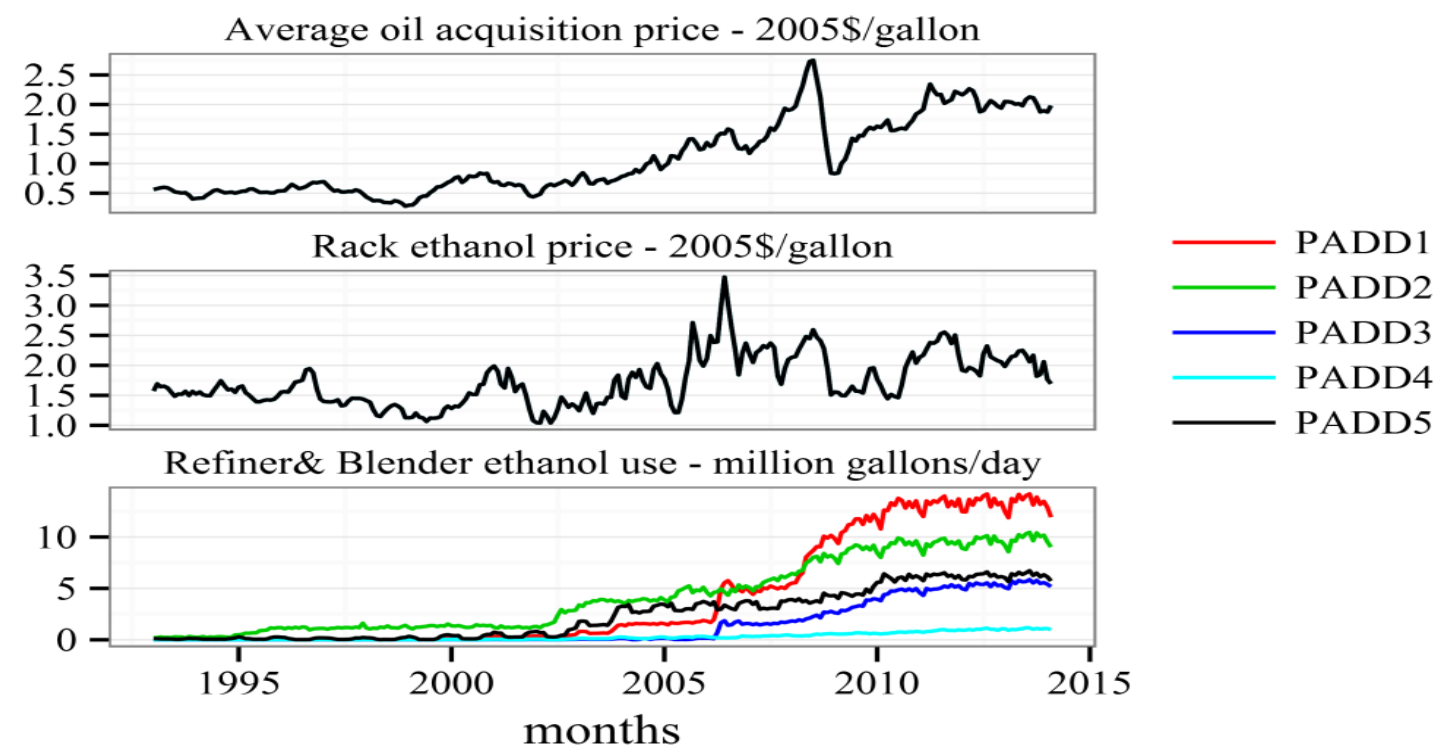

Figure E-1. Refiner oil acquisition cost, ethanol inputs and ethanol price 1994-2014

The econometric model specifications were adapted to these data and divided into two stages. The first stage is a model of the monthly total gasoline sales by PADD (1 equation), and the second stage is a simultaneous model of gasoline demand and prices by grade (6 equations). These latter set of equations are estimated simultaneously to capture the interaction between the demand and supply (represented by price) sides of the market.

Total gasoline sales are modeled as a function of:

- Weighted average gasoline prices, with the previous month's grade shares as weights

- Quarterly income

- Annual shares for HEVs and FFVs. The price differential between regular and ethanol prices was interacted with the share of FFVs to capture the flexibility of this vehicle category at the pump.

- Ethanol blend rate. Given the available data, the ethanol blend rate was calculated as the ratio of the ethanol input divided by the sum of all refiners and blenders inputs in each region.

- Monthly, regional, and oxygenated and reformulated gasoline dummy variables.

The price of each gasoline grade is specified using an error-correction formulation to reflect the dynamics of monthly gasoline prices as a function of:

- Total gasoline sales (1 month lag and change)

- Ethanol blend rate, as well as its interaction with the ethanol price 
- Refiner average oil acquisition price (1 month lag and change) interacted with the nonethanol share of refiner and blender inputs

- Average air pollution index of crude oil inputs

- Average sulfur rate of crude oil inputs

- Refinery use rate

- Monthly, regional, and oxygenated or reformulated gasoline dummy variables.

The share of each gasoline grade is modeled using a logit formulation as a function of:

- Total gasoline sales

- Regular grade price and its differentials with respect to premium and midgrade prices

- Annual shares of HEVs, FFVs, and conventional gasoline vehicles. The price differential between regular and ethanol prices was interacted with the share of FFVs to capture the flexibility of this vehicle category at the pump.

- Ethanol blend rate. The ethanol rate was interacted with the regular grade price to capture the interaction effects of the two variables.

\section{Summary of Econometric Model Results}

Total gasoline sales model. Estimation results found short- and long-run elasticities of demand with respect to the average gasoline price of -0.08 and -0.7 , respectively. These estimates are in the range of demand elasticities in the literature. Coefficients on ethanol- and vehicle-related variables had the expected signs, but are insignificant. Nonconventional gasoline vehicles lead to reductions in total gasoline sales, as would be expected. The volume of total gasoline for a given level of travel is expected to increase to compensate for the lower energy content of ethanol, as used in the current vehicle stock.

The results imply that a $1 \%$ increase in the ethanol blend rate leads to a $0.09 \%$ (multiplied by the original blend rate) increase in total gasoline sales. As an example, doubling the current E10 blend in the U.S. gasoline pool to E20 implies that the volume of total gasoline sales would increase by $0.1 * 9 \%$ or $0.9 \%$. However, a full adjustment for the lower energy content of ethanol when moving E10 to E20 implies a 3\% increase in total gasoline sales volume. Thus, this result implies that consumers do not fully adjust gasoline volumes for the energy content changes of various ethanol blends. Other potential adjustments involve shifting the demand for various gasoline grades and formulations, using more fuel- efficient vehicles and reducing the level of travel, among others.

Gasoline grades price model. This submodel provides insights into the determinants of gasoline prices by grade. This information can summarized through short- and long-run elasticities measuring the response of gasoline prices to a unit change in the determinants. The results imply that a $100 \%$ change in the oil price translates into a 39\%-44\% increase in E0 gasoline price in the short run and a 50\%-56\% increase in the long run, with the largest percent increase for regular grade gasoline. These estimates reflect the share of gasoline in a barrel of crude oil. A $100 \%$ increase in the price of ethanol leads to an $87 \%-93 \%$ increase in the price of E100 
gasoline, with the percent increases again larger for regular than the other gasoline grades; an almost one-for-one pass-through.

The interaction terms in the model allow the impacts of changes in oil and ethanol prices to be calculated for given ethanol blend rate (such as E10, E20, and flex fuel). Similarly, the impact of a change in the ethanol blend rate depends on the blend rate, as well as ethanol and oil prices. For example, if the per gallon price of ethanol and oil are the same, a 100\% increase in the ethanol blend rate from E10 to E20 would raise the price of all gasoline grades by about 2.8\%. This price difference closely matches the higher energy content of a gallon of E10 relative to E20, implying that parity pricing of ethanol on an energy basis would make it competitive with the equivalent gasoline.

Figure E-2 shows the implied elasticity of each gasoline grade price to a $1 \%$ increase in the ethanol blend rate calculated using the historical data on ethanol blend rate, ethanol price, and oil price. Figure E-2 shows that these elasticities are negative (or near zero), implying that prices would decline in 10 of the 13 years from 2001 to 2012, with only a slight variation among the grades. The magnitudes of these elasticities also tend to be larger during March to September. The years and months with positive elasticities, largely in 2006, 2008, and 2011, correspond to periods of rising ethanol prices in Figure E-2.
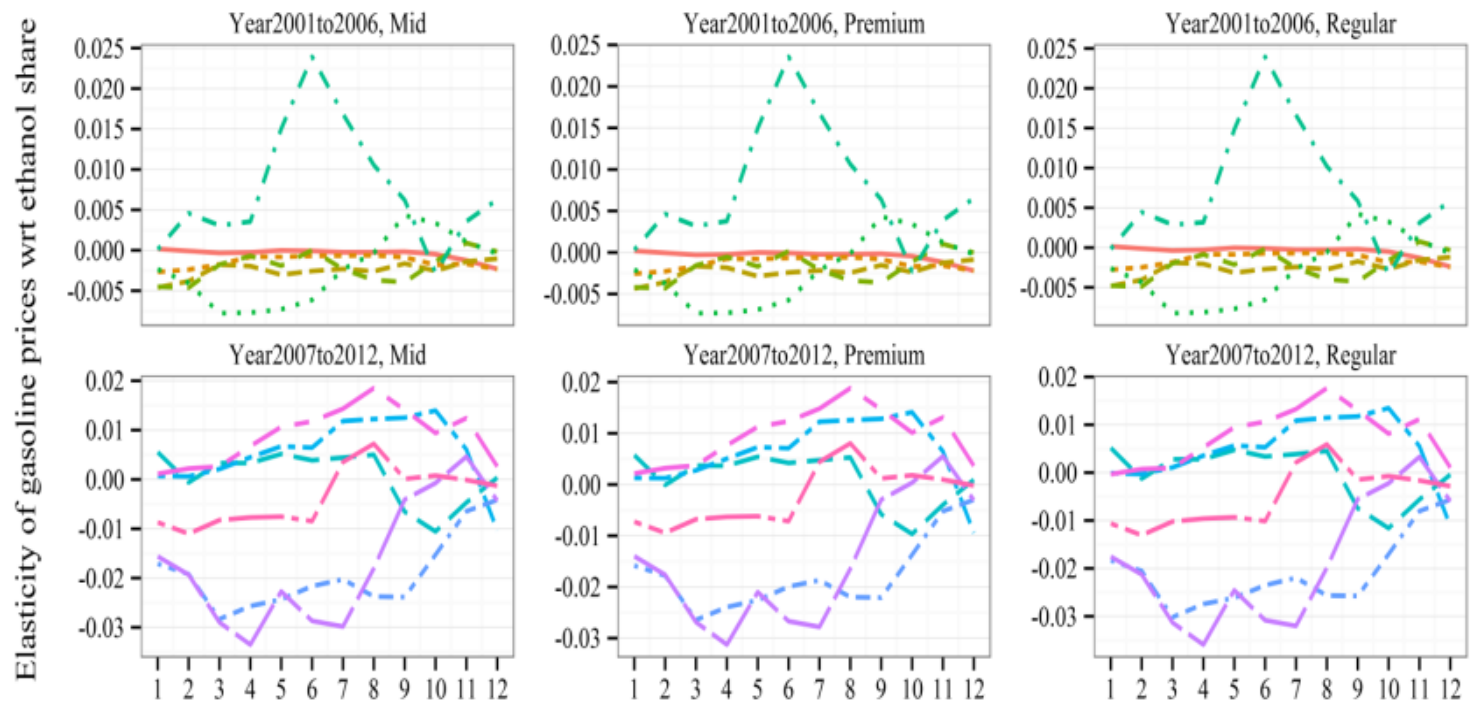

$$
-2001 \quad \cdots-\cdot 2002---\cdot 2003 \quad---2004 \quad \cdots \cdot 2005 \quad \cdot-\cdot-2006
$$

Figure E-2. Preliminary estimates of historical monthly gasoline price elasticities to a $1 \%$ increase in the ethanol blend rate by grade

\section{Model of Gasoline Shares by Grade}

This submodel estimates the impact of prices, ethanol blend, and other variables on the allocation of total gasoline among grades. The coefficients are used to calculate elasticities of the share of each gasoline grade with respect to these determinants. Given the logit formulation of the model, these elasticities depend on the initials shares of the grades and have been calculated using the 
historical data for 2002, 2004, 2008, and 2012. Given a 1\% change in the price of regular grade gasoline, holding all other prices constant the results imply that the share of regular grade gasoline would change by between $-0.1 \%$ and $0.3 \%$, that of midgrade gasoline by $1 \%-3 \%$, and that of premium grade by $-2 \%$ to $-0.5 \%$. Thus, gasoline consumers are assumed to shift their monthly use of premium gasoline in favor of lower grade fuels when regular grade prices rise. This result reflects a combination of several factors.

The total gasoline model implies that a $1 \%$ average change in the price of gasoline leads to an $0.1 \%$ change in total gasoline sales in the in the short run. In addition, regular grade gasoline represents a necessity for most vehicle owners. Premium gasoline can be considered a luxury, particularly because most vehicle manufacturers now recommend, rather than require, premium fuels because knock sensors are widely used in modern vehicles. Thus, consumers would tend to reduce premium-grade gasoline and increase regular and midgrades, as long as prices for the latter are lower than the premium-grade price. In the real world prices for all gasoline grades move together so that the impact of a change in the regular-grade gasoline on the higher grades would be even smaller.

The effects of changes in the ethanol blend rate and the share of FFVs on the distribution of gasoline across grades are similar. Overall, the results imply that a $1 \%$ increase in the share of ethanol in refiner and blender inputs or the flex-fuel share of vehicles increases the share of regular-grade gasoline by less than $0.1 \%$, but reduces the shares of midgrade and premium grade by $0 \%-1 \%$. Although these effects vary little over the course of a year, there are substantial variations across years and PADDs, with the pattern of changes in PADDs 1 and 2 being similar.

\section{Appendix E References}

Anderson, S.T. 2012. "The demand for Ethanol as a Gasoline Substitute." Journal of Environmental Economics and Management 63(2): 151-168.

Burke, P.J., and Nishitateno, S. 2013. "Gasoline Prices, Gasoline Consumption, and NewVehicle Fuel Economy: Evidence for a Large Sample of Countries.” Energy Economics 36: 363370 .

Du, X., and Carriquiry, M.A. 2013. "Flex-Fuel Vehicle Adoption and Dynamics of Ethanol Prices: Lessons from Brazil.” Energy Policy 59: 507-512.

Fuels Institute. 2014. Consumers and Alternative Fuels: Economics Are Top of Mind. Accessed August 20, 2014: www.fuelsinstitute.org/ResearchArticles/ConsumersandAlternativeFuels.pdf.

Greene, D.L. 1989. "Motor Fuel Choice: An Econometric Analysis." Transportation Research Part A: General 23(3): 243-253.

Hirshfeld, D.S., Kolb, J.A., Anderson, J.E., Studzinski, W., and Frusti, J. 2014. "Refining Economics of U.S. Gasoline: Octane Ratings and Ethanol Content." Environmental Science \& Technology. 
Klier, T., and Linn, J. 2013. "Fuel Prices and New Vehicle Fuel Economy-Comparing the United States and Western Europe." Journal of Environmental Economics and Management 66(2): 280-300.

Klier, T., and Linn, J. 2010. "The Price of Gasoline and New Vehicle Fuel Economy: Evidence from Monthly Sales Data.” American Economic Journal: Economic Policy 2.3: 134-153.

Liu, C., and Greene, D.L. 2014. "Consumer Choice of E85: Price Sensitivity and Cost of 5 Limited Fuel Availability 6." Transportation Research Board 93rd Annual Meeting. No. 143875.

Salvo, A., and Huse, C. 2013. "Build It, but Will They Come? Evidence From Consumer Choice Between Gasoline and Sugarcane Ethanol." Journal of Environmental Economics and Management 66(2): 251-279.

Setiawan, W., and Sperling, D. 2001. "Premium Gasoline Overbuying in the US: ConsumerBased Choice Analysis.” University of California Transportation Center.

Speth, R.L., Chow, E.W., Malina, R., Barrett, S.R.H., Heywood, J.B., and Green, W.H. 2014. "Economic and Environmental Benefits of Higher-Octane Gasoline." Environmental Science \& Technology. 